\title{
A Critique of Smart Cities: \\ Sidewalk Labs' Project in Toronto
}

\author{
by \\ Samuel Evans
}

A thesis submitted to the Faculty of Graduate and Post Doctoral Affairs in partial fulfillment of the requirements for the degree of

Master of Arts

in

Political Economy

Carleton University

Ottawa, Ontario

(C) 2021

Samuel Evans 


\section{Acknowledgements}

I would like to first acknowledge and thank my supervisor, Assistant Professor David Hugill for the help and guidance provided to me. I would also like to extend a sincere thank you to my second reader, Professor Jill Wigle, as well as the rest of the members on my defence committee, and the administration staff with Institute of Political Economic. I'd like to thank Tulsi for her support and belief in me throughout the writing of my thesis. Finally, I would like to thank my parents, Jane and Darrell, and my sisters, Sarah and Hayley, for their support throughout my education. 


\begin{abstract}
The term 'smart city' has become a popular buzzword in urban politics, but it has not received enough critical scrutiny given the enthusiastic adoption from many scholars, governments, and corporations. This thesis contributes to broader efforts to critically analyze the concept. My work will provide a post-mortem analysis of a now canceled smart city project in Toronto, Canada. Even though the project will not be completed, there is ample material for an analysis of the project as a representation of what an 'actually-existing' smart city would look like as a comprehensive project. My thesis argues that the Toronto project (and many other projects) are organically linked to the politics and economics of accumulation of what scholars have called "urban neoliberalism." To do so, I examine the relationship between this project and interurban competition, capitalist accumulation and commodification, and privatization and corporate control.
\end{abstract}


Table of Contents

Acknowledgements ...

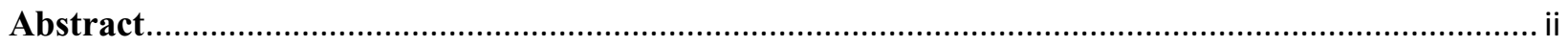

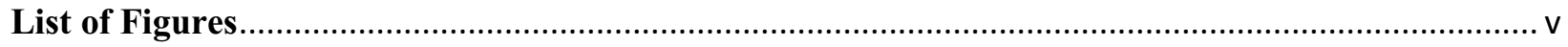

INTRODUCTION

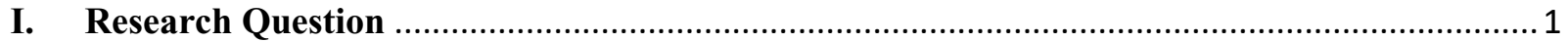

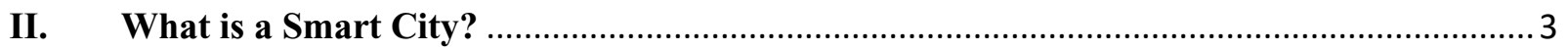

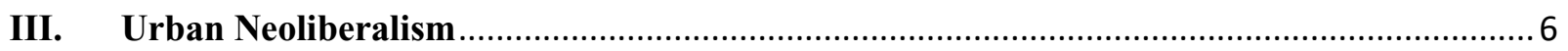

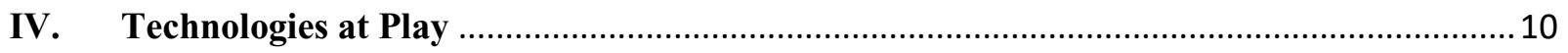

V. Sidewalk Labs, Waterfront Toronto, and the Quayside Project .......................................... 12

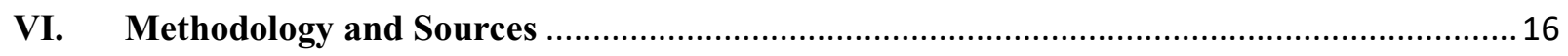

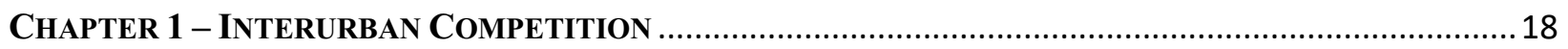

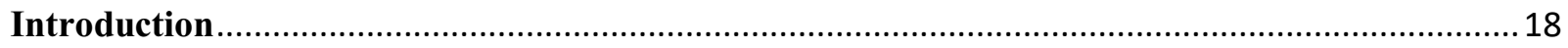

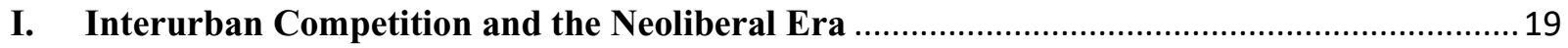

II. The Competitive Advantage of Being a Smart City ........................................................ 30

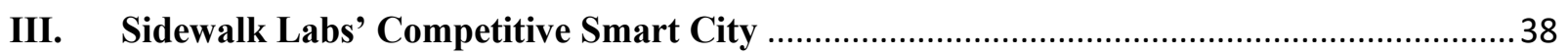

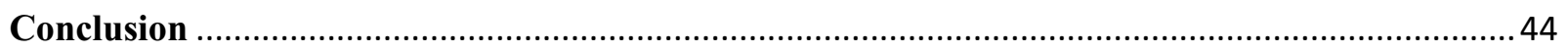

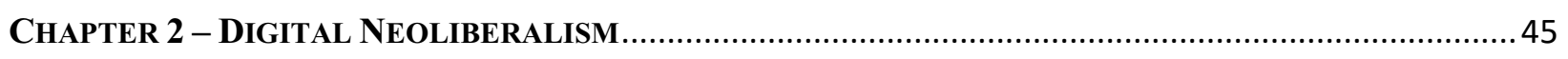

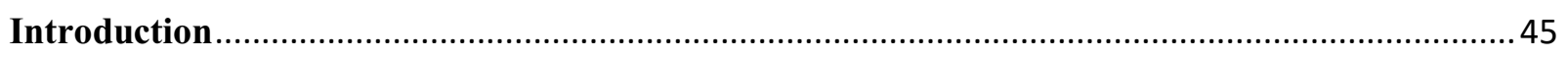

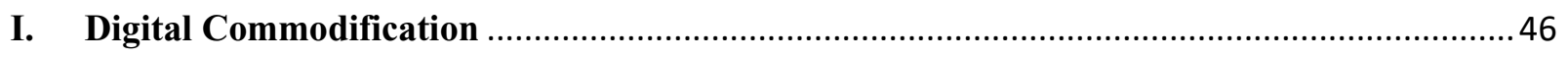

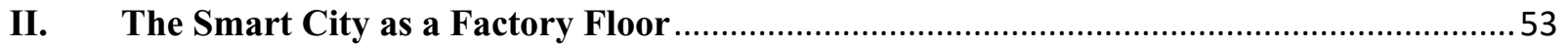

III. Sidewalk Labs' Smart City Technologies ...................................................................5

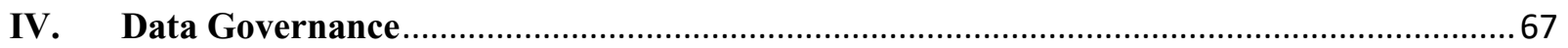

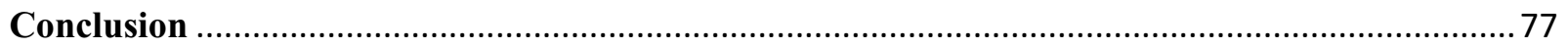

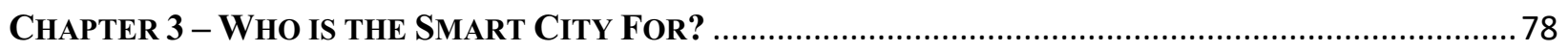

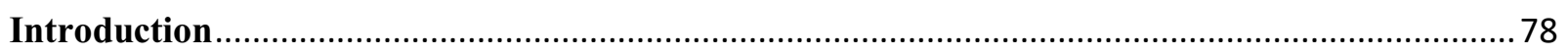

I. Urban Neoliberalism as Corporate Control ................................................................. 79

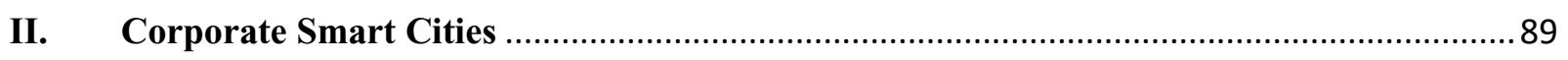

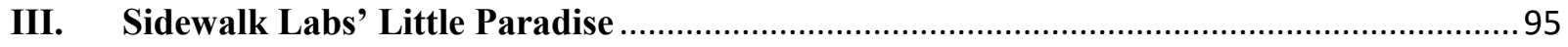

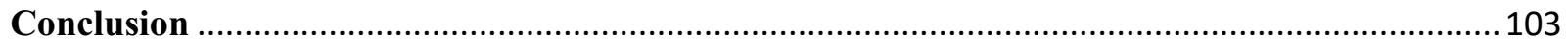

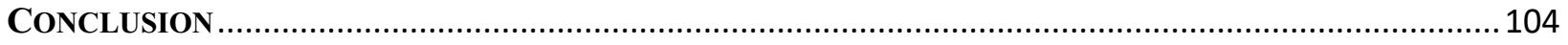

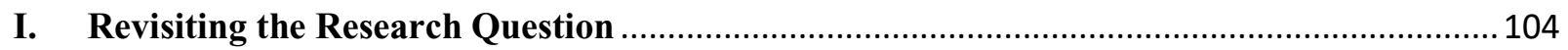

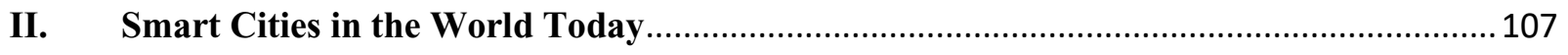




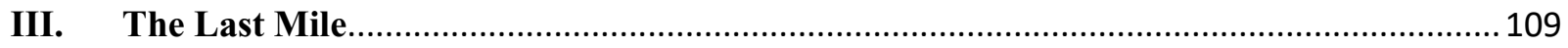

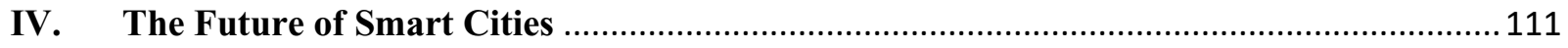

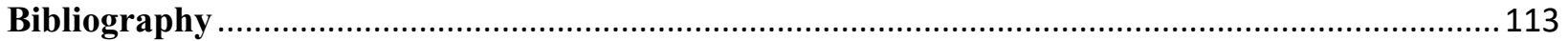




\section{List of Figures}

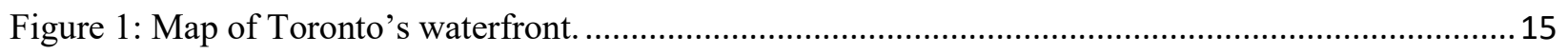

Figure 2: A screenshot of the London City Dashboard, providing details on the city.............................55

Figure 3: The pathway data would take once collected from mix-used buildings. The blue lines represent publicly accessible data, and the orange represents restricted data........................................................60

Figure 4:Data pathway in an office building using the Office Scheduler............................................... 62

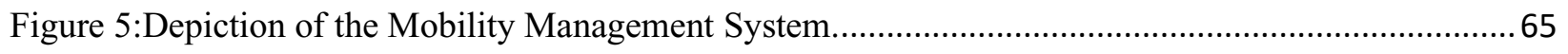




\section{INTRODUCTION}

\section{Research Question}

Since the beginning of the $19^{\text {th }}$ century, the rate at which populations around the world have been migrating into cities has increased. With technological advancement, fewer people were needed to produce food, so rural communities diminished as unemployed individuals migrated to cities in search of work. The majority of people in the world today reside in cities according to the UN, and that number is expected to increase to over two-thirds of the world's population by $2050 .{ }^{1}$ In Canada, the current percentage of people living in cities is already above 80 percent. ${ }^{2}$ As cities grow, academics and governments have continued to search for new and better ways of governing and managing the urban environment.

Along with urbanization, technological changes have accelerated rapidly. Technological innovation was and still is a root cause of urbanization but has also been a solution to issues increased urban populations create. Innovations like traffic lights and commuter transit systems are just two examples of how technologies help cities handle issues of urbanization. While technologies have always been used to solve urban issues and plan cities, in recent decades the idea of a 'smart city' has emerged and has gathered significant interest. ${ }^{3}$

The 'smart city' has become a popular buzzword in urban politics, but it has not received enough critical scrutiny given the enthusiastic adoption it has received from its "epistemic

\footnotetext{
${ }^{1}$ United Nations, "68\% of the World Population Projected to Live in Urban Areas by 2050, Says UN," United Nations (New York, 2018), https://www.un.org/development/desa/en/news/population/2018-revision-of-worldurbanization-prospects.html.

2 "Urban Population (\% of Total Population) - Canada | Data," The World Bank, accessed August 7, 2021, https://data.worldbank.org/indicator/SP.URB.TOTL.IN.ZS?end=2020\&locations $=$ CA\&start=1960\&view=chart.

3 Taylor Shelton, Matthew Zook, and Alan Wiig, "The 'Actually Existing Smart City," Cambridge Journal of Regions, Economy and Society 8, no. 1 (2015): 14-15, https://doi.org/10.1093/cjres/rsu026.
} 
community" or its wider advocacy coalition, which includes private-sector actors. ${ }^{4}$ This thesis contributes to broader efforts to critically analyze the concept. ${ }^{5}$

My work will provide a post-mortem analysis of a now canceled smart city project in Toronto, Canada. This project was started in 2018 with an agreement between the governing body, Waterfront Toronto, and Sidewalk Labs. ${ }^{6}$ The project was canceled in early 2020 due to "unprecedented economic uncertainty," according to Sidewalk Labs, caused by the pandemic which was quickly spreading into Canada at the time of the decision. ${ }^{7}$ Despite the fact that the project will not come to fruition, there is ample material provided by Sidewalk Labs to conduct an analysis of the project as a representation of what an actually-existing smart city would look like as a comprehensive project.

I have chosen to look at the Sidewalk Labs project for a number of reasons. First, it affords a good opportunity to investigate what a smart city would look like and what its proponents want to achieve. Second, it is one of a relatively small number of smart city projects that have been planned at this scale. Third, it is an early version of a model that will be more common in the future. Sidewalk Labs state that they want their project "to provide a new urban toolkit" for projects around the world. ${ }^{8}$ Fourth, the Sidewalk Labs project was going to be

\footnotetext{
${ }^{4}$ Rob Kitchin et al., "Smart Cities, Epistemic Communities, Advocacy Coalitions and the 'last Mile' Problem," It - Information Technology 59, no. 6 (2017): 275-84, https://doi.org/10.1515/itit-2017-0004.

5 Alberto Vanolo, "Is There Anybody out There? The Place and Role of Citizens in Tomorrow's Smart Cities," Futures 82 (2016), https://doi.org/10.1016/j.futures.2016.05.010.

${ }^{6}$ Waterfront Toronto, "Waterfront Toronto and Sidewalk Labs Sign Plan Development Agreement," 2018, https://waterfrontoronto.ca/nbe/portal/waterfront/Home/waterfronthome/newsroom/newsarchive/news/2018/july/wat erfront+toronto+and+sidewalk+labs+sign+plan+development+agreement.

${ }^{7}$ Moira Warburton, “Alphabet's Sidewalk Labs Cancels Toronto 'smart City' Project," Reuters, May 7, 2020, https://www.reuters.com/article/us-canada-sidewalk-idUSKBN22J2FN.

${ }^{8}$ Sidewalk Labs, "Master Innovation \& Development Plan: The Overview,” vol. 0, 2019.
} 
developed from the ground up, whereas most of the smart city literature is focused on a project that is integrating one aspect of smart city technology into an already built environment. ${ }^{9}$

My thesis argues that the Sidewalk Labs project (and many other smart city projects) are organically linked to the politics and economics of accumulation of what scholars have called "urban neoliberalism." To do so, I examine the relationship between this project and three main tenants of urban neoliberalism. In the first chapter, I look at how Sidewalk Labs reflects the neoliberal logic of interurban competition. In the second chapter, I look at how Sidewalk Labs is bound up with an emergent form of capitalist accumulation, predicated on data production, collection, analysis, and commodification. In the third chapter, I look at how Sidewalk Labs is exemplary of a broader privatization of urban governance.

\section{What is a Smart City?}

The 'smart city' concept has become a popular term for city planners, government agencies, and the private sector. ${ }^{10}$ This does not mean that this is the first time these entities have tried to use technological advancements to try and improve cities. There has always been an integration of the new technologies and a search for innovative ways to solve problems and improve the urban environment. ${ }^{11}$ According to Robert Holland, Smart Cities emerged in the 1980s from the 'Smart Growth' movement in the United States. At the time, many cities in the country had been experiencing rapid suburbanization, which created freeways leading in and out

\footnotetext{
${ }^{9}$ Francesco Paolo Appio, Marcos Lima, and Sotirios Paroutis, "Understanding Smart Cities: Innovation Ecosystems, Technological Advancements, and Societal Challenges," Technological Forecasting and Social Change 142, no. December 2018 (2019), https://doi.org/10.1016/j.techfore.2018.12.018.

${ }^{10}$ Vito Albino, Umberto Berardi, and Rosa Maria Dangelico, "Smart Cities: Definitions, Dimensions, Performance, and Initiatives," Journal of Urban Technology 22, no. 1 (2015), https://doi.org/10.1080/10630732.2014.942092.

${ }^{11}$ Taylor Shelton, Matthew Zook, and Alan Wiig, "The 'Actually Existing Smart City," Cambridge Journal of Regions, Economy and Society 8, no. 1 (2015): 14, https://doi.org/10.1093/cjres/rsu026.
} 
of cities and significant allocation of space towards parking lots for commuters. The smart growth movement was focused on the densification of cities to try and make them more efficient, walkable, and "less soil-consuming." 12 The term was injected into popular discourse and was widely recognized after global tech giants IBM, Cisco, and Siemens adopted it. ${ }^{13}$

When reviewing smart city literature, it becomes quickly apparent that there is no agreed upon definition of what a smart city entails. This is in part due to the novelty and rapid change in information and communication technologies (ICTs) in urban settings, but also because of a wide array of actors with different ideas, motives, and goals that make up the advocacy coalition. Indeed, many authors have written entire articles simply discussing the various definitions used by scholars in the field. ${ }^{14}$ While the definition of a smart city varies widely, the consistent factor is that smart cities use ICTs to gather enormous amounts of data at rapid speeds to plan and adjust activity within cities. The majority of smart city definitions are focused on physical infrastructure being infused with ICTs, creating smart water management systems, smart energy grids, smart mobility, and smart buildings, and using the ICTs to adapt and manage those systems. However, there are some that believe that a smart city requires more than just the integration of technology into the city's infrastructure. ${ }^{15}$

12 Alberto Vanolo, “Smartmentality: The Smart City as Disciplinary Strategy," Urban Studies 51, no. 5 (2014): 888, https://doi.org/10.1177/0042098013494427; Robert G. Hollands, "Will the Real Smart City Please Stand up? Intelligent, Progressive or Entrepreneurial?," City 12, no. 3 (2008), https://doi.org/10.1080/13604810802479126.

${ }^{13}$ Sarbeswar Praharaj and Hoon Han, "Cutting through the Clutter of Smart City Definitions: A Reading into the Smart City Perceptions in India," City, Culture and Society 18, no. December 2018 (2019): 2, https://doi.org/10.1016/j.ccs.2019.05.005.

${ }^{14}$ Giuseppe Grossi and Daniela Pianezzi, "Smart Cities: Utopia or Neoliberal Ideology?," Cities 69, no. July (2017), https://doi.org/10.1016/j.cities.2017.07.012; M. Batty et al., "Smart Cities of the Future," European Physical Journal: Special Topics 214, no. 1 (2012), https://doi.org/10.1140/epjst/e2012-01703-3; Michael Batty, "Big Data, Smart Cities and City Planning," Dialogues in Human Geography 3, no. 3 (2013), https://doi.org/10.1177/2043820613513390; Albino, Berardi, and Dangelico, "Smart Cities: Definitions, Dimensions, Performance, and Initiatives," 2; Hollands, "Will the Real Smart City Please Stand up? Intelligent, Progressive or Entrepreneurial?"

${ }^{15}$ Appio, Lima, and Paroutis, "Understanding Smart Cities: Innovation Ecosystems, Technological Advancements, and Societal Challenges." 
For this thesis I will be using the second approach to defining a smart city, which encompasses more than physical infrastructure. This definition finds its roots in the work of Rudolf Giffinger et al. and their study in which they ranked medium sized European smart cities. ${ }^{16}$ Giffinger et al.'s framework emphasized six distinct characteristics that a smart city would be judged on: Smart economy; Smart mobility; Smart governance; Smart environment; Smart living; Smart people. They outline the six characteristics in their report, which is meant to asses the attractiveness of cities and to help "sharpen their profile and to improve their position in the competition of cities." ${ }^{17}$ This approach to defining a smart city takes into account "hard factors' like infrastructure, industry, and the environment and 'soft factor,' which includes social and political life, housing, social and ethnic plurality, and innovative spirit. ${ }^{18}$ A similar approach to smart cities can be found in the work of Leot Leydesdorff and Mark Deakin. They have created what they call the "triple helix model" to smart cities, in which they emphasis that a smart city needs to have "intelligent communities" which would take the shape of a collaborative community to "facilitate innovation" by creating connections between citizens, businesses, governments, and educational institutions. ${ }^{19}$ While I highlight the authors of the mentioned articles, there are many that believe that soft factors like the knowledge economy are fundamental to a smart city, as exemplified in Vito Albino et al.'s article. ${ }^{20}$

There are two main reasons for me to use the conception of smart cities that goes beyond the physical infrastructure. The first is that Sidewalk Labs was clearly striving for a smart city in

\footnotetext{
${ }^{16}$ Rudolf Giffinger et al., "Smart City: Ranking of European Medium-Sized Cities," Centre of Regional Science, Vienna UT, 2007.

${ }^{17}$ Giffinger et al, 13 .

${ }^{18}$ Giffinger et al.

${ }^{19}$ Loet Leydesdorff and Mark Deakin, "The Triple-Helix Model of Smart Cities: A Neo-Evolutionary Perspective," Journal of Urban Technology 18, no. 2 (2011), https://doi.org/10.1080/10630732.2011.601111; Appio, Lima, and Paroutis, "Understanding Smart Cities: Innovation Ecosystems, Technological Advancements, and Societal Challenges," 2.

${ }^{20}$ Albino, Berardi, and Dangelico, "Smart Cities: Definitions, Dimensions, Performance, and Initiatives," 6-8.
} 
the image of Giffinger et al., as I delve into below and continue to expand on throughout my thesis. The second is that while many definitions only focus on physical infrastructure as it relates to smart cities, by changing the environment in which people live in, everyday urban life is also affected. Therefore, while many projects would only change one aspect of a city's structure and how individuals interact with it, as more projects are completed in a city, the result will be a more encompassing smart city, like how Giffinger et al. and Sidewalk Labs envision.

\section{Urban Neoliberalism}

With the emergence of any new paradigm, it is important to look back at the environment the new concept emerged from. In this case, we need to understand that smart cities emerged in the context of urban neoliberalism and is shaped by its market logics.

The neoliberal ideology holds that markets that are free from state interference offer the best form of economic development. ${ }^{21}$ Inspired by the writings of Friedrich Hayek and Milton Freedman, it is "a doctrine, loosely conceived, that argues for the desirability of a society organized around self-regulating markets, and free, to the extent possible, from social political intervention."22 Jamie Peck and Adam Tickell describe neoliberalism as something which "combines a commitment to the extensions of markets and logics of competitiveness with a profound antipathy to all kinds of Keynesian or collectivist strategies."23

\footnotetext{
${ }^{21}$ Neil Brenner and Nik Theodore, "Cities and the Geographies of "Actually Existing Neoliberalism," in Spaces of Neoliberalism: Urban Restructuring in North America and Western Europe, ed. Neil Brenner and Nik Theodore (Oxfird: Blackwell Publishing, 2002), 2-3.

${ }^{22}$ Derek Gregory et al., eds., The Dictionary of Human Geography, 5th ed. (Wiley-Blackwell, 2009), $497-498$.

${ }^{23}$ Jamie Peck and Adam Tickell, "Neoliberalizing Space," in Spaces of Neoliberalism: Urban Restructuring in North America and Western Europe, ed. Neil Brenner and Nik Theodore (Oxford: Blackwell Publishing, 2002), 3334.
} 
Peck and Tickell outline two distinct phases of neoliberalization, which they emphasize is a process rather than a state. One phase of neoliberalization is 'roll-back' neoliberalism, which is characterized by austerity, lean government, and adhering to market logics. This phase of neoliberalism can be exemplified by the Margaret Thatcher and Ronald Reagan governments' deconstruction of "anticompetitive" institutions like labour unions and social welfare programs. ${ }^{24}$ The other is 'roll-out' neoliberalism, which is preformed through the creation of new institutions and regulations which support the continuation and spread of neoliberalism. ${ }^{25}$ This phase of neoliberalism is exemplified by organization like the World Trade Organization (WTO), World Bank, and International Monetary Fund (IMF), which all enforce and spread the neoliberal project internationally. ${ }^{26}$

In the urban context, David Harvey observed the transition in urban governance to one in line with neoliberal thinking. In the 1970s governments shifted from a form of managerial governance, where they strived for full employment and the provision of local services, to what he called urban "entrepreneurialism." ${ }^{27}$ Entrepreneurial urban governance takes the form of local officials "doing the best they can to maximise the attractiveness of the local site as a lure for capitalist development." ${ }^{28}$ This commonly done through tax incentives and business-friendly regulations, and has recently included attracting the Creative Class, which is discussed below.

Under urban neoliberalism, cities are included in competitive markets through the competition for international flows of capital, investment, and the right type of "productive" individuals according to market logics. To be competitive at the international scale, cities pursue

\footnotetext{
${ }^{24}$ Peck and Tickell, 39.

${ }^{25}$ Peck and Tickell.

${ }^{26}$ Brenner and Theodore, "Cities and the Geographies of "Actually Existing Neoliberalism," 3.

${ }^{27}$ David Harvey, "From Managerialism to Entrepreneurialism: The Transformation in Urban Governance in Late Capitalism," Geografiska Annaler 71, no. B (1989): 3.

${ }^{28}$ Harvey, 5.
} 
'growth first' urban strategies that signal that they are a business-friendly environment worth investing in. Interurban competition can take on other forms as well, such as hosting cultural spectacles, political and diplomatic events, or anything that brings positive international attention to the city.

Interurban competition has spawned the idea that cities are a special kind of product that need to market themselves and create a brand. ${ }^{29}$ City branding has become a key part of urban neoliberalism with the premise that urban space is a commodity that needs to be sold same as any other commodity. In the global neoliberal era, cities need to advertise and brand themselves in order to attract the international flows of culture, tourism, and investment in order to prosper. ${ }^{30}$ One of the fundamental ways cities pursue international branding measures is through the implementing policies and redevelopments in order to rework the city into an attractive destination. Urban regions attempt to construct and market themselves as desirable sites for cultural spectacles, they dedicate urban areas as enterprise zones and privatize forms of local governance through public-private partnerships to attract business. Efforts to attract investment and capital result in cities undercutting each other. As cities provide beneficial environments for international capital, other cities are forced to go further to not lose out. ${ }^{31}$ Roll-out neoliberalism is perpetuated through interurban competition as cities are integrated into the fold of urban neoliberal doctrine as they try to not fall behind, and the reorientation of government functions in support of market logics.

\footnotetext{
${ }^{29}$ G. J. Kavaratzis, M., \& Ashworth, "City Branding: An Effective Assertion Of," Tijdschrift Voor Economische En Sociale 96(5), no. 5 (2005): 506.

${ }^{30}$ Kavaratzis, M., \& Ashworth.

${ }^{31}$ Alberto Vanolo, "Cities Are Not Products," Tijdschrift Voor Economische En Sociale Geografie 111, no. 1 (2019), https://doi.org/10.1111/tesg.12385; Stefan Kipfer and Roger Keil, "Toronto Inc? Planning the Competitive City in the New Toronto," Antipode 34, no. 2 (2002), https://doi.org/10.1111/1467-8330.00237.
} 
At the beginning of the new millennium, urban competitiveness shifted from attracting businesses via austerity and towards a competitiveness predicated on luring the 'Creative Class.' The idea is that cities need to attract the 'right type' of people, who provide economic productivity. ${ }^{32}$ The 'right type' of person is usually understood as an induvial that is tech-savvy, young, and interested in cultural attractions and the activities an urban centre has to offer.

Richard Florida, who uses the term the "Creative Class" in The Rise of the Creative Class, argues that to attract high-tech workers, urban planners need to create a city in which those types of people would be interesting in living in. This type of person is attracted to "cool" cities and city planners should dedicate their planning to creating an environment according to the Creative Class criteria. As Florida puts it, "Creative people do not move for traditional reasons," but rather, look for "abundant high-quality amenities and experiences, an openness to diversity of all kinds, and above all else the opportunity to validate their identities as creative people."33 Therefore, according to Florida, cities need to pursue urban strategies that work towards attracting the creative class through the creation of amenities and cultural location the Creative Class finds desirable. Attracting the Creative Class follows a highly speculative "build it and they will come" urban strategy. This is the logic that the City of Toronto followed in their postamalgamation planning, which focused on strategies of investing in cultural attractions and activities in an attempt to attract the 'right people' to the city. ${ }^{34}$

Finally, throughout the thesis, but particularly in the second and third chapters, I will illuminate how corporations are trying to position themselves as "obligatory passage points" for

\footnotetext{
${ }^{32}$ Richard Florida, The Rise of the Creative Class (New York: Basic Books, 2019).

${ }^{33}$ Florida, 186.

${ }^{34}$ Julie-Anne Boudreau, Roger Keil, and Douglas Young, Changing Toronto (Toronto: University of Toronto Press Inc., 2009), https://doi.org/10.3138/9781442603363.
} 
urban development. ${ }^{35}$ This is especially pertinent to the discussion on smart cities and Sidewalk Labs. In their article, Ola Soderstrom, Till Paasche, and Francisco Klauser explore the role IBM has played in the popularization of the concept of the 'smart city' and what the implications of their involvement are. The authors argue that companies like IBM (and in this case Sidewalk Labs) are taking control of the "story telling" of the urban development of a smart city. This allows them to present themselves as uniquely qualified experts in the field of smart city development. One important difference between the work of IBM and Sidewalk Labs is that the former focuses on software and consultancy, and the latter, in the case study for this thesis, takes a more comprehensive role in the development of a smart city.

\section{Technologies at Play}

In order for cities to attract the desired people in the high-tech industries some authors believe cities need to make themselves more technologically advanced. ${ }^{36}$ Therefore, both smart cities and Florida's Creative Class require ICTs to be involved in the identity of the city. Shoshana Zuboff and Jathan Sadowski have recently written books on the growing concerns involved in ICTs. ${ }^{37}$ Collecting and analyzing data is a vital aspect to smart cities in practice as they rely on data generated by the people of the city to increase efficiency and services.

Data collected on people can be used in other ways, however. Companies have learned that by collecting data on users off platforms like Google and Facebook, predictions can be made

\footnotetext{
${ }^{35}$ Ola Söderström, Till Paasche, and Francisco Klauser, "Smart Cities as Corporate Storytelling," City 18, no. 3 (2014): 307-20, https://doi.org/10.1080/13604813.2014.906716.

${ }^{36}$ Florida, The Rise of the Creative Class.

${ }^{37}$ Shoshana Zuboff, The Age of Surveillance Capitalism: The Fight for a Human Future at the New Frontier of Power, First edit (New York: PublicAffairs, 2019); Jathan Sadowski, Too Smart, Too Smart, 2020, https://doi.org/10.7551/mitpress/12240.001.0001.
} 
about the type of person they are and the things they would be interested in buying. ${ }^{38}$ In recent decades, data collection, analysis, and sale has become an important revenue stream for some of the largest companies. For example, Google posted US\$55.31 billion in first quarter profits for 2021, and Facebook who saw US\$25.44 billion over the same period, just in advertisement revenue. ${ }^{39}$ Additionally, this data can be used to manipulate people into believing certain ideologies and act in certain ways they may not have otherwise. ${ }^{40}$ The impacts of data collection and analysis can be unclear, however the dangers have been exemplified through the Cambridge Analytica scandal, which is a company that builds "psychological profiles" on people, and reportedly had impacts on the US election in. ${ }^{41}$ Therefore, the data collected can be both profitable and used to nudge people and alter their behavior.

Zuboff uses the term surveillance capitalism to describe this form of accumulation. She describes it as "a new economic order that claims human experience as free raw material for hidden commercial practice of extraction, prediction, and sale." 42 However, I tend to agree more with Sadowski's critique of Zuboff's definition. Sadowski recognizes that Zuboff considers this

\footnotetext{
${ }^{38}$ Sadowski, Too Smart; Zuboff, The Age of Surveillance Capitalism: The Fight for a Human Future at the New Frontier of Power.

${ }^{39}$ Sarah E. Needleman, "Facebook's Ad Business Drives Surge in Revenue, Following Google's Act," Wall Street Journal, 2021, https:/www.wsj.com/articles/facebook-fb-1q-earnings-report-2021-11619610405.

${ }^{40}$ Jonathan Zittrain, "Facebook Could Decide an Election Without Anyone Ever Finding Out," The New Republic, 2014, https://newrepublic.com/article/117878/information-fiduciary-solution-facebook-digitalgerrymandering; Julia Carrie Wong, "The Cambridge Analytica Scandal Changed the World - but It Didn't Change Facebook," The Guardian, 2019, https://www.theguardian.com/technology/2019/mar/17/the-cambridge-analyticascandal-changed-the-world-but-it-didnt-change-facebook; Kashmir Hill, "God View': Uber Allegedly Stalked Users For Party-Goers' Viewing Pleasure," Forbes, 2014, https:/www.forbes.com/sites/kashmirhill/2014/10/03/god-view-uber-allegedly-stalked-users-for-party-goersviewing-pleasure/?sh=37c190313141; Nicholas Confessore, "Cambridge Analytica and Facebook: The Scandal and the Fallout So Far,” New York Times, 2018, https:/www.nytimes.com/2018/04/04/us/politics/cambridge-analyticascandal-fallout.html.

${ }^{41}$ Wong, "The Cambridge Analytica Scandal Changed the World - but It Didn't Change Facebook"; Brian Resnick, “Cambridge Analytica's 'Psychographic Microtargeting': What's Bullshit and What's Legit," Vox, March 26, 2018, https://www.vox.com/science-and-health/2018/3/23/17152564/cambridge-analytica-psychographicmicrotargeting-what.

${ }^{42}$ Zuboff, The Age of Surveillance Capitalism: The Fight for a Human Future at the New Frontier of Power, Front matter.
} 
new form of accumulation to be a "rogue mutation" of capitalism, whereas he states: "We're not dealing with a technopolitical system that is outside capitalism or an aberration from it," but rather, "just variations of the same old capitalism, but now running on some new hardware and software." $" 43$

Google, whose parent corporation, Alphabet Inc, was behind the Sidewalk Labs project, not only benefits financially from the collection and analysis of data, but, according to Zuboff, it is also the creator of this process and has remained at the cutting edge of its evolution. ${ }^{44}$

\section{Sidewalk Labs, Waterfront Toronto, and the Quayside Project}

Sidewalk Labs is a New York City based urban planning and innovation company which has portfolio companies involved in various aspects of urban planning and infrastructure development. On their website, they state that "Sidewalk Labs aims to combine forward-thinking urban design and cutting-edge technology to radically improve urban life." 45 The company was conceived by Daniel L. Doctoroff, Dr. Rohit Agarwal, and a team at Google in 2015. When it was first created, the founders described the new Google backed start-up as an "urban innovation company" that would pursue technologies to cut pollution, curb energy use, streamline transportation and reduce the cost of city living. ${ }^{46}$ Sidewalk Labs is involved in a number of projects with cities across North America, however, the project that was underway in Toronto was set to be the largest and most comprehensive.

\footnotetext{
${ }^{43}$ Sadowski, Too Smart, 50.

${ }^{44}$ Zuboff, The Age of Surveillance Capitalism: The Fight for a Human Future at the New Frontier of Power.

45 "Sidewalk Labs - Home," Sidewalk Labs, accessed September 13, 2020, https:/www.sidewalklabs.com/.

${ }^{46}$ Steve Lohr, "Sidewalk Labs, a Start-Up Created by Google, Has Bold Aims to Improve City Living," New York Times, June 10, 2015, https://www.nytimes.com/2015/06/11/technology/sidewalk-labs-a-start-up-created-bygoogle-has-bold-aims-to-improve-city-living.html.
} 
Doctoroff, one of three founders of Sidewalk Labs and current Chairman and CEO, is a New York based businessman and former government official. Doctoroff began his career as an investment broker at Lehman Brothers and later at Oak Hill Capital Partners. Under Mayor Michael Bloomberg, Doctoroff was the Deputy Mayor for Economic Development and Rebuilding from 2002-2007. As Deputy Mayor of NYC, according to his bio on Sidewalk Labs' website, Doctoroff led the largest affordable housing program ever launched by an American city and the formation of new Central Business Districts and Industrial Business Zones. Doctoroff was also a significant player in the creation of PlaNYC, a 127-point plan designed to create the first environmentally sustainable 21 st century city that sets the course for a $30 \%$ reduction in global warming emissions by $2030 .{ }^{47}$

Dr. Agarwal is the head of Urban Systems at Sidewalk Labs. Agarwal holds a BA, MBA, and $\mathrm{PhD}$ in US History from Columbia University and an MA in Canadian History from Queens University. He has worked for multiple Bloomberg entities such as Bloomberg Philanthropy, Bloomberg Associates, and he was a Special Advisor to Michael Bloomberg while he was Chair of the C40 and was Director of New York City's Office of Long-Term Planning and Sustainability. During his time working for Bloomberg, Agarwal played a key role in the creation of the PlaNYC with Doctoroff. ${ }^{48}$

Craig Nevill-Manning is the third founder of Sidewalk Labs and fulfills the role of Head of Sidewalk Urban Products. Nevill-Manning previously worked for Google as a computer scientist on a number of projects including Google Maps and Google Shopping. He also worked

\footnotetext{
${ }^{47}$ Sidewalk Labs, “Our Team,” Sidewalk Labs, accessed September 15, 2020, https://www.sidewalklabs.com/team/; Lohr, "Sidewalk Labs, a Start-Up Created by Google, Has Bold Aims to Improve City Living."

48 Sidewalk Labs, "Our Team."
} 
for Google's philanthropic arm, Google.org. ${ }^{49}$ Nevill-Manning is the Google connection for Sidewalk Labs.

The other important actor to mention in this case study is Waterfront Toronto, which is described as the "public advocate and steward" of Toronto's waterfront on their website. They play a key role in the revitalization of roughly 800 hectares. The Governments of Canada and Ontario and the City of Toronto created this body with the mandate to "deliver a revitalized waterfront.. ${ }^{, 0}$ On the Board of Directors of Waterfront Toronto are 12 individuals, 4 appointed by each level of government. The board is chaired by a man named Stephen Dimond, who is the CEO of a real-estate company active in Toronto and was appointed by the three levels of government. ${ }^{51}$

In March of 2017, Waterfront Toronto released a Request for Proposal (RFP) for a partner in the development of a section of Toronto's waterfront. ${ }^{52}$ In the RFP, Waterfront Toronto outlined a series of objectives that the potential partner would aid in fulfilling for the Quayside project, a 5-hectare area in the East Bayfront neighbourhood which is a "postindustrial" brownfield development opportunity (see figure 1). ${ }^{53}$ There are four main pillars in the RFP which lay the foundation and objective for the development project in the Quayside. The first objective outlined by the document is sustainability, resiliency, and urban innovation. Waterfront Toronto was looking to make the Quayside project a large-scale pilot project to advance a new market for climate-positive urban development and building the city's reputation

\footnotetext{
${ }^{49}$ Sidewalk Labs.

50 “About Us," Waterfront Toronto, accessed August 10, 2020, https://www.waterfrontoronto.ca/nbe/portal/waterfront/Home/waterfronthome/about-us.

51 "About Us."

52 Waterfront Toronto, “Quayside RFP,” 2017, https:/waterfrontoronto.ca/nbe/portal/waterfront/Home/waterfronthome/newsroom/newsarchive/news/2017/march/ waterfront-toronto-takes-first-step-in-building-quayside.

${ }^{53}$ Waterfront Toronto.
} 
and brand globally. This would be done through the creation and incorporation of technologies with the goal being to increase efficiency and improve quality of life. The second objective, Waterfront Toronto wanted to make the Quayside a complete community. This means the availability of housing types for all families of different sizes and income levels. The area would also include a mix of public open spaces, culture, recreation, retail, education related activities, and offices. The third objective of Waterfront Toronto is economic development and prosperity. Notably, Waterfront Toronto wants to provide a space for industries like clean-tech and broader innovation-driven sectors to find a home in this area and the larger Eastern Waterfront, of which the Quayside is a small portion. The fourth objective is partnership and investment. This last objective is an acknowledgement of the limited government funding available in projects similar to this. Therefore, Waterfront Toronto was looking for a partner that has internal capacity in terms of knowledge and finances to manage financial risk in the construction of the project. ${ }^{54}$

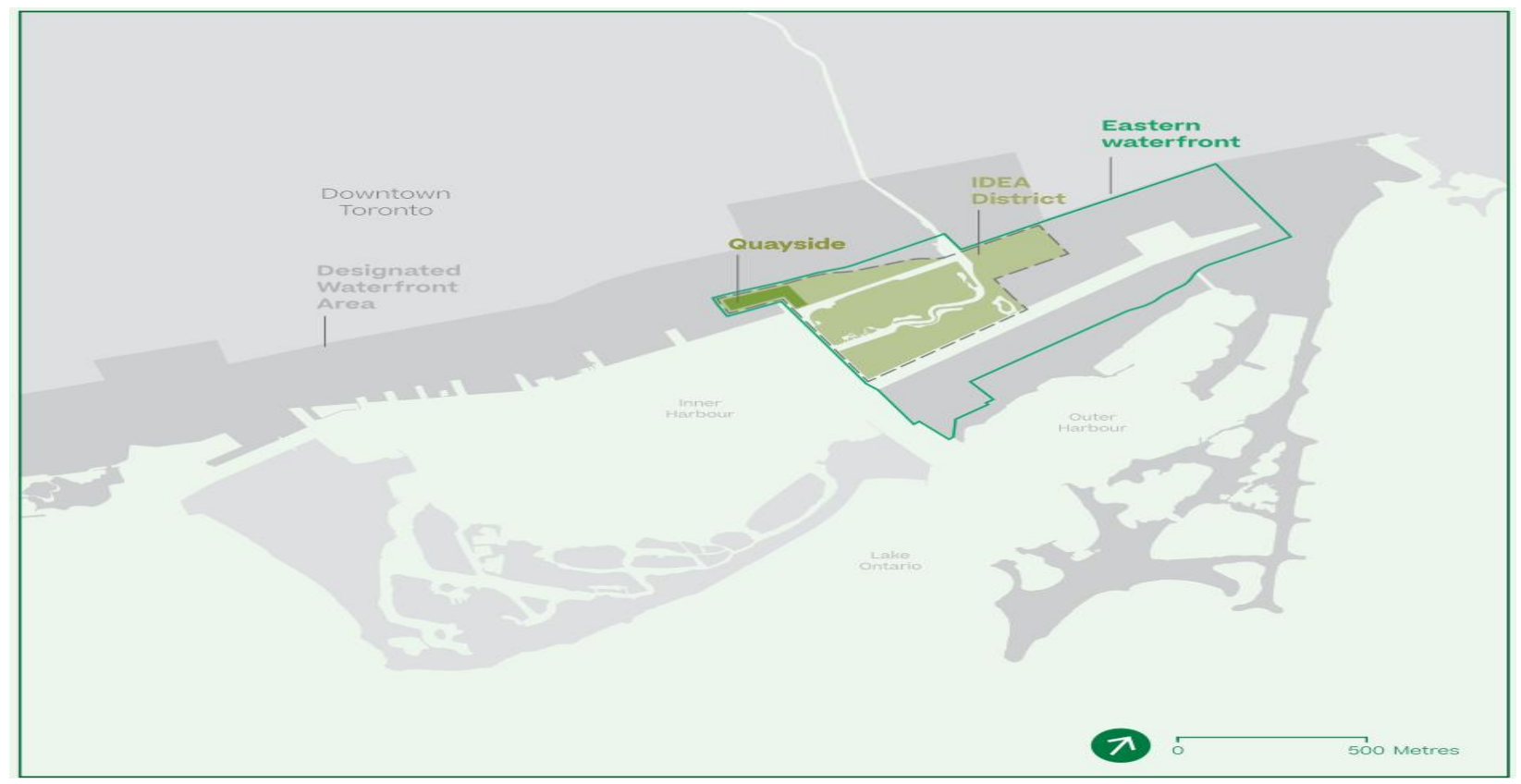

Figure 1: Map of Toronto's waterfront. ${ }^{55}$

\footnotetext{
${ }^{54}$ Waterfront Toronto.

${ }^{55}$ Sidewalk Labs, "Master Innovation \& Development Plan: The Overview."
} 
By October 2017, Sidewalk Labs and Waterfront Toronto signed a preliminary agreement for the planning and development of the Quayside project. Sidewalk Labs started holding public consultations shortly afterwards. In July 2018, Waterfront Toronto released a Plan Development Agreement (PDA) with Sidewalk Labs, "paving the way for an innovative waterfront community plan." ${ }^{" 56}$ The PDA defined and governed the relationship between the two parties as they worked together in the creation of a development plan for the Quayside. The agreement reinforces the two parties' commitment to building a community which fosters economic development, job creation, and creating a destination for people, companies, and organizations. In 2019, Sidewalk Labs published their Master Innovation \& Development Plan (MIDP), in which they outline their vision for not just the Quayside, but a larger IDEA (Innovation Design and Economic Acceleration) district they wanted to construct.

\section{Methodology and Sources}

This study is based on careful scrutiny of documents produced by Sidewalk Labs and connected secondary literature. It also draws on the work of geographers, technology theorists, and political economists. With this material, I provide a critical analysis of the growing literature on smart cities.

Sidewalk Labs increased its activity and consultations in the surrounding communities after the PDA. In June 2019, Sidewalk Labs submitted its MIDP to Waterfront Toronto for

\footnotetext{
56 “Waterfront Toronto and Sidewalk Labs Sign Plan Development Agreement," Waterfront Toronto, 2018, https://waterfrontoronto.ca/nbe/portal/waterfront/Home/waterfronthome/newsroom/newsarchive/news/2018/july/wat erfront+toronto+and+sidewalk+labs + sign + plan+development+agreement.
} 
consideration. ${ }^{57}$ This three-volume, eleven-hundred-page document, which was submitted to Waterfront Toronto will be the foundation for my discussion concerning the case study. I will also use news articles and reports from Waterfront Toronto that allow for a more encompassing view of the project by including broader perspectives.

My discussion on smart cities and urban neoliberalism relies heavily on academic sources. While I pull from a broad range of academic literature on urban neoliberalism, I pay particular attention to urban neoliberalism in Toronto, as the cite of my case study. I also pay particular attention to the work of Florida on the Creative Class.

For smart cities, I rely more on peer-reviewed articles. Additionally, I look at companies like IBM and Google/Sidewalk Labs, as well as journalistic articles in news media for their input into the smart city discourse. For critical analysis, I rely in particular on Sadoski's Too Smart and Zuboff's The Age of Surveillance Capitalism to provide the framework for grappling with the intricacies of this approach to city management. ${ }^{58}$

The smart city shift provides academics and governments the opportunity to change the way they look at cities in a massive way. While many academics acknowledge this opportunity, so far both academics and governments have fallen into the existing urban neoliberal trends that have existed since the 1970s. Local governments are in many cases the most impactful on the daily life of people, and urban policy alters the environment they live in, making the smart city concept an important idea to analyse. My thesis endeavours to demonstrate this continuation of urban neoliberalism into the smart city era in academic, political, and popular discourses, and the

\footnotetext{
${ }^{57}$ Sidewalk Labs, "Master Innovation \& Development Plan: The Overview"; Sidewalk Labs, "Master Innovation \& Development Plan: Volume 1," 2019; Sidewalk Labs, "Master Innovation \& Development Plan: Volume 2," 2019; Sidewalk Labs, "Master Innovation \& Development Plan: Volume 3," 2019.

${ }^{58}$ Sadowski, Too Smart; Zuboff, The Age of Surveillance Capitalism: The Fight for a Human Future at the New Frontier of Power.
} 
potential increased focus on market logics in the smart city era caused in part by the commodification of data.

\section{CHAPTER 1 - INTERURBAN COMPETITION}

\section{Introduction}

Neoliberal ideology stands on the premise that, among other things, open and free markets will self regulate, and resources will fall into their most efficient allocations. ${ }^{59}$ Following the neoclassical theory of resource scarcity, urban neoliberalism has created an environment in which cities must compete for the available capital before it gets allocated to another city. Especially in Canada where the largest and most consistent way for municipal governments to raise funds for services is through property tax and user fees, cities to go to great lengths to attract businesses to increase revenue. ${ }^{60}$ Governments have used different mechanisms trying to increase flows of international capital into their cities, from tax incentives, to spending in cultural attractions, to city branding initiatives. This chapter demonstrates a line of continuity between the interurban competition demanded by urban neoliberalism, Creative Class focused urban strategies, and the emergence of smart cities, as demonstrated through Sidewalk Labs' project in Toronto.

The first section of this chapter will outline the shifts in urban governance into urban 'entrepreneurialism,' and how it has evolved since the initial shift, paying particular attention to

\footnotetext{
${ }^{59}$ Brenner and Theodore, "Cities and the Geographies of "Actually Existing Neoliberalism," 2-3.

60 “Canadian City Finances Ailing from COVID-19,” RBC Economics, June 9, 2020, https://thoughtleadership.rbc.com/canadian-city-finances-ailing-from-covid-19/.
} 
the Creative Class. ${ }^{61}$ The second section will then outline how smart cities have continued the logic of interurban competition through many of the same methods. In the second section I also outline the connection between smart cities and the Creative Class. Finally, in the third section, I will focus on the main case study by demonstrating how Sidewalk Labs' plan adheres to the same template of interurban competition and the Creative Class that is discussed in section two and three. This chapter argues the logic of neoliberal interurban competition animates smart city thinking in general and the Sidewalk Labs project in particular. To demonstrate the latter, I scrutinize the Sidewalk Labs' MIDP.

\section{Interurban Competition and the Neoliberal Era}

In the post-war era and well into the 1960s governments were concerned with pursuing full employment. Policy objectives changed in the 1970s and have continued to this day with the introduction of smart cities. In the 1970s, the national governments of the industrialized capitalist states in the West like the United Kingdom and the United States began to move their attention away from managerialist type of governance. In the United States, the transition was notably marked with then President Richard Nixon declaring that the urban crisis was over. That declaration was accompanied by a reduction of allocated funds from the national government to state and local governments. ${ }^{62}$ In his description from managerialism to entrepreneurialism, Harvey states: "this shift towards entrepreneurialism is by no means been completed." ${ }^{63}$ While Harvey seemed to believe, at the time, that this transition would one day be completed, over a decade later, Peck and Tickell's article finally acknowledged that urban neoliberalism is not so

\footnotetext{
${ }^{61}$ David Harvey, "From Managerialism to Entrepreneurialism : The Transformation in Urban Governance in Late Capitalism," Geografiska Annaler 71, no. B (1989).

${ }^{62}$ Harvey.

${ }^{63}$ Harvey, 4.
} 
much a phase as a process. ${ }^{64}$ In this section I consider the urban neoliberal logic of interurban competition which smart cities emerged from. In the next section I argue that this process continues today through the introduction of the smart city.

With the reduced allocated funds from the national governments, cities in industrialized capitalist states were forced to do what they could to promote the local region to attract new business in hopes that they could fill in the funding gaps left by retrenchment. ${ }^{65}$ Attracting businesses became essential to local policy makers, especially in Canada, because they have a very limited ability to generate revenue. Property tax is the most lucrative means of collecting funds for city services because they are not able to collect income or sales tax. Cities can also rely on some funding from provincial and federal governments, however, that is not guaranteed money, and can change drastically from one government to another. ${ }^{66}$

Stefan Kipfer and Roger Keil use a series of theories to help explain the shift Toronto has taken into a competitive city. Combining world city theory, regime/growth machine theory, regulation theory, and neo-Gramscian political and local state theory, the authors describe the competitive city as a broader shift in contemporary politics. ${ }^{67}$ They explain it as "a shift in city governance understood loosely as a constellation of gendered and racialized class forces, political coalitions, ideologies, and discourses that tie civil society to policy patterns and

\footnotetext{
${ }^{64}$ Jamie Peck and Adam Tickell, "Neoliberalizing Space," Economy: Critical Essays in Human Geography, 2002, https://doi.org/10.4324/9781351159203-22.

${ }^{65}$ Harvey, "From Managerialism to Entrepreneurialism: The Transformation in Urban Governance in Late Capitalism.”

${ }^{66}$ Zack Taylor and Neil Bradford, "The New Localism: Canadian Urban Governance in the Twenty-First Century," in Canadian Cities in Transition: Perspectives for an Urban Age, ed. Pierre Filion et al., 5th ed. (Don Mills, Ontario: Oxford University Press, 2015), 197.

${ }^{67}$ Stefan Kipfer and Roger Keil, "Toronto Inc? Planning the Competitive City in the New Toronto," Antipode 34, no. 2 (2002), https://doi.org/10.1111/1467-8330.00237.
} 
administrative forms of the local state. ${ }^{\prime 68}$ The competitive city and urban neoliberalism more generally, should be understood as extending much beyond the economics of the city.

Boudreau, Keil, and Young take an in depth look at the urban effects of neoliberalism in Toronto in Changing Toronto ${ }^{69}$ In Canada, provincial governments have a large amount of the decision-making power over municipalities. When Mike Harris of the Progressive Conservative Party of Ontario was elected Premier of Ontario in 1995, he pursued roll-back neoliberal policies with the goal of lowering taxes and balancing the budget. Harris' methods of lowering the taxes of middle-class Ontarians were done largely through reducing and restructuring government. Part of their strategy to lower taxes was to download some social welfare responsibilities onto municipal governments. For this to be achievable, the Harris government believed the amalgamation of Toronto was the only way lower levels of government could assume their new responsibilities of welfare services. ${ }^{70}$ The Amalgamated Toronto included the original City of Toronto, and inner suburbs like Scarborough, Etobicoke, York, North York, East York.

An unintentional benefit of amalgamation was that it had essentially gerrymandered the city's political geography in a way that weakened the left-of-center city core via the incorporation of the larger conservative inner suburban regions. The new conservative suburban base in the city resulted in the election of conservative candidate Mel Lastman as the first Mayor of the amalgamated Toronto. However, the main reason for the amalgamation remained to follow neoliberal logic of reducing government and downloading responsibilities to lower levels

\footnotetext{
${ }^{68}$ Kipfer and Keil, 234.

${ }^{69}$ Boudreau, Keil, and Young, Changing Toronto.

${ }^{70}$ Boudreau, Keil, and Young, 72.
} 
of government, which did not have the ability to raise enough funds to provide the programs they were now in charge of. ${ }^{71}$

With the amalgamation came the writing of the new Official Plan, appropriately called TorontoPlan..$^{72}$ This was meant to provide the city a guiding document for the following 20 to 30 years and act as roll-out portion of amalgamation's urban neoliberal objectives. The Official Plan was undoubtedly growth oriented. The basic assumption of the document was that globalization creates competition among cities around the world for available capital, which is necessary for success. $^{73}$

To enable the desired growth, and to attract global capital for urban development, the Official Plan was designed to make bylaws less restrictive and more market-friendly, and therefore more competitive and attractive internationally. ${ }^{74}$ Those writing the Official Plan did this by removing density and height limits and by simplifying and reducing the number of different land designations to be less restrictive and effectively less nuanced. Planners and developers had more freedom in building large towers, even in areas that did not fit the surrounding neighbourhoods. Urban planning discourse shifted to focus and promote aestheticization in planning, which was used to argue for deregulation of urban space. Tall slim residential buildings were seen as fundamental to building a recognizable skyline of a global city. ${ }^{75}$ Loosening regulations was also promoted as a solution to sprawl, which was recognized as a problem at the time and has only increased. Today the densification of urban environments is seen by some as a key to sustainability and a solution to environmental issues, much in the same

\footnotetext{
${ }^{71}$ Boudreau, Keil, and Young, 73.

${ }^{72}$ Boudreau, Keil, and Young, 99.

${ }^{73}$ Boudreau, Keil, and Young, 103.

${ }^{74}$ Boudreau, Keil, and Young, 105.

${ }^{75}$ Boudreau, Keil, and Young, 108.
} 
way it was in the 1980 s during the Smart Growth era. ${ }^{76}$ The assertion that creating more compact and dense cities is supported by research that finds compact neighbourhoods are more livable compared to their sprawled or suburban counterparts. ${ }^{77}$

As Toronto was formulating their Official Plan, urban neoliberal views were shifting. The focus on competitiveness shifted from attracting businesses via austerity and towards a competitiveness predicated on the Creative Class. The idea is that Toronto (and other cities that wish to be globally competitive) need to attract the 'right type' of people and capital to their cities. Florida, who popularized the term the Creative Class, argues that this class of individuals are attracted to cities with cultural and recreational activities, and would dictate where international money flows depending on their criteria. ${ }^{78}$ These activities include high arts, like modern art galleries and orchestras, and outdoor activities like kayaking, trail running, rock climbing, or traditional sports like joining a soccer or baseball team.

The creative class, according to Florida, consists of a "core" group of professions which includes "people in science and engineering, architecture and design, education, arts, music, and entertainment." ${ }^{\text {79 }}$ The broader group, which Florida calls "creative professionals," includes professions like law and finance. ${ }^{80}$ Urban strategies in Toronto focused on investing in cultural attractions and activities in an attempt to attract the 'right people' to the city. ${ }^{81}$ In 2003 , the City Council of Toronto adopted a 10-year Culture Plan for the Creative City, which put Toronto in

\footnotetext{
${ }^{76}$ Hillary Angelo and David Wachsmuth, "Why Does Everyone Think Cities Can Save the Planet?," Urban Studies 57, no. 11 (2020), https://doi.org/10.1177/0042098020919081.

${ }^{77}$ Kostas Mouratidis, "Is Compact City Livable? The Impact of Compact versus Sprawled Neighbourhoods on Neighbourhood Satisfaction," Urban Studies 55, no. 11 (2018), https://doi.org/10.1177/0042098017729109.

${ }^{78}$ Florida, The Rise of the Creative Class.

${ }^{79}$ Florida, 8.

${ }^{80}$ Florida, 8.

${ }^{81}$ Boudreau, Keil, and Young, Changing Toronto, 183.
} 
position as a competitor with cities like Montreal, Chicago, San Francisco, Milan, and Barcelona. $^{82}$

The city, along with the federal and provincial governments, also created Waterfront Toronto in 2001 in order to revitalize the downtown core area that runs along the water.

Waterfront Toronto has been a key player in many developments over the years in the downtown core along the water and, of course, the case study is part of their continued work there. ${ }^{83}$ While Waterfront Toronto, and the city more generally, have been altering spaces of the downtown core to provide attractions for the Creative Class, Sidewalk Labs project would combine the ideas of a spaces for the Creative Class and a smart city.

While Florida acknowledges that the Creative Class is smaller than the much larger service class, which makes up around 45 percent of the US workforce, he insists that they have a much larger influence on the economy than the service class. ${ }^{84}$ This is where Florida gets the idea that, if city planners focusing on attracting this class of people to live and work in their cities, the rest of the city will experience positive economic impacts. Boudreau, Keil, and Young explain what the logic was behind this form of urban development:

The rational justifying this race towards economic growth and prosperity - a modern version of boosterism - could generally be synthesized as follows: 1) private accumulation creates incentives for innovation; 2) growth increases the quality of life, which then attracts more potential for prosperity; 3 ) growth creates a sense of community, because prosperity will trickle down. ${ }^{85}$

This logic, which the City of Toronto followed in their post-amalgamation planning, holds the same core logic of austerity focused competitiveness, which ruled the preceding decades. By pursuing economic policies that benefit wealthier people, the economic prosperity will trickle

\footnotetext{
${ }^{82}$ Boudreau, Keil, and Young, 190.

83 "About Us."

${ }^{84}$ Florida, The Rise of the Creative Class, 9-10.

${ }^{85}$ Boudreau, Keil, and Young, Changing Toronto, 187.
} 
down to everyone else. Before, attracting mobile capital to employ the people of the city was the focus of public policy, but now both people and capital are highly mobile, so policy makers need to make sure that they can attract people to work in their cities. Creative competitiveness is focused on performance, the reduction of the public sector through contracting out, publicprivate partnerships, and individualization. ${ }^{86}$ Creative competition strategies only target certain sectors of the economy and spaces of the city, as agriculture, low-income service, manufacturing, and anything outside of the city centre are all left out. ${ }^{87}$ The strategy that Florida has articulated, and Toronto followed is more about attracting the 'right type' of people to come and live in the city while leaving behind the majority of those who already live there.

While most policies aimed at attracting the Creative Class to Toronto, there were attempts to grow the creative class within the city through the response to urban problems. In the early 2000s there was a string of gun related incidents in the city. Deborah Leslie and Mia Hunt look at how the city of Toronto approached the neighbourhoods where most of the gun violence was taking place, which the city had classified as "at risk." ${ }^{\prime 8}$ The authors look at how the discourse of the creative class and the discourse on reducing gun violence in those neighbourhoods merged into the neoliberal policy which the city pursued in the preceding years. These incidents of gun violence happened around the same time that the city council was developing and implementing the 10-year Culture Plan for the Creative City. The resulting policy of the two discourses were several campaigns in these neighbourhoods by the government and by the private sector promoting arts. As the authors point out, these interventions foster an urban neoliberal "pull yourself up by the bootstraps" mentality in those neighbourhoods and

\footnotetext{
${ }^{86}$ Boudreau, Keil, and Young, 189.

${ }^{87}$ Boudreau, Keil, and Young, 194-195.

${ }^{88}$ Deborah Leslie and Mia Hunt, "Securing the Neoliberal City: Discourses of Creativity and Priority Neighborhoods in Toronto, Canada," Urban Geography 34, no. 8 (2013): 1172, https://doi.org/10.1080/02723638.2013.823729.
} 
promote personal and communal responsibility rather than as addressing the problem at a systemic scale. ${ }^{89}$ The policies and interventions in lower income neighbourhoods of Toronto play into the roll-out neoliberal strategies. The state was actively playing a role in constructing values, identities, and forms of citizenship which adhered to what they believed would be economically beneficial for the city. ${ }^{90}$

The string of instances of gun violence had a secondary negative impact on the city as well. When people are looking for places to move for work and to start a family, one of the metrics they might seriously consider is safety or criminal activity. Therefore, any publicity regarding violent crime can be harmful for a city's image.

Forms of popular media have an impact on cities policies and their success in the interurban competition for capital and investment. Ranking cities has been a central aspect of popular media's impacts on urban policy and discourse over the past two decades. ${ }^{91}$ Maclean's Magazine ranks the 'best places to live' in Canada according to a set of metrics like the crime severity index..$^{92}$ There are also many publications that publish annual "livability" or "cities of opportunity" rankings on cities around the world.${ }^{93}$ These rankings are designed to prop up cities the ranking creators believe have the best conditions, "ordering cities from the 'best' to the 'worst' according to parameters related to their supposed attractiveness, in order to detect

\footnotetext{
${ }^{89}$ Leslie and Hunt, 1172.

${ }^{90}$ Leslie and Hunt, 1173.

${ }^{91}$ Eugene J Mccann, “'Best Places': Interurban Competition, Quality of Life and Popular Media Discourse," Urban Studies 41, no. 10 (2004), https://doi.org/10.1080/0042098042000256314; Giffinger et al., "Smart City: Ranking of European Medium-Sized Cities."

${ }^{92}$ Claire Brownell, "Best Communities in Canada 2021: Methodology,” Maclean's, 2021, https://www.macleans.ca/economy/best-communities-in-canada-2021-methodology/.

${ }^{93}$ Laura Begley Bloom, "Survey Ranks The World's Best And Worst Cities To Live (The U.S. Did Surprisingly Well)," Forbes, February 24, 2021, https://www.forbes.com/sites/laurabegleybloom/2021/02/24/survey-ranks-theworlds-best-and-worst-cities-to-live-the-us-did-surprisingly-well/?sh=3556df943ca8; Saheli Roy Choudhury, "These Are the World's Most Livable Cities in 2021," CNBC, June 8, 2021, https://www.cnbc.com/2021/06/09/global-liveability-index-2021-world-most-liveable-cities.html; PWC, "Cities of Opportunity" (New York, 2016), www.pwc.com.
} 
potential assets with the ultimate goal of developing strategies for moving up the charts."94 The crime severity index is one of a variety of metrics, many of which adhere to the logic of interurban competition, as one might expect from a ranking designed to promote some cities over others.

Eugene McCann, in his study on popular media's impacts on urban policy finds that ranking cities creates incentives for lower ranked cities to adopt the similar policies as higher ranked cities. The "serial reproduction" of urban policies creates a "treadmill effect" which is caused by the weak competition and a crowding of the marketplace. ${ }^{95}$ The competitive nature of the neoliberal interurban market forces urban policy makers to seek out the most widely accepted public policies and reproduce them in their city or potentially fall behind.

Writing in the early 2000s, McCann points to a growing trend among popular analysts of considering "extra-economic" factors in the in the construction and legitimation of interurban competition. ${ }^{96}$ These extra economic factors typically include things like crime rate, recreation, weather, among others. Added to the discourse was Florida's book on the Creative Class was publish around the same time as McCann's study.

For a city to stand out among other cities and secure international flows of capital, some argue that it needs to be conscious of how it is viewed from the outside looking in. In the mid to late 1990s a shift in perspective of how to view a city started to take place. Public policy makers trying to attract global flows to a city has resulted in the idea that cities need to be seen as a special kind of product that needs branding and to market itself to the rest of the world. City

\footnotetext{
${ }^{94}$ Alberto Vanolo, "Cities Are Not Products," Tijdschrift Voor Economische En Sociale Geografie 111, no. 1 (2019): 12, https://doi.org/10.1111/tesg.12385.

${ }^{95}$ Mccann, “'Best Places': Interurban Competition, Quality of Life and Popular Media Discourse,” 1910; Harvey, "From Managerialism to Entrepreneurialism: The Transformation in Urban Governance in Late Capitalism," 9.

${ }_{96}$ Mccann, “'Best Places’: Interurban Competition, Quality of Life and Popular Media Discourse,” 1910.
} 
branding has become a key part of urban neoliberal entrepreneurialism, in order to attract international flows of culture, tourism, and investment. ${ }^{97}$

For Alberto Vanolo, city branding is more than city officials trying to attract international flows of capital. Vanolo argues that by branding cities, they are changing how they are perceived from lived-in environments into products, which are to be packaged, advertised, and sold on the global marketplace to extract economic value like any other commodity.$^{98}$ Under advanced capitalist economies, commodification extends into every aspect of life and the more it spreads the more it is naturalized, reducing the possibility of its limits being set. ${ }^{99}$ Therefore, Vanolo understands the commodification of cities through interurban competition as serving as the rollout phase of urban neoliberalism.

The most distinct example of cities branding themselves in recent years came in 2017 when Amazon announced that it was preparing to construct its second North American headquarters (HQ2). It published a Request for Proposal (RFP) in which it set out a list of requirements to be considered. The list included requirements such as: "potential to attract and retain strong technical talent," and, "a stable business friendly environment." 100 Unsurprisingly, cities across the continent were scrambling to put together their best pitch to secure the investment, which according to Amazon, would include roughly 50,000 well paid jobs and over US\$5 billion in capital expenditures. ${ }^{101} \mathrm{~A}$ total of 238 states, provinces, and cities from the U.S.,

\footnotetext{
${ }^{97}$ G. J. Kavaratzis, M., \& Ashworth, "City Branding: An Effective Assertion Of," Tijdschrift Voor Economische En Sociale 96(5), no. 5 (2005).

${ }^{98}$ Vanolo, "Cities Are Not Products."

99 Vanolo, 13.

100 Amazon, “Amazon HQ2 RFP,” Amazon, 2017, https://images-na.ssl-imagesamazon.com/images/G/01/Anything/test/images/usa/RFP_3._V516043504_.pdf, 6-7.

${ }^{101}$ Amazon, 1.
} 
Canada, and Mexico submitted proposals to become the home of Amazon's HQ2. ${ }^{102}$ Amazon requested that any proposals submitted respond to nine questions. A third of the questions were concerned with what sort of incentives, including tax credits, incentive payments, and any legislative changes that would be offered to benefit Amazon. Other requested information included "labour and wage rate information," as well as information about the community with respect to daily living, recreation, and crime rates. ${ }^{103}$

The Amazon case is particularly notable because of the amount of investment and employment opportunities such a large and profitable firm would create in any given city. However, Amazon's search for its HQ2 is exemplary of what happens with firms looking to open new offices, move cities, or new firms staring up. While the manner in which cities scrambled for Amazon and the publicity surrounding the interurban competition for HQ2 was more than there would be for an average firm, cities still put policies in place and develop in a way that would attract firms and workers. The neoliberal logic of interurban competition creates a system in which the possibility of a corporation like Amazon is such an opportunity for the development of the local community that local officials have no choice but to do their best to be the winning bid. This of course neglects the fact that if a company the size of Amazon was to move to many of the communities that applied, it would greatly alter the community in more ways than the policy choice officials made to attract the move. Amazon was looking for a place that was adequate for the Creative Class because that is who would be moving in to work for the company, and in doing so, replacing the local population.

102 Matt Day, “Amazon Refuses Arizona's Cactus as Bidders for HQ2 Climb to 118," The Seattle Times, 2017, https:/www.seattletimes.com/business/amazon/amazon-refuses-arizonas-cactus-as-bidders-for-hq2-climb-to-118/.

103 Amazon, "Amazon HQ2 RFP." 
This section has outlined the shifting forms of urban governance in many cities over the past 50 years, from managerialism to entrepreneurialism. Neoliberalism's concept of interurban competition has created the conceptualization of cities as a brand to be sold like a commodity on the international marketplace and the reliance on businesses and the Creative Class for urban development and economic prosperity. In the next section, I will outline how smart city discourse and practices adhere with critical elements of urban neoliberalism.

\section{The Competitive Advantage of Being a Smart City}

Smart city initiatives are a way local government can attract international flows of capital and labour. This section demonstrates that the production of smart cities is closely linked to the interurban competition for capital and prestige described above. Through urban boosterism, smart city projects allow urban regions to brand themselves as utopias for the creative class, while popular discourse on the subject judges and ranks them and the policies they pursue, increasing their prevalence.

As I outlined in the introduction, there are many different definitions of a smart city. ${ }^{104}$ However, for this work I am following the conceptualizing of a smart city in line with Giffinger et al. and Leydesdorff and Deakin, which encompases much more than just the physical

\footnotetext{
${ }^{104}$ Giffinger et al., "Smart City: Ranking of European Medium-Sized Cities"; Loet Leydesdorff and Mark Deakin, "The Triple-Helix Model of Smart Cities: A Neo-Evolutionary Perspective," Journal of Urban Technology 18, no. 2 (2011), https://doi.org/10.1080/10630732.2011.601111; Francesco Paolo Appio, Marcos Lima, and Sotirios Paroutis, "Understanding Smart Cities: Innovation Ecosystems, Technological Advancements, and Societal Challenges," Technological Forecasting and Social Change 142, no. December 2018 (2019), https://doi.org/10.1016/j.techfore.2018.12.018; Robert G. Hollands, "Will the Real Smart City Please Stand up? Intelligent, Progressive or Entrepreneurial?," City 12, no. 3 (2008), https://doi.org/10.1080/13604810802479126; Vito Albino, Umberto Berardi, and Rosa Maria Dangelico, "Smart Cities: Definitions, Dimensions, Performance, and Initiatives," Journal of Urban Technology 22, no. 1 (2015), https://doi.org/10.1080/10630732.2014.942092; Sarbeswar Praharaj and Hoon Han, "Cutting through the Clutter of Smart City Definitions: A Reading into the Smart City Perceptions in India," City, Culture and Society 18, no. December 2018 (2019), https://doi.org/10.1016/j.ccs.2019.05.005.
} 
infrastructure, including how people interact with it. ${ }^{105}$ While Giffinger et al. do not cite Florida in their study on smart cities in Europe, it is apparent that both they and Leydesdorff and Deakin view smart cities as utopias for the Creative Class.

According to Florida, cities need to target what he calls "the 3T's of economic development" to create an environment capable of attracting and retaining the creative class. ${ }^{106}$ The three T's include technology, talent, and tolerance, and without these, a city would not be able to attract and retain the creative class necessary for sustained economic development and prosperity. Giffinger et al. in their ranking of medium-sized European smart cities include a category called the "Smart Economy (Competitiveness)."107 Others believe that a smart city needs to have "intelligent communities" which would take the shape of a collaborative community to "facilitate innovation" by creating connections between citizens, businesses, governments, and educational institutions. ${ }^{108}$ Those who take a holistic approach to conceptualizing what a smart city would look like have firmly placed Florida's Creative Class in the new paradigm.

Giffinger et al.’s ‘Smart Economy’ category includes metrics like innovative spirit, productivity, economic image, and international embeddedness. These core aspects of what the authors believe make a 'Smart Economy' are identical to what Brenner and Theodore identify as "actually-existing neoliberalism." 109 Another category in the ranking system of Giffinger et al. is called "Smart People." "110 This category is where this study seemingly pulls from Florida's work

${ }^{105}$ Giffinger et al., "Smart City: Ranking of European Medium-Sized Cities”; Leydesdorff and Deakin, "The Triple-Helix Model of Smart Cities: A Neo-Evolutionary Perspective."

${ }^{106}$ Florida, The Rise of the Creative Class, 228.

${ }^{107}$ Giffinger et al., "Smart City: Ranking of European Medium-Sized Cities," 12.

${ }^{108}$ Leydesdorff and Deakin, "The Triple-Helix Model of Smart Cities: A Neo-Evolutionary Perspective"; Appio, Lima, and Paroutis, "Understanding Smart Cities: Innovation Ecosystems, Technological Advancements, and Societal Challenges," 2.

${ }^{109}$ Brenner and Theodore, "Cities and the Geographies of "Actually Existing Neoliberalism."

${ }^{110}$ Giffinger et al., "Smart City: Ranking of European Medium-Sized Cities," 22. 
the most. Within this category are metrics including "share of people working in creative industries," "social and ethnic plurality," and "level of qualification.."111

By ranking cities based on their performance in these metrics, Giffinger et al. promote Florida's three T's. discourse, and rankings like this prompt cities to adopt policies that will increase their performance in the rankings. As Giffinger et al. argue, "a top-rank in a highly reputed city ranking helps to improve the international image of a city and can therefore play a central role in its marketing strategy." ${ }^{112}$ However, with all cities striving for the same goal, the result will be what McCann describes as a 'treadmill effect.' ${ }^{113}$ Like the discussion on ranking cities and popular discourse in the previous section, smart cities are being promoted internationally. Giffinger et al. seem to believe that drawing attention to policies they deem to be good through their ranking will provide benefits for other cities. The serial reproduction of the policies will help to "sharpen their profile and to improve their position in the competition of cities." 114 Additionally, while cities pursue changes to their policies and urban development for their international image and ranking, they are making changes to the urban spaces, typically in a manner that is beneficial for urban neoliberalism.

City branding is seen as fundamental in attracting international flows of capital and prestige. The transition to a smart city in many cases can be seen as an attempt to keep up with the latest trends in urban policy so cities are seen as modern and forward thinking. This type of strategic policy implementation is not unique. Ida Andersson and Laura James explore environmental policy tourism in their 2018 article, which can help illuminate what I see

\footnotetext{
111 Giffinger et al, 22.

112 Giffinger et al., "Smart City: Ranking of European Medium-Sized Cities," 6.

${ }^{113}$ Mccann, “'Best Places': Interurban Competition, Quality of Life and Popular Media Discourse,” 1910.

${ }^{114}$ Giffinger et al, 13.
} 
happening with smart city initiatives. ${ }^{115}$ Their article was part of a larger discussion about the motives behind some environmental policies implemented in cities. As environmentalism and sustainability grew in popularity in public discourse and in urban policy making, some have argued that there have been cases where cities are 'green-washing' their policy books by using superficial environmental policies, which provides cover for the rest of their policies. ${ }^{116}$ Others criticize the policies themselves that are being implemented, arguing that too many of them are designed to be easily attainable or setting low standards to meet the basic requirements to be labeled a 'green-city,' boosting the city's brand internationally. Some policies are so narrow and specific that cities can claim to have "world-leading" environmental policies despite achieving very little. ${ }^{117}$

The lack of a concrete definition of what a smart city constitutes allows cities to brand themselves as smart cities, much the same way as cities claiming to be environmentally friendly. To demonstrate the similarities, I will use Infrastructure Canada's Smart City Challenge, which they introduced in 2017. ${ }^{118}$ This challenge was put to communities across Canada to submit a proposal to the government agency detailing what smart city initiative they wish to develop in their community. There were four winners, with the prize money depending on population, the largest amount being $\$ 50$ million and the smallest at $\$ 5$ million. ${ }^{119}$ Typically, cities and towns need to compete to secure international flows of investment from the private sector, however, in

\footnotetext{
${ }^{115}$ Ida Andersson and Laura James, "Altruism or Entrepreneurialism? The Co-Evolution of Green Place Branding and Policy Tourism in Växjö, Sweden,” Urban Studies Journal Limited 55, no. 15 (2018), https://doi.org/10.1177/0042098017749471.

${ }^{116}$ Henner Busch, "Linked for Action? An Analysis of Transnational Municipal Climate Networks in Germany," International Journal of Urban Sustainable Development 7, no. 2 (2015), https://doi.org/10.1080/19463138.2015.1057144; Andersson and James, "Altruism or Entrepreneurialism? The CoEvolution of Green Place Branding and Policy Tourism in Växjö, Sweden," 3438.

${ }^{117}$ Andersson and James, "Altruism or Entrepreneurialism? The Co-Evolution of Green Place Branding and Policy Tourism in Växjö, Sweden," 3438.

118 “Challenge," Impact Canada, accessed May 17, 2021, https://impact.canada.ca/en/challenges/smart-cities.

119 “Competition One," Infrastructure Canada, accessed May 17, 2021, https://www.infrastructure.gc.ca/citiesvilles/comp-one-prem-comp-eng.html.
} 
this case the government used the same neoliberal standard of interurban competition to find which communities are deserving of investment. Almost 200 communities sent proposals for consideration with populations ranging from Riverhead, Newfoundland and Labrador with a population of 185 , to Toronto, Ontario, with a population of just over 2.7 million. ${ }^{120}$

While the competition put on by the government of Canada is an excellent example of the interurban competition for funding and investment, typically their role is reserved to accommodating the private sector in urban neoliberalism, the main reason I bring it up is because of the content within the proposals sent in for consideration. Many of the proposals took advantage of the imprecise definition of a 'smart city' and submitted outlines that were broad in their approach, which would allow them to brand themselves as smart cities. The winning proposals included a project which aimed to reduce energy poverty, winning the $\$ 5$ million in the town of Bridgewater, ${ }^{121}$ Guelph and Wellington's proposal to create a "Circular Food Economy,"122 and Nunavut had a proposal to life promotion approach to suicide prevention, each won the $\$ 10$ million, ${ }^{123}$ and $\$ 50$ million went to a proposal to improve mobility and food access in Montreal. ${ }^{124}$

Some of the proposals sent in for consideration also reveal the connection between conceptions of smart cities and Florida's ideas on the importance of the creative class to urban economic development. For example, the City of Lethbridge, Alberta, submitted a proposal

\footnotetext{
120 “Participating Communities,” Infrastructure Canada, accessed May 11, 2021, https://www.infrastructure.gc.ca/sc-vi/map-applications.php.

121 “\$5 Million Prize Category Winner,” Infrastructure Canada, accessed May 17, 2021, https://www.infrastructure.gc.ca/cities-villes/winners-gagnants/5m-bridgewater-eng.html.

122 “\$10 Million Prize Category Winner - City of Guelph and Wellington County," Infrastructure Canada, accessed May 17, 2021, https:/www.infrastructure.gc.ca/cities-villes/winners-gagnants/10m-guelph-wellingtoneng.html.

123 “\$10 Million Prize Category Winner - Nunavut Communities,” Infrastructure Canada, accessed May 17, 2021, https://www.infrastructure.gc.ca/cities-villes/winners-gagnants/10m-nunavut-eng.html.

124 “\$50 Million Prize Category Winner,” Infrastructure Canada, accessed May 17, 2021, https://www.infrastructure.gc.ca/cities-villes/winners-gagnants/50m-montreal-eng.html.
} 
which outlined an "innovation district." 125 The innovation district as proposed by Lethbridge was not too different from what was planned in Toronto. Similarly, Cape Breton Regional Municipality outlined a plan to reduce the out-flow of population from their region through their Our Bright, Smarter Future project, which aimed to connect the region to the global economy and spur innovation. ${ }^{126}$ Cape Breton was not as concerned with attracting the Creative Class to their region but retaining members of that class from leaving. In both these examples, the local governments were concerned with attracting and/or retaining the knowledge-based labour force. The proposals are attempts to make their urban region more competitive in the neoliberal interurban competition for investment and labour.

A brief scan of Canada's largest cities also demonstrates that all have taken on smart city initiatives of various degrees. On their respective websites, they claim smart city leadership and innovation. Vancouver exclaims that some of the "technology and data to improve connection and convenience so far" includes public Wi-Fi, wired bike charging, and EV chargers for electric cars. ${ }^{127}$ Edmonton claims to be a world leader in using technology to improve services. ${ }^{128}$ Edmonton takes directly from Giffinger et al. and Leydesdorff and Deakin in their conception of a smart city, with their definition of a "smartecosystem" as one where citizens, governments, businesses, and academics work collectivly. ${ }^{129}$ Edmonton also lists a number of awards they have won in global and national competitions related to smart cities, as does Winnipeg. ${ }^{130}$ Ottawa, interestingly, has a section of their tourism website dedicated to depicting the city as a

\footnotetext{
${ }^{125}$ City of Lethbridge, "Smart Cities Challenge: City of Lethbridge Proposal," City of Lethbridge, 2018.

${ }^{126}$ Cape Breton Regional Municipality, "CBRM Smart Cities Challenge Proposal,” 2018.

${ }^{127}$ City of Lethbridge, "Smart Cities Challenge: City of Lethbridge Proposal."

128 "Edmonton: Smart City," City of Edmonton, accessed May 12, 2021, https://www.edmonton.ca/city_government/initiatives_innovation/smart-cities.aspx.

129 “Our Smart City Approach,” Smart Cities Edmonton, accessed May 12, 2021, https://smartcities.edmonton.ca/our-smart-city-approach/.

130 “Winnipeg Named One of Top 21 'Smart Cities' in Global Competition,” Economic Development Winnipeg, accessed May 12, 2021, https://www.economicdevelopmentwinnipeg.com/media/mediarelease/read,release/1376/winnipeg-named-one-of-top-21-smart-cities-in-global-competition.
} 
smart city. ${ }^{131}$ The City of Ottawa also published a Smart City 2.0 plan in 2017, in which the city sets out a vision of a connected city, smart economy, and an innovative government, which all would aling Giffinger et al. and Leydesdorff and Deakin's conception of a smart city. ${ }^{132}$ Ottawa's plan also touts "a young, entrepreneurial workfore, with a bilingual rate of $44 \%$, and more engineers, scientists, and PhDs per capita than any other Canadian city." 133

At this point I would like to maintain that I am not passing judgement on whether or not any of the above examples should or should not be considered a smart city. As we have seen, definitions of a smart city are wide ranging and the definition I am following for my thesis encompasses many different aspects of urban life. However, what I am demonstrating through the exploration of all the previous examples is that with no real definition of a smart city, cities and communities can claim the title of a smart city in many ways. The practice of officials branding their city as a smart city can take on the same issues as what was discussed with environmental policies.

A significant number of Canadian cities are implementing or have proposed smart city initiatives, as demonstrated in the applications for funding in Infrastructures Canada's Smart City Challenge. Canada's largest cities indicate that they have already achieved some smart city programs. Notably among those websites is the focus on the narrative of being a smart city. Smart city initiatives are similar to environmental policies discussed in Andersson and James' article in that some of the policies can be perceived as being more concerned with the city's image internationally than concrete and positive urban development for the people who live there. In terms of the environmental policies, the authors conclude that while many of the

\footnotetext{
131 “Ottawa Is a Smart City,” Ottawa Tourism, accessed May 12, 2021, https://ottawatourism.ca/en/meetings/why-ottawa/smart-city.

132 City of Ottawa, "Smart City 2.0," 2017, https://documents.ottawa.ca/sites/documents/files/smart_city_strategy_en.pdf.

${ }^{133}$ City of Ottawa.
} 
policies are designed in a way to benefit the city's international brand rather than being focused on enacting good sustainability policies, the outcome is positive. ${ }^{134}$ I agree that while some environmental policies can be considered as simply boosterism, any policy that is beneficial to the environment is a net positive, no matter how marginal. I do not find this to be the case for smart city policies and initiatives.

The smart city initiatives that are being implemented do not always end in something that is beneficial for everyone. Comprehensive conceptions of smart cities are inhabited by certain kinds of people, and policies are designed to attract those people specifically. Canada's larger cities pursue smart city initiatives that increase their global competitiveness through branding and attracting the highly mobile creative class. While the Cape Breton Regional Municipality was trying to retain people as it has experienced an outflow of people over the recent past, they are forced to succumb to urban neoliberal strategies of interurban competition to compete with other urban regions.

Smart cities conceptions are framed in urban neoliberal ideas of interurban competition and has adopted urban development strategies focused on the Creative Class. Cities are eager to implement policies and initiatives in a way that would frame and brand them as a smart city, signalling that they are innovative in their approaches to urban policy and good places for investment. The lack of clear definition allows cities to easily attain the title of a smart city. Definitions like that of Giffinger et al., which take a more holistic approach to the conceptualization of a smart city would entail, is what I believe all smart city projects are leading towards, and what Sidewalk Labs' project endeavoured to be. Some of Canada's largest cities

\footnotetext{
${ }^{134}$ Andersson and James, "Altruism or Entrepreneurialism? The Co-Evolution of Green Place Branding and Policy Tourism in Växjö, Sweden.”
} 
have some policies and initiatives on becoming a smart city, but not to the extent of what Sidewalk Labs was planning in Toronto.

\section{Sidewalk Labs' Competitive Smart City}

Sidewalk Labs' now canceled project in Toronto is exemplary of how smart city conceptions are organically linked to urban neoliberalism. In this section I demonstrate how the project would adhere to the pervasive ideas of interurban competition. I do this by analysing the $M I D P$ and exposing how the project was being designed and sold to Waterfront Toronto as a smart utopia for the Creative Class that would benefit Toronto's image on the global stage. In the $M I D P$, Sidewalk Labs outline how the IDEA District would be transformed into an economic hub for the tech industry and become one the greenest urban areas in North America. Particularly as it relates to smart cities, the Toronto neighbourhood was going to be built in the image of Giffinger et al. and Leydesdorff and Deakin's idea of a smart city, which, as we have seen coheres with Florida's urban neoliberal spatial economic development ideas of the Creative Class and interurban competition.

When Waterfront Toronto started their search for a partner to develop the Quayside, they published a Request for Proposal (RFP) in which they detailed what they were looking for in the development of the area. ${ }^{135}$ The RFP was discussed in the introduction to my thesis, however, I will go into more detail here. The RFP has four main components, two of which are economically focused, in the tradition of urban entrepreneurialism, request the "economic development and prosperity" be considered and to "provide a testbed for Canada's cleantech, building materials and broader innovation-driven sectors to support their growth and

\footnotetext{
${ }^{135}$ Waterfront Toronto, "Quayside RFP.”
} 
competitiveness in global markets." 136 This is where Waterfront Toronto aslo signals their explicit understanding of Tronto in the interurban competition, and implicitly their vision of this development being a destinaiton for the Creative Class. Waterfront Toronto states: "A primary objective of waterfront revitalization is to deliver key economic and social benefits that enable Toronto to compete effectively with other top-tier global cities for investment, jobs and talent." 137

The other two of the four components for consideration for proposals are "complete communities" and "sustainability, resiliency, and urban innovation." 138 The latter two components of Waterfront Toronto's RFP demonstrate an intention to build a neighbourhood which would provide the city an international brand, and a place for the Creative Class. Particularly on "complete communities," Waterfront Toronto wants applicants to the RFP to developing a community with "public open space, culture, recreation, vibrant retail, educationrelated activities and offices." 139 The RFP states that the projects should "create a globally significant demonstration project that advances a new market model for climate-positive urban developments." ${ }^{140}$ Waterfront Toronto assumes that the method used to create this climatepositive urban environment is through the incorporation of new technologies and wants the development to be used as a model for the rest of the world. The RFP seeks to create a part of Toronto which can set it apart form the rest of the world, while making it an example for others to follow, building their international brand.

In compliance with Waterfront Toronto’s RFP, a main selling point Sidewalk Labs puts into their MIDP is the promise of economic benefits that will improve the city and greater

\footnotetext{
${ }^{136}$ Waterfront Toronto.

137 Waterfront Toronto, 9.

138 Waterfront Toronto.

${ }^{139}$ Waterfront Toronto, 9.

140 Waterfront Toronto.
} 
region. When cities made the transition from managerialism to entrepreneurialism, securing international flows of capital became the priority. ${ }^{141}$ Sidewalk Labs' promises that the project would create 93,000 jobs and would generate $\$ 4.3$ billion in tax revenue for the government and $\$ 14.2$ billion in annual GDP. ${ }^{142}$ Sidewalk Labs' makes a point of highlighting this as they know that under urban neoliberalism, this is a serious point of consideration when approving a development plan in any city from a municipal government's perspective.

In a display of support for the project, the Toronto Region Board of Trade, which represents business interests in the city, initiated an open letter to the people of Toronto. In this letter they ask the people to "welcome and evaluate" the project proposed by Sidewalk Labs and that they, as experts, are in support of it. ${ }^{143}$ Others argue that it will bring to Toronto the growing industry of urban tech, and with it, more business and economic growth, echoing Florida's conception of how urban economic development is achieved. ${ }^{144}$

The MIDP outlines plans on how businesses and workers, specifically of the Creative Class, would be attracted to Toronto through the work of Sidewalk Labs. Using Florida's three T's, we can see how the MIDP targets the creative class through fulfilling each T. ${ }^{145}$ First, Technology, which is also the fundamental aspect which would have made this project a smart city. Sidewalk Labs' vision for the area in Toronto found its roots in a technological utopia which was desinged for the creative class. Indeed, the urban space was going to be used in a way that would be beneficial for Creative Class ocupations. One of the core ideas of the project was

\footnotetext{
${ }^{141}$ Harvey, "From Managerialism to Entrepreneurialism: The Transformation in Urban Governance in Late Capitalism."

${ }^{142}$ Sidewalk Labs, "Master Innovation \& Development Plan: The Overview."

143 Donovan Vincent, "30 Influential Toronto Leaders Pen Letter Supporting Controversial Sidewalk Labs Plan," Toronto Star, July 5, 2019, https:/www.thestar.com/news/gta/2019/07/04/30-influential-toronto-leaders-pen-lettersupporting-controversial-sidewalk-labs-plan.html.

${ }^{144}$ Rob Richards, Daniel Brothman, and Matthew Leibowitz, "Urban Tech Is the next Frontier in the Digital Revolution," Toronto Star, July 8, 2019, https:/www.thestar.com/opinion/contributors/2019/07/08/urban-tech-isthe-next-frontier-in-the-digital-revolution.html.

${ }^{145}$ Florida, The Rise of the Creative Class, 228-236.
} 
the ability for data on everyday activities to be monitored and analyzed for the purpose of everyday operations of the District, but for researchers and app programmers in order to spur more innovation. ${ }^{146}$ The technological integration Sidewalk Labs planned for the IDEA District will be discussed in more detail in the next chapter, for now it is important to know that Sidewalk Labs holds it as central to the District's success. While the RFP did ask for submissions to consider "technology advancements that enhance efficiencies and improve the overall quality of life for citizens," Sidewalk Labs made tech central to economic success as well. Technology was so central to the companies vision, that after the MIDP was submitted, Waterfront Toronto asked the company to release a more detailed document on the tech itself. The company released a 482-page Digital Innovation Appendix to the $M I D P$, in which they detail the level of technological integration, particularly for the purpose of data collection. ${ }^{147}$

All this tech would provide incentive for the Creative Class to relocated to Toronto, according to Florida's logic, both for the economic benefits promised by Sidewalk Labs, and because it creates the environment that is attractive to the Creative Class. Another way Sidewalk Labs' project would have fulfilled the technology requirement for Florida's criteria for a sucessful city was through the promise of a new Canadian Google headquarters. ${ }^{148}$

Bringing in Google employees to work in the IDEA district would have also fulfilled another one of Florida's T's, being talent. ${ }^{149}$ The project was aiming to make the new Canadian Google headquarters a catalyst in a much larger "new innovation campus, which would also

\footnotetext{
${ }^{146}$ Sidewalk Labs, "Master Innovation \& Development Plan: Volume 2."

${ }^{147}$ Donovan Vincent, "Foot Traffic in Stores, Pay-as-You-Throw Garbage Collection: Sidewalk Labs Shares Data Collection and Use Plans for Toronto Smart City," Toronto Star, November 15, 2019, https://www.thestar.com/news/gta/2019/11/15/foot-traffic-in-stores-pay-as-you-throw-garbage-collection-sidewalklabs-shares-data-collection-and-use-plans-for-toronto-smart-city.html; Sidewalk Labs, "Master Innovation \& Development Plan: Digital Innovation Appendix," 2019.

${ }^{148}$ Doug Alexander, "Sidewalk Labs Aims to Add Canadian Google HQ into Toronto Plans," Toronto Star, January 14, 2020, https://www.thestar.com/business/2020/01/14/sidewalk-labs-aims-to-add-canadian-google-hqinto-toronto-plans.html.

${ }^{149}$ Florida, The Rise of the Creative Class.
} 
include, a new non-profit applied research institute called the Urban Innovation Institute."150 Some in the city argue the urban tech is the next frontier of the digital revolution, and Toronto should not be left behind. An article written in the Toronto Star starts off by praising where Toronto is in the global competition for investment. The authors claim that Sidewalk Labs "looked at more than 200 potential cities globally, and they rightfully recognized Toronto as an 'ideal' spot to build the revolutionary project." 151 The article goes on to argue that with the development of the projeect, and the growth in competition and profit from the tech industry, Toronto would be well positioned to garner global flows of investment, and to attract more tech employees as well. ${ }^{152}$

Another observer notes that the privacy concerns being discussed in relation to the Sidewalk Labs project could impact Toronto's AI industry. While I will go into detail on data collection and privacy in the next chapter, Gillian Hadfield writing for the Toronto Star comments that the data governance conversation that happened around the project has farreaching consequences, particularly for AI research which requires massive amounts of data. The article argues in favour of Sidewalk Labs' proposal, as the alternative would stifle innovation, which is the same argument the Alphabet affiliate makes. Hadfield, who is the director of a AI institute, uses local boosterism to argue that "Canada's global reputation for fairness and trustworthiness" and that the project offers "great opportunity for Toronto leadership because I believe we can do better." 153

${ }^{150}$ Sidewalk Labs, "Master Innovation Development Plan: The Overview," 126.

${ }^{151}$ Richards, Brothman, and Leibowitz, "Urban Tech Is the next Frontier in the Digital Revolution."

${ }^{152}$ Richards, Brothman, and Leibowitz.

153 Gillian Hadfield, "Toronto Can Be a Global Leader in Harnessing AI to Serve Rather than Enslave Us," Toronto Star, January 7, 2020, https://www.thestar.com/opinion/contributors/2020/01/07/toronto-can-be-a-globalleader-in-harnessing-ai-to-serve-rather-than-enslave-us.html. 
Another of Florida's three T's is tolerance, which is a big emphasis throughout Sidewalk Labs' MIDP. Economists have long agreed that diversity in industries is necessairy for a health economy, but Florida credits Jane Jacobs with being among the first to ackowledge the role of diversity among firms and people. In his studies, Florida finds "a strong correlation between on the one hand, places that are welcoming to immigrants, artists, gays, bohemians, and socioeconomic and racial inegtration," and "places that experience high-quality economic growth." ${ }^{154}$ Hadfield, in her argument in favour of the Sidewalk Labs project, and more generally for a data governance structure that would allow data be sued for innovation, by highlighting Toronto's "success as the most multicultural city in the world," and how that would help it create a robust data governance structure. ${ }^{155}$

Throughout the MIDP, Sidewlak Labs brands their proposed IDEA District and pursues boosterism. The plans include detailed proposals as to how the district can lower its greenhousegas emmissions through the incorporation of technologies like the stormwater management system, which aims to recapture storm water for irigation, and systems that monitor lights and heat/air-conditioning in buildings. ${ }^{156}$ The plan also proposed the use of entirely timber buildings, which they claim is more environmentally friendly than what and would give the IDEA District a very unique look, one which would not be found anywhere alse in the world at the time. ${ }^{157}$ There is also the name of 'IDEA District,' Innovation Design and Economic Acceleration is an odd collection of buzzwords until the acronym is revealed. The IDEA District is clearly framed to be seen as a socio-technological utopia.

\footnotetext{
${ }^{154}$ Florida, The Rise of the Creative Class, 233.

155 Hadfield, "Toronto Can Be a Global Leader in Harnessing AI to Serve Rather than Enslave Us."

156 Sidewalk Labs, "Master Innovation \& Development Plan: Volume 2," 444-447.

${ }^{157}$ Sidewalk Labs, "Master Innovation \& Development Plan: The Overview."
} 
Urban neoliberalism puts cities in a position of disadvantage in relation to mobile capital in the international marketplace, where they compete with each other for resources and investment. Both Waterfront Toronto and Sidewlak Labs implicitly understood the development project as being an opportunity to position Toronto as a destination for the Creative Class and to enhance their pedigree internatioanlly. To attract capital, Waterfront Toronto wanted a project at the waterfront that would signal itself as a leading city in the world of clean-tech and innovation. As such, the Sidewalk Labs project is symblomatic of the connection between smarrt cities and urban development strategies focusing on the Creative Class.

\section{Conclusion}

In this chapter, I have argued that the project proposed by Sidewalk Labs was being designed in accordance with the neoliberal logic of interurban competitiveness. Urban policy in the 1970s, shifted from managerialism to entrepreneurialism which forced cities into competing amongst each other for available global flows of capital. Smart city initiatives have emerged as the most recent method for a city to stand out and attract mobile capital and remain competitive.

Sidewalk Labs' project would have been exemplary of neoliberal interurban competition. Starting with Waterfront Toronto signing an agreement with an Alphabet subsidiary, to the strategically named IDEA District and the unique slice of skyline of large wooden buildings, to the deep integration of tech, Sidewalk Labs wanted to build something that was different from any other city in the world. The economic factors were there as well through considerable investment in the creation of the smart city and the substantial tech campus for Google, and others who would be attracted to the district. Ultimately, all the factors mentioned above would have acted as a draw for the Creative Class. 


\section{CHAPTER 2 - Digital NeOliberalisM}

\section{Introduction}

Capitalism has always been good at finding new ways to generate profit. With the growth in digital technologies, a new form of accumulation has been identified. David Harvey uses the term "accumulation by dispossession" in his 2003 book, The New Imperialism, in which he explores neoliberal forms of accumulation. Harvey's terminology is built off Karl Marx's concept of primitive accumulation, which describes the ways in which land was seized, privatized, and commodified in the early stages of capitalism. Harvey argues that primitive accumulation was not a historical event, as Marx presents it, but an ongoing method of commodification and privatization. ${ }^{158}$ The neoliberal logic of commodification coupled with the rapid digital technological advances in the past half century have created a situation in which new forms of commodification are possible. Zuboff and Sadowski have both published books recently in which they each outline this new form of accumulation, which they each term as 'surveillance capitalism' and ‘digital capitalism' respectively. ${ }^{159}$

In this chapter, I outline how new digital forms of commodification and accumulation are being applied to urban neoliberalism through smart cities. I first outline how this mode of capitalism has emerged and what the implications are on society, borrowing largely from Zuboff and Sadowski. With an understanding of this form of capital accumulation, I apply it to urban neoliberalism through a discussion of smart cities, which are built in ways to accommodate the

\footnotetext{
${ }^{158}$ David Harvey, The New Imperialism (Oxford: Oxford University Press, 2003), 145-148.

159 Zuboff, The Age of Surveillance Capitalism: The Fight for a Human Future at the New Frontier of Power; Sadowski, Too Smart.
} 
mass inflow of data. I then explore how data collection is considered in Sidewalk Labs' project proposal, as an example of large scale, ground up, smart city developments. Finally, this chapter will consider the data governance implications not only for cities but also for wider data collection practices. I will demonstrate how ideas in data governance, which are similar to Sidewalk Labs proposed Urban Data Trust (UDT), are attempts to further reorient the role of government to be replaced by private sector actors.

\section{Digital Commodification}

In this section, I describe the form of accumulation that has emerged over the past twenty years, with particular attention paid to how it operates and its consequences in relation to urban neoliberalism. Before discussing Zuboff and Sadowski and their analysis on the changes that neoliberalism is undergoing, it is important to understand their various definitions and terminology on the subject. I briefly reviewed these concepts in the introduction to this thesis, however, I will provide more discussion here.

Zuboff uses 'surveillance capitalism' to explain the business model that monetizes human behavior. However, Zuboff seems to believe that the monetization of human behavior is not a logical continuation of neoliberal capitalism, but a "rogue mutation."160 Sadowski, on the other hand, rejects Zuboff's conception of the digital turn of neoliberalism as simply a deviation from the norm, and approaches the topic with his broader concept of "digital capitalism," in which it is understood as "just variations of the same old capitalism, but now running on some new hardware and software." ${ }^{161}$ Particular attention will be placed on Zuboff's book, however, for the

\footnotetext{
${ }^{160}$ Zuboff, The Age of Surveillance Capitalism: The Fight for a Human Future at the New Frontier of Power, front matter.

${ }^{161}$ Sadowski, Too Smart, 50.
} 
simple reason that she has a quite in depth look at Google, which falls under the same parent company, Alphabet, as Sidewalk Labs. Throughout this section I will refer to the different concepts depending on the author I am focusing on. However, this thesis understands the emerging digital neoliberal logic in the same manner as Sadowski's concept of 'digital capitals.'

In The Age of Surveillance Capitalism, Zuboff chronicles the creation of the practice of what she calls surveillance capitalism through the discovered use of 'behavioral surplus.' According to Zuboff, surveillance capitalism took root at Google through the economic struggles which emerged in the aftermath of the dot-com bubble of the late 1990s and early 2000s. Before the market crashed, Google executives were adamant on keeping ads off their search engine. However, as tech start-ups were decimated from the bubble created by venture capitalists and an over saturated tech industry of unproven companies, Google was pressured to find monetization opportunities in their search engine or go under. ${ }^{162}$

What separated Google from competing search engines like Yahoo was the collection and analysis of 'exhaust data,' which was considered by many in the industry as a waste by-product. Google used algorithms to mine this data, which is collected from users' behavior online to find patterns and ultimately predict correct searches, effectively enhancing the quality of their search engine. This was done through correlating previous searches by the individual and others in the database to accurately predict what the user was searching for. ${ }^{163}$ Google's chief economist, Hal Varian, who did not join the company until 2002, is quoted as describing the process as: "every action a user preforms is considered a signal to be analyzed and fed back into the system." 164 Originally, this data was used to improve the search functions of the Google search engine.

\footnotetext{
162 Zuboff, The Age of Surveillance Capitalism: The Fight for a Human Future at the New Frontier of Power.

163 Zuboff, 68.

164 Zuboff, 69.
} 
However, after the dot-com bubble shook Silicon Valley, Google needed to find a way to mine this data for profit.

Google turned to advertising to keep their search engine financial sustainable. Instead of attaching advertisements to key words like other search engines, Google started to treat the exhaust data they were collecting and analysing as behavioral surplus by reorientating the data analysis from strictly improving search accuracy to also finding and placing relevant advertisements. Even in the early stages of their transition to monetized data collection, ads on Google were considered more effective than its competitors. ${ }^{165}$ Google was able to accomplish this because their ads are linked to the search queries and past queries to get a better understanding of the individual and their preferences. Until this point, advertising was largely a guessing game, linking placement of ads with the people who would be there to see them, both virtually and in the real world. However, the predictive ability of their search engine has much larger implications than the placement of more relevant advertisements on people's screens.

Data collection has by now extended well beyond the scope of online searches. One of the most frequently reported and widely known ways tech companies collect data on us is through Amazon's Alexa device, a small voice activated personal assistant. Numerous reports have come out through the media of people claiming that their Alexa's have acted strangely and activated when no one is around or when no one in the room used the device's activation word. ${ }^{166}$ Amazon has now released a website where you can go back and listen to all the audio

\footnotetext{
165 Zuboff, 76.

${ }^{166}$ Dorian Lynskey, “'Alexa, Are You Invading My Privacy?' - the Dark Side of Our Voice Assistants | Amazon Alexa | The Guardian," The Guardian, 2019, https:/www.theguardian.com/technology/2019/oct/09/alexa-are-youinvading-my-privacy-the-dark-side-of-our-voice-assistants; TJ McCue, “Amazon Alexa Accused Again Of Spying: Here Is Another Solution," Forbes, July 30, 2019, https://www.forbes.com/sites/tjmccue/2019/07/30/amazon-alexaaccused-again-of-spying-here-is-another-solution/?sh=7f0d6db465f3; Grant Clauser, “Amazon's Alexa Never Stops Listening to You | Wirecutter," The New York Times, August 8, 2019, https://www.nytimes.com/wirecutter/blog/amazons-alexa-never-stops-listening-to-you/; Geoffrey A. Fowler, "Hey,
} 
that Alexa devices have recorded from your home. One journalist listened to four years' worth of audio from his own device and found that it had recorded sensitive information about him and his family when no one had activated the device. ${ }^{167}$

Voice activated virtual assistants are not the only way companies are collecting data on their users. Insurance companies have started offering deals for costumers who are willing to put what is essentially a tracking device in their car, which sometimes is simply our phone. ${ }^{168}$ The idea is that good drivers or people who rarely drive will receive better rates for their safe driving. However, the insurance company "tracks speed, acceleration, braking and distracted driving, such as texting and physical interactions with your phone while driving," as well as time of day. ${ }^{169}$

The market for smart devices is growing in profitability and in the variations in products. Personal health devices like Fitbit, which is owned by Google, have access to a significant amount of data. And while Google has said that it will not be using any data collected for advertising purposes, "that leaves plenty of other information for Google to gather, including users' locations, device info, friends' lists, messages, profile photos, participation in employee wellness programs, and usage logs." ${ }^{170}$ Uber has created something which they call 'God View' through the data collected from people using their ride for hire platform, including trip locations

Alexa: Stop Recording Me - The Washington Post," The Washington Post, 2019, https:/www.washingtonpost.com/technology/2019/05/06/alexa-has-been-eavesdropping-you-this-whole-time/.

${ }^{167}$ Fowler, "Hey, Alexa: Stop Recording Me - The Washington Post."

${ }^{168}$ Mike Juang, "New Kind of Auto Insurance Can Be Cheaper, but Tracks Your Every Move," CNBC, October 6, 2018, https://www.cnbc.com/2018/10/05/new-kind-of-auto-insurance-can-be-cheaper-but-tracks-your-everymove.html.

${ }^{169}$ Erica Alini, “Insurance Apps That Track Your Driving Could Now Yield Premium Increases," Global News, March 21, 2021, https://globalnews.ca/news/7704732/auto-insurance-app-usage-based-insurance-surchargescanada/.

${ }^{170}$ Kari Paul, “'Tossed My Fitbit in the Trash': Users Fear for Privacy after Google Buys Company," The Guardian, November 6, 2019, https://www.theguardian.com/technology/2019/nov/05/fitbit-google-acquisitionhealth-data. 
and time of day. ${ }^{171}$ Smart home appliances are also a booming market which are expected to reach a market size of US $\$ 78.7$ billion by $2027 .{ }^{172}$ Smart appliances and other home smart tech like automated vacuum cleaners, such as the Roomba, mean that an enormous amount of data is being collected on people. As more things we interact with become part of a connected network, the increasing volume of data will allow these tech companies to get a clear picture of who we are and how we operate. ${ }^{173}$

The insight into people that is provided through the collection and analysis of data has more concerning implications. Zuboff uses a concept she calls instrumentarianism to explore the phenomena. Zuboff defines instrumentarianism as: “... the instrumentation and instrumentalization of behavior for the purposes of modification, prediction, monetization, and control."174 'Instrumentation' is the material architecture that renders, interprets, and actuates the human experience. 'Instrumentalization' refers to the social relations which is used by the "puppet master" or the capitalists controlling the instrumentation to transform individuals' behavior into desirable market ends. ${ }^{175}$ Google's use of the behavioral surplus data to personalize ads was just the beginning of these possibilities. As Zuboff explains: "Under surveillance capitalism, the 'means of production' serves the 'means of behavioral modification."'176

Zuboff's concern with Google and other surveillance capitalists' companies and her larger concept of instrumentarianism, is the control it enables these companies to possess over people. She seems to believe that surveillance capitalism, as explained through her concept of

\footnotetext{
${ }^{171}$ Hill, “'God View': Uber Allegedly Stalked Users For Party-Goers' Viewing Pleasure.”

172 "Global Smart Home Appliances Market to Reach \$78.7 Billion by 2027," Yahoo Finance, June 3, 2021, https://finance.yahoo.com/news/global-smart-home-appliances-market-124900560.html.

${ }^{173}$ Rani Molla, "People Say They Care about Privacy but Buy Devices That Can Spy on Them," Vox, May 13, 2019, https://www.vox.com/recode/2019/5/13/18547235/trust-smart-devices-privacy-security.

${ }^{174}$ Zuboff, The Age of Surveillance Capitalism: The Fight for a Human Future at the New Frontier of Power, 352.

175 Zuboff.

${ }^{176}$ Zuboff, 351.
} 
Instrumentarianism, is not particularly different than totalitarianism. For her, what separates the two is where totalitarianism seeks to control through "engineering the soul," instrumentarianism seeks to engineer behavior. ${ }^{177}$ The source of power in instrumentarianism comes from the predictability of human behavior, enabled through the vast amount of data collected on people in their daily lives.

Zuboff argues that the logic of instrumentarianism comes from B.F. Skinner's work in the 1970s on behavior. In his 1971 book Beyond Freedom and Dignity, Skinner takes the stance that humans do not have free will to the extent that is generally understood. He believed that the environment that surrounds us plays an enormous role in dictating our lives, stating, "the environment not only prods or lashes it selects." 178

Sadowski takes a different approach to exploring the implications of the vast amounts of data and information that is being collected on people, however, the conclusion is very much the same. Sadowski uses philosopher Gilles Deleuze to explore the controlling ability of the new form of neoliberal accumulation, which he calls digital capitalism. Control, for Deleuze, is not achieved through the threat of violence, but rather setting up the parameters of what is and what is not allowed. From there, people can act "freely", as long as they remain within set parameters set by those in control. ${ }^{179}$

From the early use of data by Google, the collection of online behavior has now allowed companies to model their platforms to a variety of ends. Potentially the most consequential of these outcomes so far has been conducted by Facebook. Through specific placement of a small

\footnotetext{
177 Zuboff, 353.

${ }^{178}$ B.F. Skinner, Beyond Freedom and Dignity (Indianapolis/Cambridge: Hackett Publishing Company Inc., 1971).

179 Sadowski, Too Smart, 40.
} 
banner that informed certain Facebook users of friends that had voted or planned on voting, Facebook believes they increased the total voter turnout in the 2012 U.S. Presidential election by 340,000 votes. ${ }^{180}$ While the total number of votes Facebook believed they generated through their experiment was relatively small in comparison the total turnout, it was just an experiment, and could be worked on to be more consequential. Another infamous example stemming from Facebook was the Cambridge Analytica scandal. Through data collected via Facebook, Cambridge Analytica, a British data analytics company owned by a supporter of then U.S. Presidential nominee Donald Trump, potentially changed the 2016 presidential election in the U.S., and has actively built and sold "psychological profiles" on people. ${ }^{181}$ More recently, Facebook and YouTube (part of Google) has had to take measures to curate what is seen online in an attempt to reduce the spread of misinformation about the Covid-19 pandemic and vaccines. ${ }^{182}$

As the profitability of data collection and analysis has grown, companies are trying to gain the ability to collect as much data as possible in order to turn it into behavioral surplus and generate company profits. Smart cities take a similar approach as these companies, particularly through the alternative uses of the exhaust data that would be produced in urban areas. In this section I explored the work of Zuboff and Sadowski on the emerging form of capitalist accumulation. In the next section I make the connection between digital capitalism and urban neoliberalism more apparent through smart cities.

\footnotetext{
${ }^{180}$ Zittrain, "Facebook Could Decide an Election Without Anyone Ever Finding Out."

${ }^{181}$ Confessore, "Cambridge Analytica and Facebook: The Scandal and the Fallout So Far"; Wong, "The Cambridge Analytica Scandal Changed the World - but It Didn't Change Facebook."

${ }^{182}$ Gerrit De Vynck and Rachel Lerman, "Facebook and YouTube Are Still Full of Covid Misinformation," The Washington Post, July 22, 2021, https://www.washingtonpost.com/technology/2021/07/22/facebook-youtubevaccine-misinformation/.
} 


\section{The Smart City as a Factory Floor}

In the last section, I outlined the technological change that has taken place in neoliberal logics of accumulation since the turn of the century by examining the work of Zuboff and Sadowski. In this section, I will outline how similar ideas of data collection and analysis are being applied to smart cities. I refer to smart cities as a factory floor in the subtitle of this section due in part to the commodification of behavioral surplus, which would be collected in a smart city, and in part due to the supervisory role city planners can have with such technologies imbedded in a city.

While the definition of what a 'smart city' is contested, the majority of definitions involve ICTs and the collection and analysis of data to some degree. As I have pointed out in the introduction to this thesis, most smart city definitions are focused on physical infrastructure infused with ICTs. ${ }^{183}$ Notably, however, was Giffinger et al.'s study on smart cities does not analyse ICTs in urban development and infrastructure to the same extent that many others do. Only one metric is focused on ICTs out of the 30 in their study. ${ }^{184}$ However, their focus was more on the socio-political aspects that create a smart city, rather than on physical infrastructure.

Like the 'smart city' concept, the idea of 'big data' does not have a widely accepted, specific definition. ${ }^{185}$ However, without getting into the literature of data studies, I will use the Kitchin's definition of big data, which consists of “massive, dynamic, varied, detailed, interrelated, low cost datasets that can be connected and utilised in diverse ways." ${ }^{186}$ Kitchin outlines

\footnotetext{
${ }^{183}$ Appio, Lima, and Paroutis, "Understanding Smart Cities: Innovation Ecosystems, Technological Advancements, and Societal Challenges."

${ }^{184}$ Giffinger et al., "Smart City: Ranking of European Medium-Sized Cities."

185 Rob Kitchin, "The Real-Time City? Big Data and Smart Urbanism," GeoJournal 79, no. 1 (February 2014): 1-14, https://doi.org/10.1007/s10708-013-9516-8.

${ }^{186}$ Kitchin, 3.
} 
three categories of collected data: directed, automated, and volunteered. ${ }^{187}$ Directed and volunteered data are for the most part the type of data collection that the previous section focused on. Directed data is collected on a specific person or place by a human operator like a CCTV camera or any kind of spatial or biometric scanner. Volunteered data is gifted by users from the use of sites like Facebook or Twitter. Automated data is what smart city conceptualizations are built on. This data is collected through the use of a system or device, like a cell phone or the use of a bus pass. ${ }^{188}$ The important distinction between directed and automated data collection is the removal of direct human operation. By removing the requirement of a human operator more data can be collected at higher rates with little knowledge of those from which the data is being gathered. This means that everyday urban life is now a source of capitalistic extraction for behavioral surplus and its subsequent commodification. Sidewalk Labs has its own definitions of data, which will be explored in the next section.

Like the recent digital turn in capitalist accumulation, smart cities proponents like Sidewalk Labs use the same methods of algorithmic data collection and analysis to plan and operate cities. Returning to Infrastructure Canada's Smart City Challenge, we can see how many of the proposals involved data collection for improved efficiency. The winning proposals for the creation of a circular food economy and another to reduce energy poverty both would require the collection and analysis of data. ${ }^{189}$

For short term management, city officials rely on city dashboards (see figure 2), which have increased in use since the 1990 s, to provide them with real-time data on what is

\footnotetext{
187 Kitchin.

188 Kitchin.

189 “\$10 Million Prize Category Winner - City of Guelph and Wellington County”; “\$5 Million Prize Category Winner."
} 
happening. ${ }^{190}$ These dashboards collect and display information that can help city officials see problems and act on them in real time to resolve any issues rapidly. A great example of a dashboard was developed by University College of London's Centre for Advanced Spatial Analysis (CASA), which informs citizens on the transport system, traffic, weather, among other things. Using urban data has recently been used for public health authorities to map levels of Covid-19 infection rates, helping decide on the distribution of vaccination. ${ }^{191}$

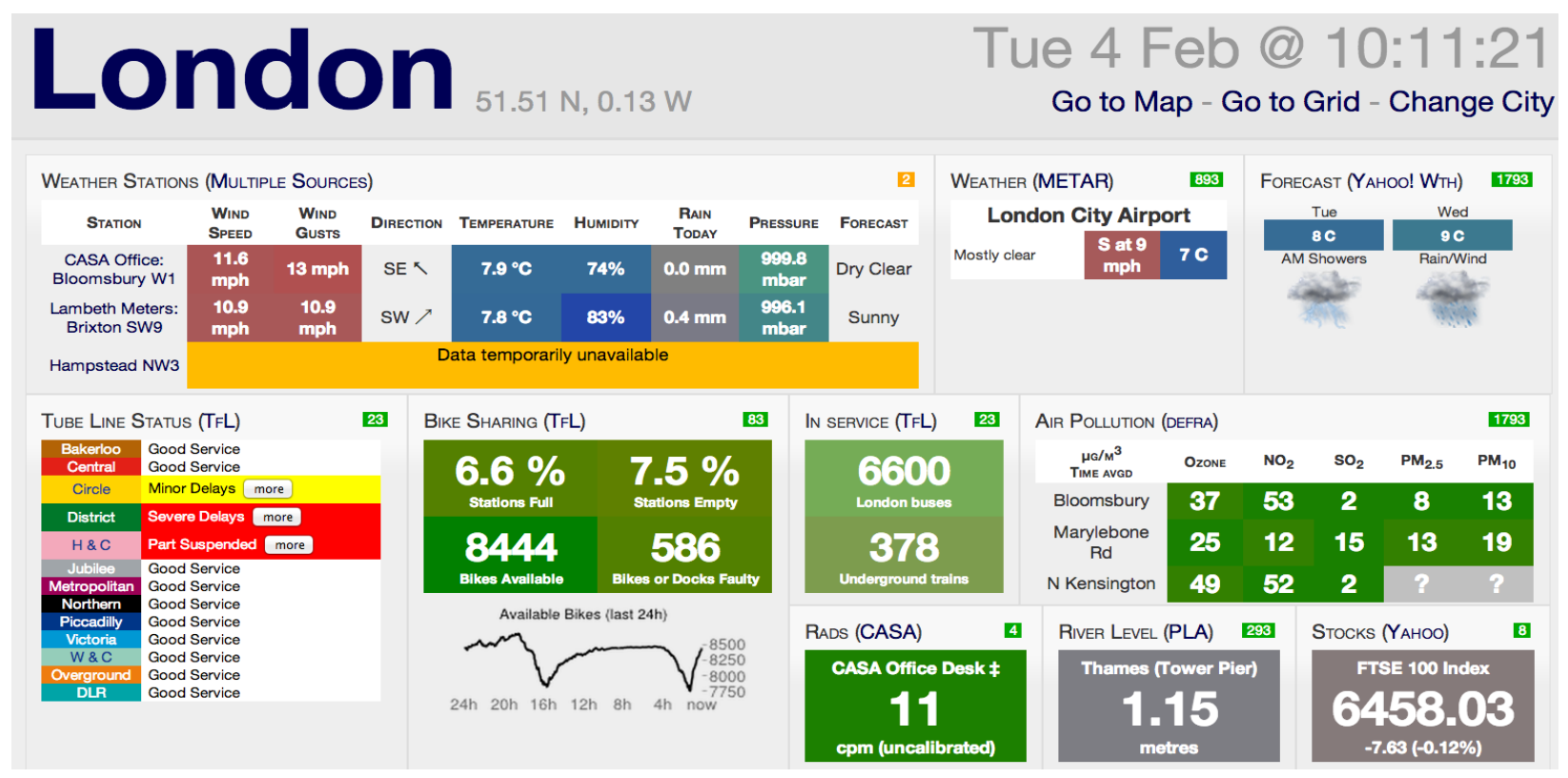

Figure 2: A screenshot of the London City Dashboard, providing details on the city. ${ }^{192}$

Sadowski likens the control of products and services in this form of urban neoliberalism to a 1969 sci-fi novel Ubik. In an early chapter of that text, the main character is attempting to leave their apartment which Sadowski equates to a smart home. All the smart appliances,

\footnotetext{
${ }^{190}$ Teresa Scassa, "Crime Data and Analytics: Accounting for Crime in the City," in Data and the City, 2017, 59-71, https://doi.org/10.4324/9781315407388.

191 Jackie Perez, "COVID-19 Pop-up Vaccination Clinic Held in Ottawa Hotspot Postal Code," CTV News, April 17, 2021, https://ottawa.ctvnews.ca/covid-19-pop-up-vaccination-clinic-held-in-ottawa-hotspot-postal-code1.5391698; "Mapping Products,” Ottawa Public Health, accessed August 10, 2021, https://www.ottawapublichealth.ca/en/reports-research-and-statistics/mapping-products.aspx.

192 “CityDashboard: London,” Centre for Advanced Spatial Analysis, accessed July 20, 2021, https://citydashboard.org/london/.
} 
however, require payments to perform their task, like the door which, when he went to open it, said "Five cents, please." ${ }^{\text {"193 }}$ Real life examples of smart tech dictating space can also be seen through a new form of domestic abuse report on by the New York Times. New patterns of abuse emerged through the remote access of smart tech, abuse that took the form of cranking or turning off thermostats, blaring music in the middle of the night, and changing locks. ${ }^{194}$ Control over a smart city's services could reflect the above discussion. While it may not (immediately) involve as many microtransactions for services like opening doors or result in harassment if you act out of line, the examples above demonstrate the effects of control over spaces through automation and algorithms.

While there may be less concern about governments collecting individual data, there are already practices in place for governments to sell data to the private sector or third parties. In the neoliberal era, as we have seen in the previous chapter, governments, especially local governments, are hard pressed to collect enough funds to provide services that their citizens require and expect. This has led some industrious cities to sell their collected data. ${ }^{195}$ Alternatively, others argue that this data should be publicly accessible to all. ${ }^{196}$ Whether governments sell the data or simply publish it for all to use, there can be some serious implications for the citizenry as we have seen from the insights from Sadowski and Zuboff. The collection of data in urban spaces creates a new form of commodification in urban neoliberalism by applying digital capitalist logics of accumulation in the urban environment.

\footnotetext{
193 Sadowski, Too Smart, 111.

194 Sadowski, 113.

195 Kalev Leetaru, “When Will Cities Begin To Monetize Their Residents’ Data?,” Forbes, July 19, 2018, https:/www.forbes.com/sites/kalevleetaru/2018/07/19/when-will-cities-begin-to-monetize-their-residentsdata/?sh=34563c924661.

196 Sidewalk Labs, "Master Innovation \& Development Plan: The Overview."
} 
Data collection in cities is something people are concerned about. Spurred by the announcement of the deal between Waterfront Toronto and Sidewalk Labs, researchers at McMaster University surveyed Canadians to get a better idea of their concerns about urban data collection. ${ }^{197}$ They found that most people were relatively concerned about the collection and analysis of their data. These anxieties were particularly prevalent among young, university educated respondents. While most people surveyed were strongly opposed to the collection and use of data for private profit through targeted advertisement and behavioral modification, this sentiment was less prevalent for things like public transport. ${ }^{198}$ Canadians also wanted more control over their data, such as being able to opt out, view, correct, and delete their data. ${ }^{199}$ This study demonstrates that people want to hold a significant level of authority over their data, which is antithetical to what smart cities, and Sidewalk Labs, want. Particularly the ability to opt out of data collection in a smart city, if widely chosen, would greatly curtail a smart city's ability to preform the tasks it is designed to preform.

Smart cities are predicated on the notion of collecting urban data and using it to operate the city, and as we have seen in the previous section, the collection and use of data has grown to be a key revenue stream for some of the largest companies in the world. Smart cities cohere with the market logics of urban neoliberal commodification by turning the city into a factory floor by collecting behavioral surplus from the activity within the city. Additionally, the information being received by city officials provides them with a managerial level of oversight on the city and citizens. In the next section, we will look at how Sidewalk Labs proposed to collect data, use it, and how they addressed privacy concerns through their proposed data governance framework.

\footnotetext{
197 Sara Bannerman and Angela Orasch, "Privacy and Smart Cities: A Canadian Survey," Canadian Journal of Urban Research 29, no. 1 (2020).

198 Bannerman and Orasch, 33.

199 Bannerman and Orasch, 34.
} 


\section{Sidewalk Labs' Smart City Technologies}

Data collection and analysis has become one of the most profitable forms of accumulation through targeted advertising and behavioral modification. Smart cities seek to use the same logic of behavioral modification to manage and operate urban spaces and their inhabitants. In the last section, I outlined the logic of data collection inherent in smart city conceptions both in practice and in theory. In this section, I will use Sidewalk Labs' proposal to demonstrates how data collection and analysis is central to smart city developments and governance.

Volume 2 of the MIDP contains the plans proposed by Sidewalk Labs concerning technological innovation, in other words, what puts 'smart' in the smart city. Chapter five of this volume specifically speaks to the technological innovations and how they will be implemented and used. In this chapter of the MIDP, Sidewalk Labs outlines four core components to what they believe make a comprehensive approach to handling the challenges digital innovation creates. ${ }^{200}$ Two components speak to the creation of the ability to monitor data generated in the urban setting. The first of which is a commitment to "establish open digital infrastructure that provides a shared foundation for using urban data." The second is a plan to release a minimal set of digital services in order to start servicing the district. ${ }^{201}$ The other two components relate to the digital governance Sidewalk Labs proposes for the data collected, in the form of clear standards that make data publicly available and secure, and the creation of a trusted process for

\footnotetext{
${ }^{200}$ Sidewalk Labs, "Master Innovation \& Development Plan: Volume 2."

201 Sidewalk Labs, 377.
} 
responsible data use. ${ }^{202}$ This section focuses on the first two components, while in the next section, data standards and practices are examined.

Sidewalk Labs has two main propositions in their MIDP to ensure that data is generated, collected, and used. The first is the commitment to establish digital infrastructure that would provide open and accessible data to the public. The digital infrastructure would include sensors throughout the IDEA District, physical mounts to provide locations for future innovations, and ubiquitous internet connectivity for the district. What is noteworthy is Sidewalk Labs' definition of urban data, which is: “information gathered in the city's public realm, its publicly accessible spaces, and even some private buildings. ${ }^{" 203}$ Therefore, Sidewalk Labs believes that data from all over the IDEA District should be collected for their goals of efficiency and innovation. This includes streets, parks, shops, and offices.

The second part to Sidewalk Labs plans to create a smart city is to release what they refer to as a minimal set of digital services for the district. Sidewalk Labs stresses that the purpose of these digital services is not to act as a monopoly in the district, but to generate competition, and share the data to promote innovation and development of new services. These services range from an "outcome-based building code," which is a real-time building monitor system that tracks “noise, nuisances, and structural integrity," to active stormwater management which would retain and reuse stormwater for irrigation. ${ }^{204}$

Below are diagrams (figures 3, 4, and 5) from MIDP Volume 2, chapter 5. They outline the route data will travel and what sort of information would be stored, processed, and analyzed. The blue lines represent publicly accessible data, and the orange represents restricted data. In the

\footnotetext{
202 Sidewalk Labs.

203 Sidewalk Labs, 377.

204 Sidewalk Labs, 444-447.
} 
next section of this chapter, I examine Sidewalk Labs' ideas on urban data governance, which will discuss the governance structures and regulations. There I also look at the different classifications of data and what each mean. For now, it is important to get a visual representation of the level of urban infrastructure infused with sensors to gather data that was going to be built into the IDEA District.

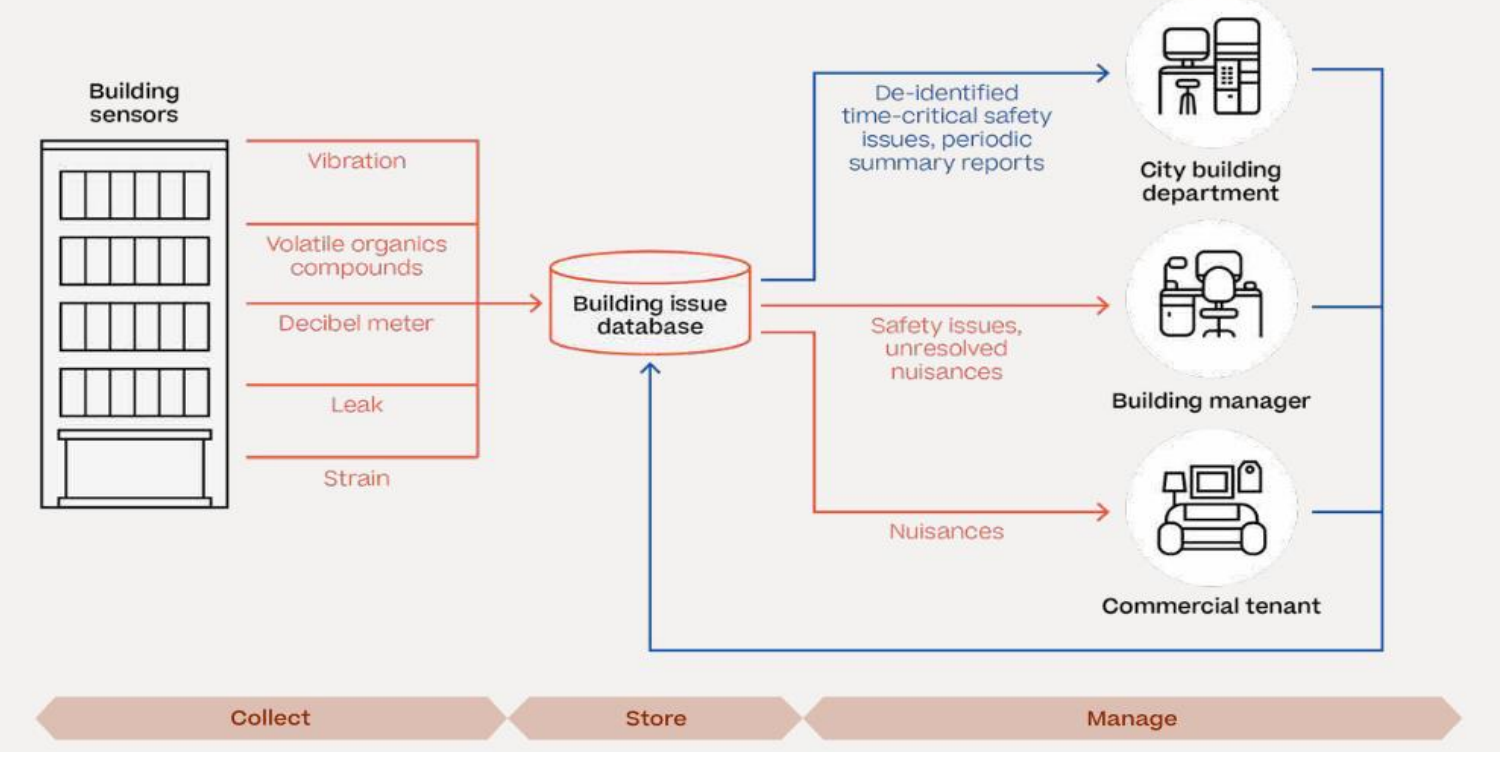

Figure 3: The pathway data would take once collected from mix-used buildings. The blue lines represent publicly accessible data, and the orange represents restricted data. ${ }^{205}$

First is a diagram on data monitored in a mixed-use building (Figure 3). Sidewalk Labs believes that the key to creating a sustainable and inviting urban environment is to have residential, commercial, and light industrial in close proximity. To make this feasible, Sidewalk Labs proposes their outcome-based building code system that would involve the monitoring of several types of building regulations on an ongoing basis. Sidewalk Labs argues that the collection of data would be "necessary to ensure the industrial spaces would comply with

\footnotetext{
${ }^{205}$ Sidewalk Labs, 441.
} 
regulatory conditions, such as noise and odour requirements." 206 Of course, the monitoring will be done on more than just the industrial spaces. The goal was to ensure that everyone in the district would comply with the regulations through real-time surveillance. Because the information would be traceable to specific hallways, for example, it would be restricted under their data governance proposal. With the data being restricted in order to make sure that it is not traceable to any one individual, Sidewalk Labs argues that "the balance of impact of collecting environmental data would weigh in favour" of their proposal. ${ }^{207}$ Data would be used to enforced noise bylaws, measure air quality, and structural integrity, but certain data would also be accessible to third parties. ${ }^{208}$

Like the mixed-use building, and potentially in the same building, the office space in the IDEA District would include sensors that would allow for the automatic control of the environment (Figure 4). According to the proposal information from energy-related sensors would help the "Office Scheduler" tool optimize building energy use, with aggregated and deidentified data made publicly accessible to third parties. This data would be 'de-identified,' like the data discussed above, so it would not be traceable to any one individual when it becomes accessible to third parties through the Urban Data Trust (further discussion in the next section). ${ }^{209}$

\footnotetext{
206 Sidewalk Labs, 448.

207 Sidewalk Labs, 449.

208 Sidewalk Labs, "Master Innovation \& Development Plan: Digital Innovation Appendix,” $2019,82$.

209 Sidewalk Labs, 451.
} 


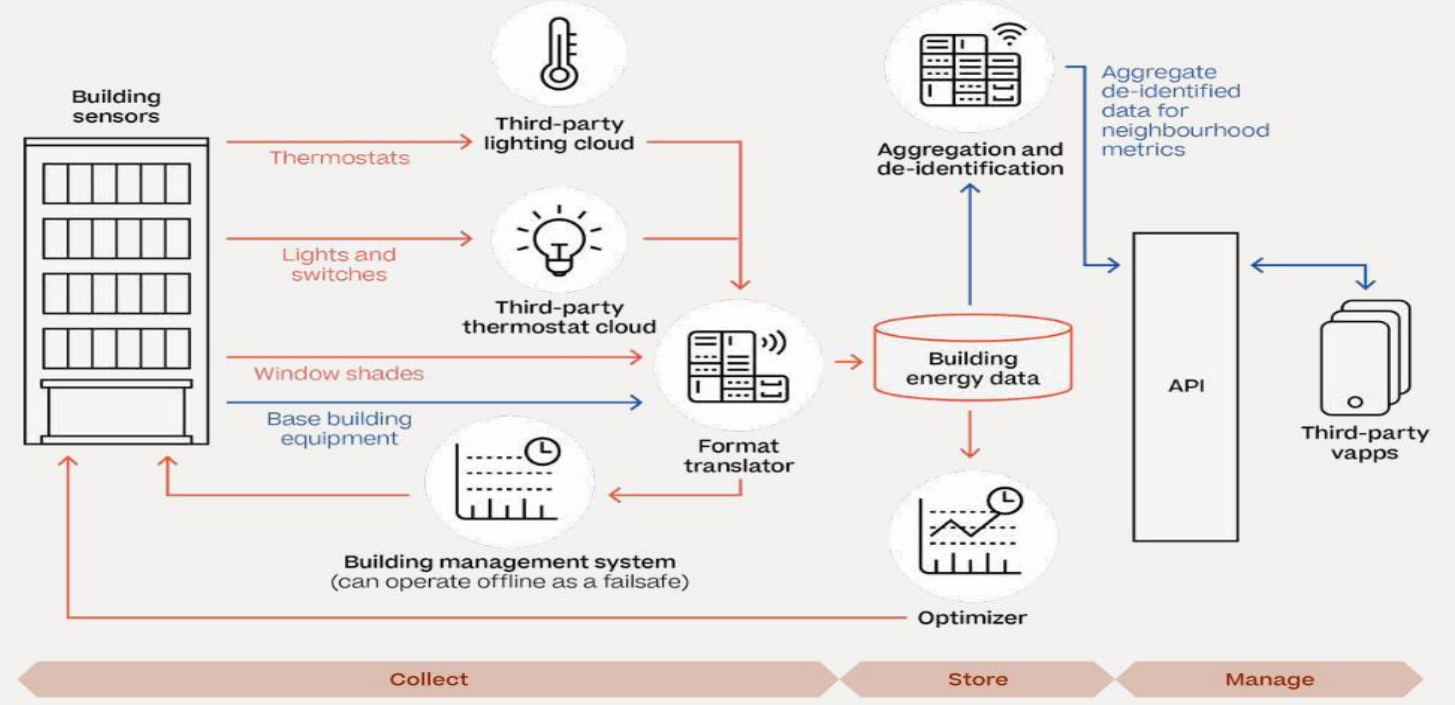

Figure 4:Data pathway in an office building using the Office Scheduler. ${ }^{210}$

Data collection and monitoring is increasingly a common occurrence in the workplace.

One of the most infamous examples has been Amazon's surveillance on their workers in warehouses, drivers, and according to Business Insider, their office workers will be included soon too. ${ }^{211}$ Amazon also has recently used modern and traditional surveillance tactics to ensure a favourable outcome on a union vote their workers have conducted. ${ }^{212}$ In recent months, due to the Covid-19 pandemic, worker surveillance has increased because employees are being forced to work from home due to restrictions. ${ }^{213}$ The above examples of workplace surveillance can take the form of tracking bracelets, or devices in cars to monitor movement to keep track of

${ }^{210}$ Sidewalk Labs, 451.

${ }^{211}$ Annabelle Williams, "5 Ways Amazon Monitors Its Employees, From AI Cameras to a Spy Agency," Business Insider, April 5, 2021, https://www.businessinsider.com/how-amazon-monitors-employees-ai-camerasunion-surveillance-spy-agency-2021-4; Francis Agustin, "Amazon Reportedly Wants to Track Customer Service Workers' Biometrics," Business Insider, August 12, 2021, https://www.businessinsider.com/amazon-trackcustomer-service-workers-biometrics-2021-8.

${ }^{212}$ Annie Palmer, "How Amazon Prevents Unions by Surveilling Employee Activism," CNBC, October 24, 2020, https://www.cnbc.com/2020/10/24/how-amazon-prevents-unions-by-surveilling-employee-activism.html.

${ }^{213}$ Claire Brownell, "The Workplace of the Future Will Probably Remain under Surveillance," MacLean's, December 15, 2020, https://www.macleans.ca/work/the-workplace-of-the-future-will-probably-remain-undersurveillance/; Shiran Weitzman, "How Remote Work Is Changing Workplace Intelligence," Forbes, August 17, 2021, https://www.forbes.com/sites/forbesfinancecouncil/2021/08/17/how-remote-work-is-changing-workplaceintelligence/?sh=34aa9d7952ef. 
breaks, or software to record keyboard inputs, mouse movement, and in some cases using the built-in camera of a computer to take pictures in intervals.

While it seems like alarmism to connect Sidewalk Labs' plans to have smart thermostats, lights, and shutters, with the tactics of other large tech corporations which perform surveillance on workers, it normalizes workplace monitoring. Already, employers are looking for ways to supervise workers through technological innovations. While currently most of that is done in warehouses, as exemplified by Amazon, companies are looking to include office workers in this form of management. With the pandemic, companies have started using this technology to monitor their employees with the pretense that because they are at home, they need to ensure they are staying focused, but this sort of surveillance could easily be transfer to the workplace of an office building. Again, there is nothing in the MIDP that suggests evidently that Sidewalk Labs wants to enable employers to manage workers in the same manner as they seem to want to manage the public space of the IDEA District, however, as I shall demonstrate in the next section, Google has a method of embedding themselves, and then expanding their exploitation, through what Zuboff calls the cycle of dispossession. ${ }^{214}$

Below (Figure 5) is a diagram of data collected in the "Mobility Management System.."15 This system would collect information about local traffic, store that information in databases, and make non-restricted data publicly accessible to third parties. Sidewalk Labs was also investigating the use of heat-mapping technologies like radar thermal, and infrared in the IDEA District. These forms of data collection would be used to count "how many customers visited a

\footnotetext{
${ }^{214}$ Zuboff, The Age of Surveillance Capitalism: The Fight for a Human Future at the New Frontier of Power.

215 Sidewalk Labs, 452-453.
} 
store at Quayside or whether a certain space is ideal for leasing" according to the company. ${ }^{216}$ The idea appears to be that Sidewalk Labs wants to be able to control and manage urban space and traffic similar to the way they can online. Google has become of the largest companies in the world in large part due to the profitability they have discovered through the behavioral surplus through users interacting with their search engine, and later other services they offered.

These diagrams are useful for getting a visual understanding of the extent of the integration between everyday life and monitoring technologies that Sidewalk Labs proposes. We are already integrated into technologies that track and monitor our actions and behaviors, but this would integrate those technologies into the urban environment around us, and urban governance. The previous section demonstrated that with the information already gathered we can be nudged into various decisions, opinions, or actions that we may not have come to otherwise through the creation of psychological profiles and curating what is seen online. This is the danger with allowing ICT integration in urban environments, especially when led by powerful, unaccountable, and monopolistic corporations, which is the topic for the third chapter.

\footnotetext{
${ }^{216}$ Vincent, "Foot Traffic in Stores, Pay-as-You-Throw Garbage Collection: Sidewalk Labs Shares Data Collection and Use Plans for Toronto Smart City."
} 


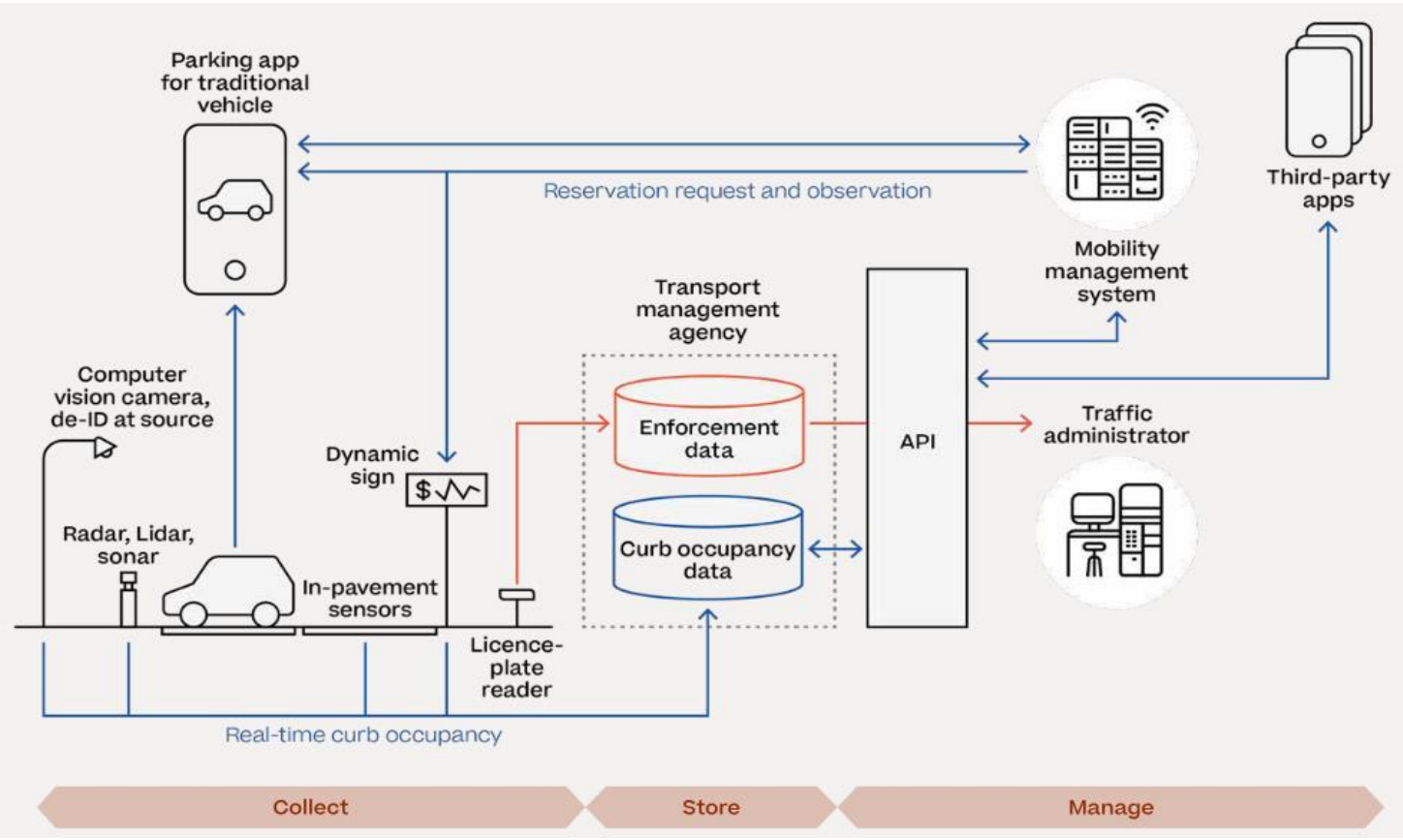

Figure 5:Depiction of the Mobility Management System. ${ }^{217}$

For smart cities, rather than needing to have a Facebook account or be using Uber, urban digital infrastructure like what was proposed by Sidewalk Labs in their MIDP will be omnipresent and all-encompassing. A city designed to monitor and collect data for the purpose of analysing behavior would gather immense amounts of data that would not be possible to collect through methods that exist currently to the same extent. While Sidewalk Labs and proponents of smart city initiatives often argue that data collection and analysis will provide benefits of efficient services and sustainability, the value of that data would be much greater than that. Sidewalk Labs seems to believe that through turning urban space into something like cyberspace that Google controls, they can collect behavioral surplus and improve governance, similar to how Google improved their search engine in the beginning and later how they became profitable.

217 Sidewalk Labs, “Master Innovation Development Plan: Volume 2,” 453. 
These companies have pioneered these processes and continue to be at the cutting edge of innovation in data commodification. As we enter the age of the smart city, these companies will be uniquely relied upon for their technical knowledge. ${ }^{218}$ Tech companies jealously guard their innovations and software from would-be competitors, and there are serious dangers related to governments placing too much reliance on the big tech companies and the services they provide, which is discussed in more depth in the next chapter. Allowing these companies into more aspects of our lives only increase the potential influence they will hold over individuals. Already, through data, private enterprises can invade our personal lives to impact us through targeted advertising or decide through algorithms what we see online. These initial digital services proposed by Sidewalk Labs were meant to collect the data of people using them, and possibly even when they are not using them. This is true for the environmental monitors as well, which would be unavoidable.

The dangers of what Sidewalk Labs was proposing did not go unnoticed. Upon the publication of their MIDP, officials from Waterfront Toronto were quoted, describing it as "frustratingly abstract" and "repetitive." ${ }^{219}$ The ambiguity in the MIDP resulted in Sidewalk Labs publishing a Digital Innovation Appendix to further outline the company's vision for the development. While Waterfront Toronto called the appendix an improvement, there were still issues. One issue that Waterfront Toronto took aim at was the "pay-as-you-throw" garbage disposal system, which is exemplary of larger concerns about urban governance in a smart city. The theoretical benefits would be having landowners pass the cost of waste removal off to residents, which would in turn, incentivise residents to produce less waste. One issue Waterfront

\footnotetext{
${ }^{218}$ Kitchin, "The Real-Time City? Big Data and Smart Urbanism."

${ }^{219}$ Vincent Donovan, "Waterfront Toronto Advisory Panel Still Has Concerns about Sidewalk Labs ' Data Collection, New Report Says," The Toronto Star, February 26, 2020, https://www.thestar.com/news/gta/2020/02/26/waterfront-toronto-advisory-panel-still-has-concerns-about-sidewalklabs-data-collection-new-report-says.html.
} 
Toronto took up with this particular proposal was that it would negatively impact lower-income residents more than others, and that it "introduces a new form of surveillance." 220

The role of these private corporations in smart cities will be explored more in the next chapter. Here, I demonstrated the ways in which Sidewalk Labs' MIDP follows the general conceptions of smart cities in terms of data collection and analysis, but also striving to use that data for digital capitalist means of accumulation. In the next section, I delve into the growing field of study on data governance as urban governance.

\section{Data Governance}

New technologies and algorithms provide city planners with the information needed to assess and alter a city's dynamic at a much faster and more accurate or impactful way than has ever been possible. However, as Martijn de Waal puts it:

If computers are indeed used to run the city, rather than merely to analyse it, this could lead to new spatial regimes. What are the power structures and ideologies operative in the ways data are collected, categorized, analysed, and acted upon? How does that effect the production and experience of place and our ability to act?221

The governance structure for the data generated by a smart city is still being debated, and

Sidewalk Labs provides their ideas in the proposal. The company also believes that publicly accessible data is necessary to fully utilize and realize their vision for the smart city project that they were undertaking in Toronto. ${ }^{222}$ In this section I discuss the solutions provided by Sidewalk Labs on concerns over privacy, as well as discuss the idea of an 'information fiduciary' which would act as the authority of data governance in place of government. Sidewalk Labs' idea for

\footnotetext{
${ }^{220}$ Donovan.

${ }^{221}$ Martijn de Waal, "A City in Not a Galaxy: Understanding the City through Urban Data," in Data and the City, ed. Rob Kitchin, Tracey P Lauriault, and Gavin McArdle (New York: Routledge, 2018), 21.

${ }^{222}$ Sidewalk Labs, "Master Innovation \& Development Plan: The Overview."
} 
data governance and the literature on information fiduciaries continue the roll-back and roll-out of urban neoliberalism through the reduction of state regulations in favour of private actors.

Sidewalk Labs was building the project in Toronto with the idea that it had the potential to create a new economic and technological hub in the city and the country. ${ }^{223}$ In the MIDP, Sidewalk Labs refer to a program in Estonia created by the government, which allows citizens to conduct government related services and programs via the internet. ${ }^{224}$ This program, known as "X-Road," allows citizens to file taxes, apply for a bank loan, view medical bills, and automatically registers kids for school, since it knows the child's date of birth. Some information gathered by X-Road is publicly accessible through a set of published standards. Sidewalk Labs credits this information gathering and sharing as the catalyst to Estonia's path to becoming hub of technological innovation particularly in blockchain and cybersecurity. ${ }^{225}$

Sidewalk Labs believes that data gathered on people belongs to no one in particular, depending on where it is gathered. For example, the company believes that data collected on individuals while they are in public or publicly accessible spaces like parks, retail stores, lobbies, and courtyards does not belong to the people who are producing it. ${ }^{226}$ This makes it easier for it to be commodified, turning public spaces of the IDEA District into an urban neoliberal space of accumulation. While Sidewalk Labs makes the claim that the data is a shared resource, it is only of any utility to some, and can be detrimental to many others. Therefore, while the data belongs to no one in particular, is certainly does not belong to many of the people producing the data.

\footnotetext{
223 Sidewalk Labs.

${ }^{224}$ Sidewalk Labs, "Master Innovation \& Development Plan: Volume 2."

225 Sidewalk Labs, 400-401.

${ }^{226}$ Sidewalk Labs, 426.
} 
With this level of data collection and the goal of that data being largely publicly accessible, Sidewalk Labs recognizes that there is a need to develop a governance structure, or perhaps they just realized that there would be political pushback. To address any data concerns, they provide an outline of what they believe should be instituted for urban data governance, while ensuring most of the data will be publicly accessible. The desire for this is to make data more easily accessible for "researchers and the community in real time and make it easy for third parties to build new services" to get the same tech innovation benefits seen in Estonia. ${ }^{227}$ Repeatedly stated throughout the MIDP is Sidewalk Labs' commitment to make the urban data being publicly available to everyone, including companies. Sidewalk Labs' views open data as a given for their IDEA District to reach its potential as an economic and technological innovation hub. In the MIDP, Sidewalk Labs states "no single company, organization, or agency should own the data or database used by cities." ${ }^{228}$ It is in Sidewalk Labs' (Google's) best interest to keep the data from becoming something that is governed by the public, as they would not want Google and other tech companies exploiting them. Therefore, this statement is misleading because it is present as if Sidewalk Labs is concerned with the same things as residents (extraction and commodification of behavioral surplus) but while keeping the possibility for digital logics of accumulation to take place, through the imposition of open and accessible data.

Zuboff discusses the "dispossession cycle" tech companies, particularly Google, go through in "order to achieve their ultimate destination as a system of facts through which surplus extraction is normalized." 229 This four-stage cycle is meant to explain the process in which Google encroaches in unoccupied space in daily life, and then normalizes their presence there. I

\footnotetext{
${ }^{227}$ Sidewalk Labs.

${ }^{228}$ Sidewalk Labs, 403.

${ }^{229}$ Zuboff, The Age of Surveillance Capitalism: The Fight for a Human Future at the New Frontier of Power, 137.
} 
believe that the dispossession cycle can be applied to what Sidewalk Labs was proposing in their IDEA District. The first stage, incursion, "seduces, ignores, overwhelms, or simply exhausts adversaries. ${ }^{" 230}$ This stage is exemplified through Sidewalk Labs MIDP and its multitude of artist renditions of a futuristic Toronto neighbourhood, promises of economic prosperity and a new Google headquarters, and the company's attempt to incorporate significantly more land than was originally agreed to.

The three other stages of the dispossession cycle are what normalizes the encroachment done by the first stage. While the project was canceled the full cycle will not be exemplified, the MIDP does outline the beginning of the normalization process, which Zuboff calls, habituation, adaptation, and redirection. The second stage is demonstrated by people becoming habituated with the incursion, "with some combination of agreement, helplessness, and resignation." 231 Adaptation is done through satisfying immediate demands of the government, courts, and the public. Finally, Google creates a new rhetoric, design, and method in order to redirect, and appear compliant with any social or legal demands. ${ }^{232}$

Sidewalk Labs would have accommodated the final three stages through their plans for data governance within the IDEA District. Anticipating the pushback from the general public on data collection and it then being publicly available, Sidewalk Labs proposes the creation of a process for responsible data use. Sidewalk Labs sees this process being anchored in a Responsible Data Use (RDU) Assessment. The RDU would be developed and implemented by a newly created non-profit organization which is referred to as the Urban Data Trust (UDT). The UDT, as proposed by Sidewalk Labs, would be headed by a board with five members, which

\footnotetext{
${ }^{230}$ Zuboff, 138.

231 Zuboff, 139.

${ }^{232}$ Zuboff, 139.
} 
would include an expert on data governance/privacy, and representatives from the community, the public sector, an academic, and from local business. The UDT would oversee the creation of the RDU assessment process and approving applicants for data collection and use. Sidewalk Labs provides the following recommendations for the RDU guidelines: (i) Use of urban data must have a beneficial purpose; (ii) Transparency and clarity; (iii) Data minimization, security, and de-identification by default; (iv) Publicly accessible by default; (v) No selling or advertising without consent; (vi) Responsible artificial intelligence principles required. ${ }^{233}$

Sidewalk Labs identifies five different types of data and separates them into categories which would each require certain levels of accessibility. First there is non-personal, which is data which cannot identify a person. Second is aggregate data, which is about people in general and cannot be connected to any one person in particular. Third is de-identified data which is data that was collected on a particular individual but has undergone a process to make them nonidentifiable. Fourth kind of data is personal information, which has a legal definition and is protected under Canadian privacy laws. Finally, there is transactional data. This last type of data is "information individuals consent to providing for commercial or governmental services."234 Sidewalk Labs goes to some lengths arguing as to why the newly created UDT should not be assessing the collection of transactional data, which is rooted in the fact that this form of data does not pertain to any specific geographical area (i.e., IDEA District).

Consent is a concept that should be explored more. Zuboff demonstrates how surveillance capitalists exploit user agreements to gain consent from individuals for data collection and sale. ${ }^{235}$ Gaining this form of consent will also have the data being collected fall

\footnotetext{
233 Sidewalk Labs, 424-425.

234 Sidewalk Labs, 426.

${ }^{235}$ Zuboff, The Age of Surveillance Capitalism: The Fight for a Human Future at the New Frontier of Power.
} 
under 'transactional data' and therefore fall outside the purview of the UDT and its RDU

assessment. Sidewalk Labs views the IDEA District and the digital infrastructure there as being a catalyst for technological innovation and they seem to believe that there will be high demand for the data collection opportunities in the area. Sidewalk Labs believes that there will be competition in the creation of digital infrastructure in the region. However, what is not clear is how some of these digital infrastructures will be instituted. If a company that develops an app for a service or to connect to a service in the area, why would they not also require users sign off on a user agreement that allows for that company to collect and sell their data to third parties, or use it themselves for alternative reasons? Again, this would fall outside the jurisdiction of the UDT.

There is also a clear dissonance between people's desire for privacy rights and not doing anything to protect their privacy. This phenomenon has drawn the attention of scholars who have identified two paradoxes in relation to data privacy. ${ }^{236}$ The 'privacy paradox' characterizes people's desire for privacy while their seemingly indifference to it in action. ${ }^{237}$ For example, the most popular pass code is 1234 , and many people use the same password for multiple accounts. Similarly, while many people do not trust social media accounts, they still share personal information on them. ${ }^{238}$ The 'control paradox' describes the idea that people are less concerned about their data privacy as long as they have some level of control over it. ${ }^{239}$ Numerous studies have exemplified the strong desire from people to have data privacy, however, is contradicted by the growing smart tech industry. One study across six countries including Canada found that 63 percent of respondents "find connected devices "creepy" and 75 percent do not trust the way

\footnotetext{
${ }^{236}$ Liesbet van Zoonen, "Privacy Concerns in Smart Cities," Government Information Quarterly 33, no. 3 (July 1, 2016): 472-80, https://doi.org/10.1016/j.giq.2016.06.004.

${ }^{237}$ Alyson Leigh Young and Anabel Quan-haase, "Privacy Protection Strategies on Facebook: The Internet Privacy Paradox Revisited," Information, Communication \& Society 16, no. 4 (2013).

${ }^{238}$ van Zoonen, "Privacy Concerns in Smart Cities."

${ }^{239}$ van Zoonen.
} 
their data is shared by those devices. ${ }^{240}$ However, of those people surveyed, 70 percent said they owned one or more connected devices. ${ }^{241}$

Sidewalk Labs' UDT proposal appears to be an adaptation on an idea articulated a few years before the MIDP was written. In 2016, Jack M. Balkin, a legal scholar, wrote an article on what he calls information fiduciaries. ${ }^{242}$ His work was a part of the growing legal conversation on how data should be interpreted in the law. Balkin focuses on the relationship with data collection and use and the First Amendment of the U.S. constitution. Data collected in public has been protected under the First Amendment starting with citizens recording police officers and other public officials in public spaces. Balkin, believes that logic could extend to anything that happens in public settings as being open to the collection of data. ${ }^{243}$ Sidewalk Labs obviously believes this to be the case in the Canadian legal system as well.

A fiduciary is someone who has special obligations of loyalty and trustworthiness towards another person, according to Balkin. ${ }^{244}$ Professions that hold a position of fiduciary obligations are, for example, lawyers, doctors, and accountants. These are people that, due to their work, have knowledge of their clients they may not want others to know for various reasons. Therefore, rather than the content of this information being the important part, it is rather the relationship in which it is produced. In Balkin's words, he argues that "instead of focusing on the form of information as digital data, we may need to focus instead on its social characterization or social function." ${ }^{245}$ There are two basic duties that fiduciaries must perform.

\footnotetext{
${ }^{240}$ Molla, "People Say They Care about Privacy but Buy Devices That Can Spy on Them."

${ }^{241}$ Molla.

242 Jack Balkin, "Information Fiduciaries and the First Amendment," UC Davis Law Review 49, no. 4 (2016).

${ }^{243}$ Balkin.

244 Balkin.

245 Balkin, 1196.
} 
The first is to cause no harm to the interests of their client. The second, and closely related, is that the fiduciary must not create potential or actual conflicts of interest. ${ }^{246}$

There are several factors in the relationship between users and online service providers like Google and Facebook that are closely related to traditional fiduciaries. First, users are in a position of significant vulnerability compared to the online service providers in similar ways as a patient is to a doctor or a client to a lawyer. Second, users are in a position of relative dependence as many of the online service providers are unique in what they offer ${ }^{247}$ This adds to the lack of proactive action on protecting personal information from being collected. ${ }^{248}$ Additionally, this becomes more prevalent when infrastructure is infused with ICTs, putting people and governments in positions where they may be "locked-in" with services from one particular company. ${ }^{249}$ Third, in many cases, these service providers hold themselves to the public as experts in their field. Finally, companies like Facebook, Google, and Amazon hold valuable information on users, which the users know, and these companies know users know, which leads them to present themselves as trustworthy stewards of our information. ${ }^{250}$ Because of the relationship between users and online service providers and the asymmetries in power and vulnerabilities, Balkin is arguing that these companies fall well within the framework of a fiduciary. However, Balkin is rather restrained when discussing how far these fiduciary obligations should go for these companies.

While Balkin argues that online service providers should fall under the legal classification of a fiduciary, their relationship should not "require the same degree of obligation,

\footnotetext{
${ }^{246}$ Balkin.

247 Balkin.

${ }^{248}$ Molla, "People Say They Care about Privacy but Buy Devices That Can Spy on Them."

${ }^{249}$ Kitchin, "The Real-Time City? Big Data and Smart Urbanism," 10.

${ }^{250}$ Balkin, "Information Fiduciaries and the First Amendment."
} 
loyalty, and protection" that applies to traditional fiduciaries. ${ }^{251}$ In a traditional fiduciary relationship, clients pay the professionals whose services are being used. This economic reason is a large factor in why fiduciaries are compelled to uphold their obligations of privacy. The economic relationship of one party paying the other, does not exist or exists to a significantly smaller extent for online service providers like Google and Facebook, and potentially even less so when urban infrastructure is what is collecting the data. These companies provide free services which are offset by the data users generate on their website, which the companies use for financial gain. Online service providers are also different to traditional fiduciaries in terms of the data collected. Traditionally, there is a lot less uncertainty. For example, you know what you tell your doctor and who your doctor is. The amount of information that is collected by a company like Google is difficult to comprehend, and it is even more difficult to understand how that information is used. For this reason, as Balkin explains, contract or property models for data privacy protection would not be nearly as effective as a fiduciary relationship. ${ }^{252}$

Balkin does not believe that free or heavily subsidized services like the ones offered by Google or Facebook are inherently in violation of fiduciary obligations, after all, as Balkin puts it “"fiduciary' does not mean 'not-for-profit." ${ }^{\prime 253}$ Additionally, Balkin rather cynically believes that online services should not be required to have our best interests in mind. Uber may have to protect our privacy but is not required to not tells us to not take a trip somewhere due possible dangers.

While this concept of information fiduciaries has picked up steam in legal circles and to some extent in the US capital, some authors disagree with the idea. There are clear contradictions

\footnotetext{
${ }^{251}$ Balkin, 1221.

252 Balkin.

${ }^{253}$ Balkin, 1227.
} 
between what is in the best interest for the users of the online services and the companies that profit from the users' activity. To point to a few, reducing sensationalism, making them less addictive, and enhancing personal privacy are all things that would be beneficial to the users. However, these same steps would help users, and cut into the profitability of the platforms..$^{254}$

Sylvie Delacroix and Neil D. Lawrence propose a data trust much in the same model as Balkin's information fiduciaries. However, what makes their proposal unique is that they explore the possibility of a marketplace of data trusts similar to that of financial institutions or internet companies. They believe that it is important to provide people with the opportunity to choose which model of data governance best suits them. For example, "some Trusts may heavily favour the furthering of some 'public good' endeavour by making some data freely accessible to some organizations, while others may prioritize the maximization of financial returns."255

If current conceptions of smart cities like the Sidewalk Labs project are going to be implemented, there is going to need to be a data governance structure in place. In the MIDP, Sidewalk Labs provided a proposal for a UDT, which they see as the best option for a governing body for the data collected. However, both Balkin and Sidewalk Labs believe that data should be allowed to be used for capitalist accumulation in the same manner as outlined by Sadowski and Zuboff, which undermines the public and social function of data. Through the collection of data in smart cities, urban neoliberal ideology will be turning urban environments into spaces of accumulation, through the marketization of data, privatization of policy, and the enclosure and control of profit-making spaces. Even if information fiduciaries are to be implemented, and they

\footnotetext{
${ }^{254}$ Lina M. Khan and David E. Pozen, “A Skeptical View of Information Fiduciaries,” Harvard Law Review 133, no. 2 (2019).

255 Sylvie Delacroix and Neil D Lawrence, “Bottom-up Data Trusts: Disturbing the 'One Size Fits All' Approach to Data Governance," International Data Privacy Law 9, no. 4 (November 1, 2019): 243, https://doi.org/10.1093/idpl/ipz014.
} 
act "in the best interest of their clients," private corporations are taking the role of governance over this important issue.

\section{Conclusion}

Technological changes have created a new mode of capitalist accumulation, based on data collection and analysis and are becoming part of how cities are operating day-to-day. In the first section of this chapter, I outlined the creation of this new form of neoliberal capitalist accumulation, and the wider implications that have emerged from it. Notably, the same methods used for targeting advertisements at certain people can be used to influence and modify their behavior.

Smart cities want to use data collection and analysis for similar ideas of control and predictability as used by private corporations through behavioral surplus. The collection of behavioral surplus is cause for concern, especially when coupled with the role private corporations are seeking to play in the smart city paradigm, which will be the focus of the next chapter, but is exemplified through the existence of Sidewalk Labs. Sidewalk Labs' project endeavoured to apply digital capitalist methods of commodification and accumulation to urban neoliberalism through smart cities. Additionally, adhering to urban neoliberal logics, the governance of the data collected was going to be controlled by a separate body, further reducing government's role in the governance of cities. The reduction of government and expanded role of corporations is taken up in the next chapter. 


\section{ChAPTER 3 - WhO IS The SMART City For?}

\section{Introduction}

While technocracy is not a concept unique to urban neoliberalism, neoliberal influence on it has created a particular approach which makes space for private firms to take the place of governments on many issues. Some approaches to smart cities follow this logic of private technocratic governance and corporate participation in urban development. Building off the last chapter, aspects of the technocratic governance rely on data driven decision making. While the last chapter analysed how data is collected, used, and governed, this chapter looks at decision making processes and the role of private corporations in smart cities.

A component of urban neoliberalism is the idea that free and open markets are the most efficient method of allocating the scarce resources available and providing services. The idea is that because free markets are profit oriented, inefficiencies will be eliminated to maximize profit. $^{256}$ The fixation on maximizing profits has given rise to a reliance and almost sanctification of data and algorithms. Zuboff refers to those who create and manage the algorithms and data as a "priesthood of computer scientists." ${ }^{257}$ In the introduction to a special issue of Social Epistemology, the authors note a naive approach to science, which becomes "scientism, that is, the fetishism of science, rather than a scientific approach to reality which includes the socialinstitutional production of scientific knowledge." 258 I use the two previous quotes to demonstrate two aspects of data driven decision making. The first is that, even though algorithms are already

\footnotetext{
${ }^{256}$ Brenner and Theodore, "Cities and the Geographies of "Actually Existing Neoliberalism," 2-3.

257 Shoshana Zuboff, The Age of Surveillance Capitalism: The Fight for a Human Future at the New Frontier of Power, First edit (New York: PublicAffairs, 2019), 79.

${ }^{258}$ Justin Cruickshank and Ross Abbinnett, "Social Epistemology A Journal of Knowledge, Culture and Policy Neoliberalism, Technocracy and Higher Education: Editors' Introduction,” 2019, https://doi.org/10.1080/02691728.2019.1638983, 274.
} 
calculating and making decisions that impact our daily lives, most people are ignorant of how they work and affect them. Only those who have the proper education and knowledge ("proper" in the sense that it adheres to urban neoliberalism) can truly understand the processes that go into the decision making of these algorithms. The second quote speaks to the assumption that by collecting data and putting it through algorithms, the result is factual and unbiased.

In this chapter, I demonstrate that the neoliberal conception of expertise and technocracy is not only prevalent in, but fundamental to, smart cities. In the first section, I outline the idea of efficiency and expertise in urban neoliberalism and how corporations have etched out a role to play. This is followed by highlighting how private corporations are playing a key role in the development of smart cities in theory and in practice. Finally, I demonstrate how Sidewalk Labs embodies these conceptions of urban neoliberal thinking in smart cities.

\section{Urban Neoliberalism as Corporate Control}

This section explores the prevalence of the term 'technocracy' in the second half of the twentieth century and how it is understood from a neoliberal perspective. I demonstrate that it coincides with the transition to entrepreneurialism of city governance. I start by discussing technocracy, how it interacts with democracy, and how private firms have over the years wedged themselves into positions where they are typically considered to be the experts in urban development and governance. Through this process, companies are positioning themselves as obligatory passage points. ${ }^{259}$ Finally, I explore the practice of constructing new cities, the logic behind them, and the special kind of new city designed, owned and operated by private actors.

\footnotetext{
${ }^{259}$ Söderström, Paasche, and Klauser, "Smart Cities as Corporate Storytelling."
} 
Technocracy finds its political legitimacy in the idea that people can rule over others based on technical knowledge and expertise. ${ }^{260}$ This places technocracy in tension with democracy as it hands-off decision-making powers from the democratic process to a class of individuals who are considered above the people based on their expertise. However, a more contemporary definition of technocracy claims that democracy and technocracy are compatible. Proponents argue that technocracy "can bolster a broadly democratic system of government by increasing its 'output legitimacy' in specific policy domains." ${ }^{261}$ This contemporary neoliberal definition of technocracy is intended to create space for expert decision making. In the first chapter of an edited volume titled The Technocratic Challenge to Democracy, Christopher Bickerton and Carlo Invernizzi Accetti outline the split in definitions from the classical understanding of technocracy and the contemporary definition. While the classical definition of technocracy, taken from Plato's The Statesman, is blatantly anti-democratic, they argue that the contemporary definition tries to make it more acceptable and compatible within a democracy. ${ }^{262}$

To see how technocracy interacts with democracy, it is useful to outline two views of democracy. The first view is the "liberal view," which holds that the state should be primarily concerned with the freedoms that are enjoyed by the individual. The second view is the "aggregative view" which is focuses on popular sovereignty and the collective. ${ }^{263}$ Technocracy is not inherently a neoliberal form of governance, and it can appear in different political structures such as the former Soviet Union, which endeavoured to use technocrats to organize and sustain a planned economy. However, neoliberal forms of technocracy are distinct from traditional forms

\footnotetext{
${ }^{260}$ Christopher Bickerton and Carlo Invernizzi Accetti, "Technocracy and Political Theory," in The Technocratic Challenge to Democracy, ed. Eri Bertsou and Daniele Caramani (New York: Routledge, 2020), 29.

${ }^{261}$ Bickerton and Accetti, 31.

${ }^{262}$ Bickerton and Accetti.

${ }^{263}$ Ignacio Sanchez-Cuenca, "Neoloberal Technocracy: The Challenge to Democratic Self-Government," in The Technocratic Challenge to Democracy, ed. Eri Bertsou and Daniele Caramani (New York: Routledge, 2020), 44.
} 
through the intimate link to neoliberal understandings of economics. This link is what shapes the contemporary definition of technocracy, as proponents argue that the entire policy domain of economics and finance should be left to the experts. ${ }^{264}$ Therefore, in neoliberal conceptions of technocracy, experts who are perceived to have a special economic knowledge are smore valued, regardless of any other factors that may be present. Additionally, the economy is not a small segment of public policy but interacts with all aspects of life.

Urban neoliberal technocratic governance started to take shape through the elections of Ronald Reagan in the U.S. and Margaret Thatcher in the U.K., exemplified by the Thatcher government's White Paper, Streamlining the Cities, published after her 1983 election. ${ }^{265}$ In the libertarian view, big city governments are inherently inefficient, due in large part to the imposition of redistributive levies. Therefore, libertarians argue that big cities should be governed by multiple municipalities in order to compete for population and investment. Stemming from the White Paper and libertarian ideologies, this idea was put into practice in the U.K. by the Thatcher government in $1986 .{ }^{266}$

The idea that cities need to compete with each other has become normalized. As I discussed in the first chapter, cities around the world compete for status and prestige to gain all the benefits that follow, namely investment, labour, and economic growth. Some cities in Canada, however, amalgamated by their provincial governments to reduce government spending and download services. Also discussed in the first chapter was that cities in North America experienced a reduction in government spending on social welfare, and in some cases a

\footnotetext{
264 Sanchez-Cuenca, 45-46.

${ }^{265}$ Michael Herbbert, "Planning, Knowledge, and Technocracy in Historical Perspective," in Planning and Knowledge: How New Forms of Technocracy Are Shaping Contemporary Cities, ed. Mike Raco and Federico Savini (Bristol: Policy Press, 2020), 28.

${ }^{266}$ Herbbert, 28-29.
} 
downloading of these services onto municipal governments that did not have the funding or revenue streams to provide these services. An argument of the reduction in services was the neoliberal ideology of smaller, more efficient governments. In Ontario, the Harris governments' argument for amalgamation of Toronto was that "it is clear to Ontario taxpayers that maintaining 815 municipalities in the province's current fiscal climate is simply unrealistic."267 The Harris government argued that "taxpayers want a smaller, more efficient public sector, and fewer levels of government." 268

While the processes were different, the end goal for the Thatcher government and the Harris government were the same. Thatcher kept municipal governments divided in order to spur competition among them, whereas the Harris government's decision to amalgamate Toronto's municipalities was driven by the desire to reduce government spending and download services on lower levels of government. Streamlining and efficiency were the goals of both governments.

In contradiction to claims that technocracy is complementary to democracy, public participation in urban planning has not improved with the introduction and increasing reliance on neoliberal technocratic governance. A great way to understand the impacts of neoliberal technocrats on public participation and democracy is through Sherry Arnstein's 1969 article in which she outlines what she calls the "Ladder of Citizen Participation." 269 While in democracies there are always calls for public participation, which are "vigorously applauded," there are degrees to its effectiveness in democratizing policy decisions. ${ }^{270}$ The ladder has eight rungs that are separated into three categories: degrees of citizen power, degrees of tokenism, and non-

\footnotetext{
${ }^{267}$ Julie-Anne Boudreau, Roger Keil, and Douglas Young, Changing Toronto (Toronto: University of Toronto Press Inc., 2009): 72, https://doi.org/10.3138/9781442603363.

${ }^{268}$ Boudreau, Keil, and Young, 72.

${ }^{269}$ Sherry R Arnstein, “A Ladder Of Citizen Participation,” Journal of the American Planning Association 35, no. 4 (1969), https://doi.org/10.1080/01944366908977225.

${ }^{270}$ Arnstein, 216.
} 
participation. Public participation is meant to allow for the redistribution of decision-making power by having the public directly involved. However, there are ways to have public consultations without enabling the redistribution of power. This creates a frustrating process for those not in positions of power and provides cover for those that are in positions of power by allowing them to claim to have engaged the public and considered their points of view. ${ }^{271}$

Toronto provides an example of the growth of private technocratic consultancies and their relationship with the public. In Toronto, shortly after amalgamation and while the Official Plan was being written, city officials were more focused on what the opinions were of 'experts' than the citizenry of the city. ${ }^{272}$ One particularly notable example provided by Boudreau, Keil, and Young, was the battle over planning regulations in terms of building height and density. I briefly discussed in the first chapter on the push for Toronto to portray itself as a global city, and one such way was to build a more iconic skyline. This issue pitted citizens of the city against a private urban development firm.

As conversations in urban planning change towards aesthetics, beauty and a city's need for slim, tall (and high density) buildings, the average citizen is at a disadvantage in feedback on proposed projects. Private urban development firms employing professional architects and planners have more credibility, allowing them to take a privileged position in the judgment of projects, over residents who live in the area and would have to live with the result. This trend has only intensified, especially for smart cities, where tech is integrated in ways which have impacts well beyond the surface. In the smart city dynamic, everyday citizens are at a disadvantage compared to Google in understanding the technologies at play in smart city development and

\footnotetext{
271 Arnstein, 216-217.

272 Boudreau, Keil, and Young, Changing Toronto, 108-109.
} 
their implications in everyday life. This is especially true in the process of a company like Sidewalk Labs conduct public outreach, where they control the conversation.

The expert led development of Toronto post-amalgamation is exemplified through the reduced interactions and consultations with the people of Toronto in the development of the Official Plan. Public consultations were replaced with more consultations with internationally recognized experts or sector-based focus groups, who were invited to give their thoughts in a series of 'town-halls,' which the public played a very limited role. ${ }^{273}$ For example, in 1999, a town hall was held with experts and some invited community leaders while the general public had the option to watch the proceedings on a screen at a different location. The people of Toronto were left with an email address to submit any comments or concerns they had on the developing Official Plan. ${ }^{274}$ In the authors estimation, the consultations conducted by the City of Toronto during the years that the Official Plan was being drafted were "little more than a token gesture of informing without actually involving" the people of the city. ${ }^{275}$

Before the popularization of the smart city concept, created according to the corporate visions, corporations like IBM, public participation in urban neoliberal governance and development was limited. In the next two sections, I analyze how this reduction in public participation has reduced further in part due to the technologies related to the development of such a city, and partly because of the positioning of private tech companies as obligatory passage points.

The same year IBM signalled their intent to move into urban governance through technological software and consultancy, the world experienced a financial crisis. Resulting from

\footnotetext{
273 Boudreau, Keil, and Young, 109.

274 Boudreau, Keil, and Young, 109.

275 Boudreau, Keil, and Young, 110.
} 
the 2008 crisis was the deepening of neoliberalism as policymakers sought new innovative ways to govern. Slow growth following the crisis and increasing welfare requirements created motivation among policy makers for the search for "more entrepreneurial governance models and mechanisms that will convert messy urban places into spaces for investment and accumulation." ${ }^{276}$ Core to this search for new and innovative urban neoliberal governance models was a way to promote forms of expertise and to reduce political interference and disruption.

Neoliberal interpretations of technocracy are highly politicized, despite the fact that advocates push the idea that it is depoliticizing. Traditional conceptions of technocracy are placed within scientifically objective truths. Contemporary conceptions of technocracy, however, frame neoliberal technocrats not as "scientists or engineers with high problem-solving capacity, but economists or experts in finance who use their technical knowledge in service of certain political ideas about the relationship between democracy and the market."277

Neoliberal conceptions have given rise to the growth of the private consultancy industry in place of public planning departments, but that is not the only way private actors are inserting themselves into key positions of governance. Many companies, but particularly tech companies, are trying to position themselves as obligatory passage points for governance and, as will be discussed in the next section, in urban development. ${ }^{278}$

Concern has been expressed by some Canadian politicians on the federal government's apparent reliance on Cisco, for example. Over the past two years, the Canadian government has

\footnotetext{
${ }^{276}$ Federico Savini and Mike Raco, "The Rise of a New Urban Technocracy," in Planning and Knowledge: How New Forms of Technocracy Are Shaping Contemporary Cities, ed. Mike Raco and Federico Savini (Bristol: Policy Press, 2020), 3.

277 Sanchez-Cuenca, "Neoloberal Technocracy: The Challenge to Democratic Self-Government," 45.

${ }^{278}$ Ola Söderström, Till Paasche, and Francisco Klauser, "Smart Cities as Corporate Storytelling," City 18, no. 3 (2014), https://doi.org/10.1080/13604813.2014.906716.
} 
awarded Cisco \$210 million in contracts for networks, most of which were sole-sourced contracts. ${ }^{279}$ In a committee hearing on the subject, Paul Glover, the president of Shared Services Canada, acknowledged that there is a growing reliance on Cisco, but noted that "most networks around the planet run on Cisco or Cisco gear." ${ }^{280}$ Companies want to be seen as the expert in their field so that governments and other private firms go to them for their goods and services and even become synonymous with it. When it comes to urban governance and planning, that can place these companies in unique positions of authority urban governance and development. I will discuss the tech side more closely in the next section, but even in new urban areas that are being built without the distinction as a smart city, companies are positioning themselves as cornerstones to urban development and governance.

The resurgence in the announcement of new city developments around the world since the 1990s, can in part be seen as local governments pursuit of international flows of capital and investment. These highly speculative forms of urban neoliberal strategy are consistent with Harvey's entrepreneurial form of urban governance, and potentially go beyond it. While new master planned urban districts are not something that is new to human civilization, what is new is the unprecedented influence of private actors in these cities. ${ }^{281}$ Previous state-lead new city developments have been "superseded by a prevailing urban entrepreneurial logic characterized by exclusionary new city plans and escapist urbanism, largely for the economic elite."282

\footnotetext{
279 Jesse Snyder, “Top Official Defends Ottawa’s Procurement Practices Following Report on Sole-Sourced Contracts to U.S. IT Giant," National Post, April 28, 2021, https://nationalpost.com/news/top-official-defendsottawas-procurement-practices-following-report-on-sole-sourced-contracts-to-california-it-giant.

280 Jesse Snyder, "Ottawa Frequently Awarding IT Contracts Solely to Cisco, Part of Long-Standing Government Dependency on Networking Giant," National Post, March 2, 2021, https://nationalpost.com/news/politics/ottawafrequently-awarding-it-contracts-solely-to-cisco-part-of-long-standing-government-dependency-on-networkinggiant.

${ }^{281}$ Sarah Moser and Laurence Côté-Roy, "New Cities: Power, Profit, and Prestige," Geography Compass 15, no. 1 (2021): 1-2, https://doi.org/10.1111/gec3.12549.

282 Moser and Côté-Roy, 2.
} 
In a growing number of cases, companies are no longer just playing a small role in urban development and governance but are building and taking control of an urban area of a city. Private cities and private urban areas within cities have had a resurgence in much of the world. According to Sarah Moser, there are over 15 new private cities and even more private urban areas being developed around the world. ${ }^{283}$ In an interview with Forbes, Moser notes that "private cities are appealing to many governments who want instant urban and economic development and believe that outsourcing to the private sector is efficient and lucrative."284 They act as a kind of special economic zone, where rules and regulations are decided by a CEO rather than a mayor, which run alongside the national laws of the country which the city resides in. A driving factor for the creation for new cities is to try and attract new capital investment. As such, many new developments are created as special economic zones to attract capital with businessfriendly policies. ${ }^{285}$

However, the control over these "cities" that the companies have goes well beyond business and labour policies. The Forbes article referenced above was written by Wade Shepard while he was visiting Danga Bay, Malaysia. While touring the 20,000-person mixed use urban area, he was stopped by a security guard and told he was not allowed to take pictures with the camera hanging around his neck. Shepard responded by asking if that means that none of the 20,000 residents owned a camera, which the security guard confirmed as correct. Shepard concluded that "of course, that wasn't true, but there was nothing that I could do: I was in a small city-sized development that was $100 \%$ privately-owned and operated by the Chinese developer

\footnotetext{
${ }^{283}$ Wade Shepard, "Inside The Rise Of Private Cities: 'Priority Of Management Is Profit, Not The Needs Of Citizens," "Forbes, January 31, 2020, https://www.forbes.com/sites/wadeshepard/2020/01/31/inside-the-rise-ofprivate-cities-priority-of-management-is-profit-not-the-needs-of-citizens/?sh=36eb4710c9c2.

284 Shepard.

285 Moser and Côté-Roy, "New Cities: Power, Profit, and Prestige," 5.
} 
Country Garden. The word of the company was law." ${ }^{286}$ Relating back to previous chapter on data, it becomes more apparent what the dangers are from allowing data collection and harvesting happen in an urban environment which is completely controlled by a monopolistic corporation. While this is not the extent of control that was being given to Sidewalk Labs in Toronto, in a later section of this chapter I demonstrate that the company has ambitions to receive this kind of urban governance control.

Mark Lutter, CEO of the Charter Cities Institute (CCI) believes that more private control and competitive business environments in cities is key for lifting populations out of poverty. ${ }^{287}$ This line of thinking is at the extremes of urban neoliberal thinking, or perhaps libertarian is a more apt description. An entirely private city would be taking the neoliberal idea that open, unregulated markets are the best method for economic prosperity, and applying it to everyday urban life and governance. Titus Gebel, in an article published by the Foundation for Economic Education, argues that private cities would be better than our current structure. Gebel envisages "for-profit, private enterprise that offers protection for life, liberty, and property in a given territory — better, cheaper, and freer than existing state models."288

Moser and Laurence Cote-Roy, rightly highlight the key contributions which have created this phenomenon of new corporate cities. A slew of neoliberal policy choices has led to the creation of an environment that promotes private technocratic consultancies and the associated governance. Financialization of infrastructure and real estate and the latter's emergence as a key investment, liberalization and deregulation of economies, and the insertion

\footnotetext{
${ }^{286}$ Shepard, "Inside The Rise Of Private Cities: 'Priority Of Management Is Profit, Not The Needs Of Citizens."”

287 "Introduction to Charter Cities," Charter Cities Institute, accessed July 1, 2021, https://www.chartercitiesinstitute.org/intro\#why.

288 Titus Gebel, "Private Cities: A Path to Liberty - Foundation for Economic Education," Foundation for Economic Education, April 22, 2016, https://fee.org/articles/private-cities-a-path-to-liberty/.
} 
of tech companies in urban development and governance have all created space for the new sector. The emphasis on expert and technocratic urban governance has reached a point where in the U.K., almost half of all practicing planners work for private consultancies ${ }^{289}$ Entrepreneurial urban governance has created this highly speculative form of urban governance in which the government simply hands control of urban development and governance to corporations.

This section demonstrated the role of technocrats in neoliberal ideology and how that has had far reaching residual effects. Neoliberal ideology exemplified at the local scale through Thatcher and Harris's urban policies created the market for, and reliance on, neoliberal technocrats, which in turn created space for the private sector role in urban planning and governance at a much larger scale. In the next section, I outline how private companies, particularly tech companies, are vying to be the key ingredient in smart city development.

\section{Corporate Smart Cities}

In the last section I outlined how corporations grew into positions of power through neoliberal technocratic decision making since the 1970s, and in the urban context, with the transition into the entrepreneurial city. ${ }^{290}$ In this section, I will demonstrate how smart cities are specifically a technocratic construction of urban environments, and more clearly outline how corporations are positioning themselves as obligatory passage points for smart city developments.

Technocracy has increasingly been positioned as the best approach to solving urban challenges and smart cities are clearly a practice of technocratic rule. By turning government and

\footnotetext{
289 Savini and Raco, "The Rise of a New Urban Technocracy," 4.

${ }^{290}$ David Harvey, "From Managerialism to Entrepreneurialism: The Transformation in Urban Governance in Late Capitalism," Geografiska Annaler 71, no. B (1989).
} 
governance into algorithmic decision making supported by experts, a form of urban governance is created that is highly technocratic and prescriptive, which has been described as automated management. ${ }^{291}$ In their chapter on smart cities and technocracy, Kitchin et al. explain that smart city forms of technocracy are different from previous versions, largely caused by the rapidly growing capabilities of technologies. While technical skill and technological systems in city planning and management is nothing new, the systems have consisted of "human-in-the-loop," where technocratic experts are in key decision-making positions. With algorithms and automation, however, the relationship with the system is one of "human-on-the-loop" where the system is automated, but a human can intervene, or "human-off-the-loop" where humans have not interaction with the algorithms. ${ }^{292}$ Furthermore, the shift in technocratic tools and abilities are changing governance methods. Prior to smart city developments, urban governance was generally conducted through regulation and discipline. For example, smart city algorithms can sequence traffic lights in a manner to nudge behavior, rather than inducing self discipline. Now, with the capabilities of surveillance and algorithms, technocracy is shifting to behavioral modification, as outlined in Chapter $2 .{ }^{293}$

Cities today have new positions related to smart city technocracy like Chief Information Officers and other computer scientist positions, which would not be found even a decade ago. There is a considerable array of actors involved in promoting smart cities beyond the municipal bureaucracies. Parallel to this growth is technocratic consultancies offering their specialist smart city services. There is a wide range of actors in the smart city "epistemic community" of experts and professionals who present their voices as authoritative. Private companies present a separate

\footnotetext{
${ }^{291}$ Martin Dodge and Rob Kitchin, "The Automatic Management of Drivers and Driving Spaces," Geoforum 38, no. 2 (2007), https://doi.org/10.1016/j.geoforum.2006.08.004.

${ }^{292}$ Rob Kitchin et al., "Smart Cities, Algorithmic Technocracy and New Urban Technocrats," Planning and Knowledge, 2019, 202, https://doi.org/10.2307/j.ctvkjb1z8.20.

${ }^{293}$ Kitchin et al, 202.
} 
but related group from government officials and academics, which have a vested interest that overlaps with the epistemic community. All these parties combine to create an advocacy coalition, promoting smart cities. ${ }^{294}$

The Smart City Challenge put on by Infrastructure Canada discussed in earlier chapters is a good example of a multi-disciplinary group within the advocacy coalition. To decide the winning proposals, Infrastructure Canada put together a panel of jurors. On the website, the panel is described as "made up of diverse professionals who are accomplished and publicly recognized in fields related to smart cities." ${ }^{295}$ Of the dozen jurors, half of them had some mention of tech in their biographies, and the majority of jurors work in private sector consulting. While most panelists having some experience in the tech sector may seem appropriate for a smart city challenge, it creates a bias within the panel. There are no privacy or data governance advocates on the panel, something that should be of high importance for a group deciding on funding for a smart city initiative. It is important to consider the impacts on the people of these urban areas beyond the basic functions of the project.

While there are many actors in the smart city advocacy coalition, one among them is seeking profits through the creation of corporate smart cities. Tech corporations are pushing hard to seen as experts in the field of smart city technologies and systems. Soderstrom, Paasche, and Klauser have observed that this desire to be seen as leaders in smart cities is an attempt to become an obligatory passage point in the process of creating a smart city. ${ }^{296}$ Essentially, these companies want to create a market in which a government needs to consult one of the 'leading' smart city experts like an IBM, Cisco, or Google, to create a smart city. Companies are

\footnotetext{
${ }^{294}$ Kitchin et al, 203-204.

295 “The Jury,” Infrastructure Canada, May 7, 2019, https://www.infrastructure.gc.ca/cities-villes/membersmembres-eng.html.

${ }^{296}$ Söderström, Paasche, and Klauser, "Smart Cities as Corporate Storytelling."
} 
aggressively pursuing this position in practice and in discourse. Companies, particularly IBM, are placing themselves as key agents to solutions of urban problems, solutions that are technological and technocratic in nature. For example, IBM appears to be positioning itself in the realm of software and consultancy work as exemplified in Taylor Shelton, Matthew Zook and Alan Wiig's analysis on IBM's "Digital On-Ramps” in Philadelphia. Other companies like Sidewalk Labs and Cisco, appear to be positioning themselves in the physical technologies and the built environment. Just as Cisco has positioned themselves as an obligatory passage point for the Canadian Government, other companies are trying to position themselves as necessary for the development and operation of smart cities. Cisco, for example, is so integrated into every inch of the Songdo development in South Korea that they are practically synonymous with it.

Companies including IBM, General Electric, Huawei, and others are placing significant investments into urban developments around the world..$^{297}$

In the previous chapter I mentioned the booming market for smart home appliances and the same holds true for smart city technologies. There is considerable disagreement among market projections as to what the worth of smart cities will be for private investors. Some believe that the market is US\$ 219.6 billion by 2023 , and others project US\$ 820.7 billion by $2025 .{ }^{298}$ According to a report from Global Industries Analytics Inc. published this year, the global smart

${ }^{297}$ Hannah Rebentisch et al., "Unicorn Planning: Lessons from the Rise and Fall of an American 'Smart' MegaDevelopment," Cities 101 (June 1, 2020), https://doi.org/10.1016/j.cities.2020.102686; Robert G. Hollands, “Critical Interventions into the Corporate Smart City," Cambridge Journal of Regions, Economy and Society 8, no. 1 (2015), https://doi.org/10.1093/cjres/rsu011.

298 "Smart Cities Market Size, Share and Global Market Forecast to 2025," MarketsandMarkets, 2020, https://www.marketsandmarkets.com/Market-Reports/smart-cities-market-542.html; "IoT in Smart Cities Market Insights by Size, Demand, Industry Insights, Opportunities, Future Growth Rate, CAGR Status Till 2023," MarketWatch, June 2, 2021, https://www.marketwatch.com/press-release/iot-in-smart-cities-market-insights-bysize-demand-industry-insights-opportunities-future-growth-rate-cagr-status-till-2023-2021-06-02?tesla=y. 
cities market will reach a value of US $\$ 2.5$ trillion by $2026 .{ }^{299}$ The projections vary widely most likely because of the uncertainty of what to include in the smart city market. While there are differences in projections, all projections have the smart city market growing rapidly over the next few years. Once companies have positioned themselves as an obligatory passage point both in general terms as discussed by Soderstrom, Paasche, and Klauser, or for specific projects like in Songdo, it can be very profitable. Canadian politicians are right to be concerned about the governments increasing reliance on Cisco for day-to-day operations over their networks. The more money the government invests into one company, the more reliant the government becomes on that company.

Many of the new and private cities mentioned in the last section were being touted as smart cities. Of course, like I discussed in the first chapter, labelling a city as a smart city is a way many developers and city officials are using to attract business and investment. A project in the works in Nevada serves as a great example of demonstrating the connection between competitive, technocratic, smart cities. The vision of this project, which has been endorsed by the Governor of Nevada, would be that the State government allow companies to set up "innovation zones" across the state, not within cities (it is unclear where specifically these zones would be, but it is clear they would be their own urban area not a special district within an already existing city). These zones would be controlled by an "alternative form of government" which would be made up of a three-person board who would act as supervisors, and in exchange for being able to govern themselves, the companies would not ask for tax breaks or incentive packages. Of course, the company behind the development would have the majority say as to who sits on the board.

299 “Global Smart Cities Market to Reach \$2.5 Trillion by 2026,” Cision PR Newswire, June 29, 2021, https:/www.prnewswire.com/news-releases/global-smart-cities-market-to-reach-2-5-trillion-by-2026-301322145.html. 
The zones, as proposed currently, are reserved for companies 'doing 'innovative' work; relating to blockchains, healthcare, robotics, renewable energy research, biometrics, autonomous vehicles, and similar cutting-edge research." However, cities like the Nevada example tend to be business focused and can entirely leave out citizens of these cities as almost a by-product of the innovation. $^{300}$

The literature is already filled with critiques of smart city initiatives for their lack of citizen involvement and seemingly technocratic nature. In response to this, corporations like IBM and Cisco have reframed their smart city initiatives as 'citizen-focused.' Paolo Cardullo and Kitchin have created a "Scaffold of Smart Citizen Participation" which they built off the work of Sherry Arnstein ladder of participation. ${ }^{301}$ Using Arnstein's ladder of participation, it becomes apparent that there are unique challenges with public participation in smart city initiatives. Due to the highly technical aspects of the ICT technologies involved, any in depth public participation involving those technologies can be difficult without prior knowledge of how the systems and technologies operate.

Building new developments on greenfield site makes it easier for companies to avoid public participation. The private city being planned in Nevada is being advertised as a place for tech companies and their employees to live and work. Companies can simply avoid any demands for public participation and consultations, since there are no people living there now. Of course, while it is beneficial for the companies, it is not the same for the people. A private city would be

\footnotetext{
${ }^{300}$ Sam Metz, "In Nevada Desert, a Technology Firm Aims to Be a Government," Associated Press , February 13, 2021, https://apnews.com/article/blockchains-smart-city-nevada-e53b6c504ccaf9071 cbfb607074eb719; Joshua Nevett, "Nevada Smart City: A Millionaire's Plan to Create a Local Government," BBC News, March 18, 2021, https://www.bbc.com/news/world-us-canada-56409924.

${ }^{301}$ Paolo Cardullo and Rob Kitchin, "Being a 'Citizen' in the Smart City: Up and down the Scaffold of Smart Citizen Participation in Dublin, Ireland," GeoJournal 84, no. 1 (2019), https://doi.org/10.1007/s10708-018-9845-8.
} 
essentially ruled by the governing company, as Shepard realized in his article while he was walking the streets of a private section of a city.

This section demonstrated that smart cities are unequivocally technocratic endeavours. Through technologies and algorithms, smart city proponents want to govern the city through modifying behavior for increased efficiency within the city, and companies want to reap the profits. Neoliberal interpretations of technocracy have allowed space to be created for private sector consultancies in the urban governance and development ecosystem. That space is now being increasingly filled by tech corporations like Google, IBM, and Cisco, as they position themselves as necessary pieces to a smart, efficient, and technocratic city of the future. In the next section I will explore how Google through Sidewalk Labs plans to do just that.

\section{Sidewalk Labs' Little Paradise}

So far, this chapter has demonstrated that corporate-built (and sometimes owned and operated), smart, technocratic cities are increasing in popularity around the world. The belief that Sidewalk Labs and other companies pursuing similar objectives is that through monitoring devices and decision-making algorithms, solutions will be found for urban problems in cities, or simply increase the efficiency of cities. That is the same urban neoliberal approach taken by Sidewalk Labs in the planning process of their Toronto project.

Sidewalk Labs' project in Toronto was, like most smart city projects, an exercise in technocratic development and governance. In fact, from the top down the whole project was a technocratic practice, and Sidewalk Labs was not the beginning of technocratic governance in the city. Even before the company got involved, Waterfront Toronto was created as an entity to 
govern as technocrats. The governing body is made up of unelected experts tasked with revitalizing the area along Toronto's south which runs along Lake Ontario. ${ }^{302}$ Waterfront Toronto's board is made up of ten members plus the chair. The chair is a man named Stephen Diamond who is the CEO of DiamondCorp, a Toronto based real-estate development firm. On the Waterfront Toronto website, they proclaim that Diamond "has established a reputation for creating value for investors." 303 The remainder of the board consists of experts with technical knowledge in various fields such as economics, technology, and former politicians. ${ }^{304}$ This organization has the authority to award contracts, as it did with Sidewalk Labs, giving it the ability to fundamentally change the city.

The main focus in this thesis is on Sidewalk Labs, however, which I briefly discussed in the introduction to my thesis. The company was founded by former city officials from New York City under Mayor Michael Bloomberg and Google computer scientists. ${ }^{305}$ The CEO of Sidewalk Labs, Dan Doctoroff, was the deputy mayor of New York City under Michael Bloomberg from 2002 through 2008, then became the CEO of Bloomberg LP through $2014 .^{306}$

Another layer of technocracy is the new "community-based governance-structures" that the company wants to have created for the management of the district. ${ }^{307}$ One the has already been discussed is the Urban Data Trust (UDT). The UDT, if it were to be adopted as proposed by

\footnotetext{
302 "Who We Are,” Waterfront Toronto, accessed July 12, 2021, https://www.waterfrontoronto.ca/nbe/portal/waterfront/Home/waterfronthome/about-us/who-we-are.

303 “Stephen Diamond, Chair," Waterfront Toronto, accessed July 10, 2021, https:/www.waterfrontoronto.ca/nbe/portal/waterfront/Home/waterfronthome/about-us/who-weare/board + of + directors + bios/stephen + diamond $\% 2 \mathrm{C}+$ chair.

304 "Board of Directors," Waterfront Toronto, accessed July 10, 2021, https:/www.waterfrontoronto.ca/nbe/portal/waterfront/Home/waterfronthome/about-us/who-weare/board+of+directors.

305 Sidewalk Labs, "Our Team."

${ }^{306}$ Christina Farr and Jillian D’Onfro, “Google Sister-Company Sidewalk Has a Secret ' Yellow Book' with Its Plans to Reinvent Cities , plus Possible Sites beyond Toronto," CNBC, June 27, 2018, https://www.cnbc.com/2018/06/25/alphabet-sidewalk-yellow-book-secret-plans-sites.html.

307 Sidewalk Labs, “Master Innovation Development Plan: Volume 3,” 2019, 68.
} 
Sidewalk Labs, would have been made up of largely technocrats, with one elected official representing the residents of the IDEA district. According to Sidewalk Labs, the UDT should include a data governance expert, an academic, and representatives from business, the public service, and the community. ${ }^{308}$ Another new entity that the MIDP proposed was a non-profit Open Space Alliance (OSA), which would operate in the IDEA district similar to organizations which operate in other parts of Toronto, like the Brick Works and Grange Park. The OSA would be tasked with using public space to pilot innovations and would act with an "expectation of experimentation." ${ }^{309}$ Most notably, however, is that Sidewalk Labs proposes their non-profit to be partially funded and operated by private stakeholders, including businesses and landowners within the IDEA district. In the MIDP, Sidewalk Labs promises a new Google headquarters in the IDEA district, providing them with partial oversight of the UDT and OSA.

In the MIDP Sidewalk Labs requests that several regulatory changes be made at various levels of government for the proposed IDEA District to function as they planned. Sidewalk Labs calls their modified regulatory framework the "Innovation Framework." 310 Sidewalk Labs argues that their "targeted regulator adjustments" are necessary to meet Waterfront Toronto's priorities of urban innovation, job creation, and sustainability. ${ }^{311}$ These regulatory changes would require cooperation between three levels of government, from city to provincial and finally federal.

One of the regulatory changes would create the Waterfront Transportation Management Association (WTMA) and allow several capacities related to traffic and parking in the area. The new authorities Sidewalk Labs wanted the government to bestow on the WTMA range from the mundane, like the authority to use a different set of signage, to more advanced, like the ability to

\footnotetext{
308 Sidewalk Labs, "Master Innovation Development Plan: Volume 2," 2019, 420.

${ }^{309}$ Sidewalk Labs, "Master Innovation Development Plan: Volume 3," 68.

310 Sidewalk Labs, "Master Innovation Development Plan: Volume 3," 2019, 72.

311 Sidewalk Labs, 72.
} 
monitor and track cars for when they stopped in order to be able to charge them for parking and collect those funds directly. Other changes include changings in the building code to allow for some of Sidewalk Labs innovations to be constructed, like the mass timber buildings, providing funding for organizations the company wants to create, like the WTMA, and of course, data governance changes. ${ }^{312}$

These regulatory changes and the creation of governing entities exemplify Sidewalk Labs desire to develop the section of land in Toronto in their own image, rather than complying with the city and other levels of government's existing laws. Similar to how the debate around the building code discussed in the first section of this chapter, the experts decided that they know the best path forward and recommended the regulatory changes necessary for that path to be taken. While Sidewalk Labs is not asking for nearly as much authority as some of the private cities discussed earlier in this chapter, there is no reason to provide any authority over a section of the city to the private sector. As we shall continue to see, and unsurprisingly, the similarities are ingrained in the ideology of Sidewalk Labs.

Private technocratic urban developers can struggle to meaningfully engage the public, and Sidewalk Labs experienced the same problem in development of the MIDP. Sidewalk Labs did appear to go to some lengths to involve the public in their project, however. Upon publication of their MIDP in 2019, Sidewalk Labs boasted of having heard from 21,000 Torontonians in person, 280,000 views of their live streamed events, and 75 experts across six "expert advisory groups." 313 From the public consultations Sidewalk Labs gathered seven themes from the feedback. All of the seven themes gathered by Sidewalk Labs were positive input from the community that would have made the new development a better addition to the city of

\footnotetext{
${ }^{312}$ Sidewalk Labs, 74.

${ }^{313}$ Sidewalk Labs, "Master Innovation \& Development Plan: The Overview."
} 
Toronto. Some of the concerns voiced by the people in the public consultations include transparency, proof that the concepts proposed have utility and are beneficial, and the integration of "tech for tech's sake," rather than having a greater purpose for the community. However, despite the constructive feedback provided by the surrounding community, Sidewalk Labs seems to have ignored it to maintain their vision. For example, in response to concerns of tech for tech's sake, Sidewalk Labs created their proposal for the UDT, and the Responsible Data Use Guide. Sidewalk Labs response to concerns that tech would be integrated into the IDEA district just for the sake of tech was to create a board of decision-makers made up of mostly like-minded people with one representative for the public, and to propose a set of guidelines for responsible data use with the core belief that data should be collected and published for the sake of technological innovation. ${ }^{314}$ It is difficult to see how the response from Sidewalk Labs is nothing short of the realization of what the people of Toronto were concerned of.

Placing the public participation of Sidewalk Labs' project according to Arnstein's ladder, it can be viewed as little more than tokenism. While the public appeared to provide rather constructive feedback, and Sidewalk Labs appears to have understood what the premise of the peoples' concerns were, their response was unrelated. Sidewalk Labs clearly had an idea of what they wanted to construct in Toronto, and feedback from citizens was construed to fit their agenda. A some have put it, the act of public consultations conducted by Sidewalk Labs was little more than "theater." 315

The most crystalizing example of Sidewalk Labs consultations was with the Indigenous community. Sidewalk Labs asked an Indigenous design studio to host an Indigenous consultation

\footnotetext{
${ }^{314}$ Sidewalk Labs, 76.

315 Josh O'Kane, "Indigenous Group Speaks out over 'Grossly Misleading' Sidewalk Labs Consultation,” The Globe and Mail, October 25, 2019, https://www.theglobeandmail.com/business/article-indigenous-leaders-speakout-over-grossly-misleading-sidewalk-labs/.
} 
workshop, which was attended by 15 people including Indigenous architects and designers. The group provided Sidewalk Labs with 14 recommendations and several Indigenous design principles. However, upon the publishing of the MIDP, members of the Indigenous group noticed that none of their recommendation made it into the MIDP, while Sidewalk Labs touted their in-depth consultations with the Indigenous community. In an article published in The Globe and Mail, members of the Indigenous group expressed that they felt the consultations were nothing more than a check-the-box exercise for Sidewalk Labs. ${ }^{316}$

While the project started to face mounting criticism, some came forward in support of the project. Many of those individuals were people who are generally seen as in positions of authority, even if it is not entirely relevant to the topic at hand. I have mentioned in earlier pages that the Toronto Region Board of Trade organized a letter, signed by 30 "influential leaders" of Toronto, in support of the project. These "influential leaders" were mostly former local politicians, CEOs of various companies and organizations, and university officials, as well as Richard Florida. Tellingly, an urban studies professor at the University of Toronto who specializes in tech and innovation "calls the letter a 'strong signal that there are many wellrespected organizations, institutions and individuals in the city who support the opportunity to work with Sidewalk." ${ }^{317}$ Former Finance Minister, Janet Ecker, whose name is among the signatories, resorts to local boosterism in her argument for the development project. Ecker argues that it is good for the city, "this is a big reputational boost — the fact Google wants to do this here." ${ }^{318}$

\footnotetext{
316 O’Kane.

317 Vincent, "30 Influential Toronto Leaders Pen Letter Supporting Controversial Sidewalk Labs Plan."

318 Vincent.
} 
Probably one of the most concerning parts about Sidewalk Labs was exposed by a media report from The Globe and Mail in which the authors, Tom Cardoso and Josh O'Kane detail internal documents outlining the vision of the Google affiliate. ${ }^{319}$ The document was created by the founders of Sidewalk Labs and is known as the "yellow book." It is designed as a pitch book for the company and provide employees with inspiration. The book includes in the vision of Sidewalk Labs as having power to levy its own property taxes, track and predict people's movement, and control some public services. The authors claim that the document is "peppered with reference to Disney theme parks and noted futurist Buckminster Fuller, it says Sidewalk intended to 'overcome cynicism about the future.",320 While there was never any significant probability that Waterfront Toronto was going to allow Sidewalk Labs to rule over the IDEA district as if it was a sovereign state, the company clearly believes that is not only achievable somewhere, but is desirable. Given the rise of popularity in privately owned and operated cities, there is a considerable prospect that Sidewalk Labs and Google are given the opportunity to build such a city. Within the book there is a list of other prospective locations for Sidewalk Labs to develop, mostly in the US. ${ }^{321}$

The yellow book provides a further glimpse into the desires of Sidewalk Labs, and I believe that those desires are not unique to the Alphabet owned company. Sidewalk Labs wants authority similar to a government, much in the same way as the private city that was discussed above. Within their private city, Sidewalk Labs would use data to determine how the police

\footnotetext{
319 Tom Cardoso and Josh O'Kane, “Sidewalk Labs Document Reveals Company ' s Early Vision for Data Collection , Tax Powers , Criminal Justice," The Globe and Mail, October 30, 2019, https://www.theglobeandmail.com/business/article-sidewalk-labs-document-reveals-companys-early-plans-for-data/.

${ }^{320}$ Cardoso and O'Kane.

${ }^{321}$ Farr and D’Onfro, “Google Sister-Company Sidewalk Has a Secret ' Yellow Book' with Its Plans to Reinvent Cities , plus Possible Sites beyond Toronto."
} 
would react to certain calls but concedes that "policing of serious crimes and emergencies would be 'likely to remain within the purview of the host government's police department."'322

The yellow book provides evidence of Sidewalk Labs desire to become an obligatory passage point in smart city developments, not just in Toronto, but in developments all over the world. As I highlighted in earlier pages, the company was planning to use Toronto as a testbed for smart city technologies, to be replicated in other cities. Since the cancellation of the Toronto project, the company has been busy filing patents for their proposed technological innovations. ${ }^{323}$ By holding patents on smart city technologies, Sidewalk Labs becomes an obligatory passage point, as stated, and gives them a strong position in the growing smart city market.

Sidewalk Labs did not bring technocracy to Toronto, but it certainly would have made the city's governance more technocratic. To reconcile with any privacy concerns stemming from Sidewalk Labs desire to have the data collected in the IDEA district open and accessible, the company formulated a technocratic governance body made up of experts. While the MIDP did not have Sidewalk Labs retaining a significant amount of governing control over the area, other documents publish in the media clearly demonstrate the companies desire to govern a private city.

\footnotetext{
${ }^{322}$ Cardoso and O’Kane, "Sidewalk Labs Document Reveals Company's Early Vision for Data Collection , Tax Powers , Criminal Justice."

${ }^{323}$ Catherine McIntyre, "Sidewalk Labs Ramps up Patenting of Technologies Conceived for Now-Defunct Toronto Smart City," The Logic, April 6, 2021, https://thelogic.co/news/sidewalk-labs-ramps-up-patenting-oftechnologies-conceived-for-now-defunct-toronto-smart-city/.
} 


\section{Conclusion}

Sidewalk Labs and their proposed project in Toronto exemplifies a relatively recent shift in urban governance towards technocracy and corporate control. The obsession with efficiency and the consequential growth of technocratic forms of governance since the Thatcher and Reagan years has created the environment in which corporations can play a significant role in urban development and governance. Urban governance consultancies have carved out a profitable place for them in the policy-making sector. Especially with new and ever-increasing developments in technologies, tech companies like Google and IBM continue to position themselves as pivotal pieces to the future of cities through their expertise in technologies related to smart cities. Smart cities themselves are a further step into technocratic governance not only because of the perception that tech companies are the only ones with the technical knowledge to build and operate smart cities. Through data collection and analysis, algorithms can preform rapid decision making to govern the city without human intervention.

Urban neoliberal conceptions of urban technocracy and governance has led to conceptions of cities that include much larger private involvement. Neoliberal understandings of governance have led to some to propose and even pursue a city in which the spaces are governed in the same manner as a corporation in the form of private cities/urban areas and "innovation zones." While there are numerous examples of the ideology of private-sector technocrats becoming the governing body in cities, or at least portions of cities, Sidewalk Labs was not in such an extreme position. Nonetheless, Sidewalk Labs stated in their MIDP that this project was to act as a template for future projects, where they may conceivably have more governing authority for the long-term. 


\section{CONCLUSION}

\section{Revisiting the Research Question}

With the increased reliance on data and algorithms in many aspects of life, smart cities are more than likely here to stay. Increasing urbanization cause polluted cities, which are engulfed in smog and gridlock streets filled with traffic. Global warming means cities need to find new and innovative ways to become more environmentally friendly, and some argue that cities are part of the solution to global warming. ${ }^{324}$ Daily life has been increasingly connected to ICTs through smart wearable tech and smart homes, and those ICTs to each other. All these factors contribute to arguments in favour of a more digitally integrated, smart city. However, the paradigm of how smart city initiatives are planned and implemented remains a topic of debate. My thesis provided a post-mortem into the largest Canadian project that was planned to be completed in Toronto's waterfront by the Google affiliate, Sidewalk Labs.

My thesis argues smart city projects are often heavily linked to the politics of urban neoliberalism and associated forms of capital accumulation, and to outline this connection, I used Sidewalk Labs' project to act as the model for smart city projects. The project is a good opportunity to investigate what a smart city would look like and what it wants to achieve because of the relatively small number of smart city projects have been started at this scale that have been completed, and it appears that projects like the one in Toronto are increasing in frequency. Most

\footnotetext{
${ }^{324}$ Angelo and Wachsmuth, "Why Does Everyone Think Cities Can Save the Planet?"
} 
of the smart city literature in academia is focused on a project that is integrating one aspect of what a smart city could include into an already built environment. ${ }^{325}$

I identify three ways that smart cities are consistent with urban neoliberalism, and neoliberal logics of accumulation. The first is through the consistent logic of interurban competition. Much of the present methods of interurban competition has been influenced by Florida's ideas on the Creative Class. ${ }^{326}$ While cities and their officials are always working to find new ways to organize and operate a city, smart cities are notable in that they are used as a branding tool. By labeling themselves as smart cities, they are attempting to attract the Creative Class. City officials believe that by developing their city in a way that would attract the Creative Class, their city would benefit economically. So smart cities are both policy choices and development plans to make cities more efficient through technological integration, while using those policies and development plans to brand the city as a desirable destination for the Creative Class. In this way, the Creative Class development strategies and many conceptions of smart cities have merged to create a smart city which is populated by the Creative Class, and Sidewalk Labs' project was exemplary of this combination.

The second aspect of urban neoliberalism that I use to analyse smart cities is the emergence of digital capitalism. This new form of capital accumulation is not a "rouge mutation," as Zuboff puts it, but the logical next step in the market logic of commodification, coupled with technological innovations which have created mass production of user data. ${ }^{327}$ Smart cities are built on the idea of mass surveillance and data collection, applying digital

\footnotetext{
${ }^{325}$ Francesco Paolo Appio, Marcos Lima, and Sotirios Paroutis, "Understanding Smart Cities: Innovation Ecosystems, Technological Advancements, and Societal Challenges," Technological Forecasting and Social Change 142, no. December 2018 (2019), https://doi.org/10.1016/j.techfore.2018.12.018.

${ }^{326}$ Florida, The Rise of the Creative Class.

327 Zuboff, The Age of Surveillance Capitalism: The Fight for a Human Future at the New Frontier of Power.
} 
capitalism logics to urban neoliberalism, allowing for commodification of behavior in urban spaces.

While smart cities promise to have solutions to many problems in cities, they open up whole new issues, like the dangers associated with data collection and data governance, the regulation of space, and capture revenue generated from it. These issues, of course, are prevalent even without smart cities, but integrating data collection into the built environment around the citizens of a city would make it more unavoidable than it already is. This is especially true with Sidewalk Labs' plan to collect a considerable amount of data with the mindset that it would be accessible for those interested in using it for research or profits. This issue I believe will be prevalent in all smart cities, but even more so with cities that are ground-up projects headed by a tech company like the one discussed in this thesis.

In the second chapter I also discuss some forms of governance models being discussed in academic circles. This discussion takes place in relation to Sidewalk Labs' proposal of their UTD. While Sidewalk Labs does propose an oversight body for the data collected in order to quell fears of privacy concerns, which did not end up helping in the end, the company's outlook is that data should be freely accessible for the most part, in order to foster innovation. The information fiduciary proposed by Sidewalk Labs is consistent with the urban neoliberal ideology of roll-back and roll-out neoliberalism by limiting government in favour of the private sector.

In the final chapter, I discussed the neoliberal interpretation of technocracy and how that has led to the growth in private urban consultancies holding positions of authority and the emergence of private cities around the world. Without the urban neoliberal technocratic connection to market logics of expertise, companies like IBM, Cisco, and Google would not be 
able to take on projects to the scale of Songdo or Toronto. Waterfront Toronto, the governing body which awarded the contract to Sidewalk Labs, is itself made up of technocratic experts. Neoliberal conceptions of technocracy are prevalent in today's governance models; however, smart cities would take that undemocratic form of decision making and place it even more out of reach of the everyday citizen. Sidewalk Labs is an example of decades of urban neoliberalism turning to the private sector for expertise and efficiency.

In the concluding thoughts of my thesis, I discuss where smart cities stand today as a practice, as well as the resistance they are facing, continuing to pay attention to the case study of Sidewalk Labs. I finish by sharing my thoughts on the future of smart cities.

\section{Smart Cities in the World Today}

While there is a lot of excitement and investment into smart cities, there is also a general lack of success, stemming from several issues. India has aggressively pursued a smart city agenda for 100 cities, culminating in over 5,000 different projects, which were expected to be completed in five years each. This year 33 cities were supposed to be completed according to the plan, however, the Business Standard found that only 42 percent of those cities met the deadline. Of the over 5,000 projects, 49 percent remain unfinished. ${ }^{328}$

Songdo is an example of a completed smart city which has been built in a similar image as Sidewalk Labs smart city in Toronto was going to be. Labelled the "city of the future" the project was completed in 2015 on a 1,500-acre area just outside of Seoul. Designed to be a gateway into South Korea for foreign business, the 300,000 resident-capacity has only managed

\footnotetext{
${ }^{328}$ Priyanka Gulati, "49\% of over 5,000 Projects for Smart Cities Unfinished as Deadline Nears," Business Standard News, July 4, 2021, https://www.business-standard.com/article/current-affairs/nearly-49-of-smart-citiesincomplete-targets-distant-as-deadlines-loom-121062500133_1.html.
} 
to fill a population a third that size, with some observing that it feels like a "Chernobyl-like ghost town." ${ }^{329}$ The city has failed to attract foreign businesses despite the tax incentives, and other perks offered to them for locating in the smart city. So, while the city is finished, it is difficult to call it a success.

Another example of a failed smart city development can be found in Massachusetts. Union Point, just outside of Boston was positioned to become a smart city at the junction of a few smaller communities, on the land of an old naval base. This project went through a number of challenges to the development. The developers were initially partnered with General Electric, but they eventually backed out. To fill their place, the project made an aggressive run at becoming the location of Amazon's second North American headquarters but failed to secure the investment. The project fell through and remains undeveloped. ${ }^{330}$

Of course, Sidewalk Labs' project also was canceled in the end, adding to the already sizable list of failed smart city projects. While the company blamed Covid-19 pandemic as the cause for the cancelation of their contract with Waterfront Toronto, there is reason to believe that this was just one of many reasons. After the announcement that the project was to be cancelled, the mayor of Toronto, John Tory stated at a tech conference that as the pandemic started "Sidewalk was expecting a "bargain-basement price," due to the pandemic, and because the City refused to give in to these demands, the project ultimately fell through." 331 However, Sidewalk Labs was facing a lot of pushback from the surrounding community on the issue. Therefore,

\footnotetext{
${ }^{329}$ Harry Pettit, "Smart City in South Korea Turns into a 'Chernobyl-like Ghost Town,"' Daily Mail Online, March 28, 2018, https://www.dailymail.co.uk/sciencetech/article-5553001/28-billion-project-dubbed-worlds-SmartCity-turned-Chernobyl-like-ghost-town.html.

${ }^{330}$ Rebentisch et al., "Unicorn Planning: Lessons from the Rise and Fall of an American 'Smart' MegaDevelopment."

${ }^{331}$ Isabelle Kirkwood, "Waterfront Toronto Pushes Back Sidewalk Labs Deadline, Responds to CCLA Lawsuit," Betakit, January 2020, https://betakit.com/waterfront-toronto-pushes-back-sidewalk-labs-deadline-responds-to-cclalawsuit/.
} 
while smart cities have gained considerable attention in academic, business, and popular media, the concept faces points of contention impeding adoption.

\section{The Last Mile}

In Kitchin et al.'s 2017 article, they discuss the 'last mile' problem smart cities are facing, as resistance to the concept halts total adoption. They outline what is working against the advocacy coalition. The first point of contention comes from the planners and the city's bureaucracies themselves, which they describe as large and complex organizations containing multiple entrenched departments in their ways of working and thinking. Kitchin et al. also acknowledge that in bureaucracies there are internal and external politics at play, and one observer recognized politics as hurting Sidewalk Labs' hope of creating a smart city in Toronto. ${ }^{332}$ In the summer of 2019 , over half a year before the project was finally canceled, The Premier of Ontario, Doug Ford, voiced his concerns about the project. He did not criticize the project from the privacy perspective, as many others did, but as the project being bad for taxpayers. ${ }^{333}$ After these comments, the Toronto Star published an article in which they speculated that Ford "is answering the rallying call of the local development industry looking to get a rival out of town." 334

While there is much support for smart city initiatives from those within the advocacy coalition there is an existing industry in urban development which is not interested in inviting in

\footnotetext{
${ }^{332}$ Kitchin et al., "Smart Cities, Epistemic Communities, Advocacy Coalitions and the 'last Mile' Problem."

${ }^{333}$ Robert Benzie and David Rider, "Ford Warns an Expanded Sidewalk Labs Community Is 'a Terrible Deal for Taxpayers," Toronto Star, August 12, 2019, https:/www.thestar.com/politics/provincial/2019/08/12/ford-warns-anexpanded-sidewalk-labs-community-is-a-terrible-deal-for-taxpayers.html.

334 Star Editorial Board, "We Shouldn't Settle for More of the Same on Toronto's Waterfront," Toronto Star, August 19, 2019, https://www.thestar.com/opinion/editorials/2019/08/19/we-shouldnt-settle-for-more-of-the-sameon-torontos-waterfront.html.
} 
a new behemoth of a competitor. David Olive, a business analyst, predicted the failure of the Sidewalk Labs project a month before the premier signaled his concerns. According to his analysis, the lack of experience was fatal to the project's aspirations, and this is another point of contention, according to Kitchin et al., in the push for smart cities. ${ }^{335}$ Not necessarily just Sidewalk Labs" inexperience, but the fact that there is a "sense that the majority of smart city technology is not yet mature and unsuitable for mainstream." 336

While there is some resistance within government, there is also resistance among civil organization and citizens' groups. There was a legal challenge from the Canadian Civil Liberties Association (CCLA) filed in April of 2019. The CCLA also sent a letter to three levels of government (federal, provincial, and municipal), threatening litigation if the project is not "reset." The goal of the lawsuit is to end the development agreement between Waterfront Toronto and Sidewalk Labs for the development of the Quayside in Toronto. The suit claims that "the collection of private data invades various civil liberties laid out in the Canadian Charter of Rights and Freedoms." The CCLA claimed that Waterfront Toronto was acting beyond their mandate in allowing Sidewalk Labs to collect and analyse data on people. Notable, the suit claimed that Sidewalk Labs would dissuade or altogether block individuals from associating freely and anonymously. ${ }^{337}$

The Sidewalk Labs project has also spawned groups like \#BlockSidewalk. This group was created in protest to Sidewalk Labs being awarded the contract. According to their website,

\footnotetext{
335 David Olive, “Why the Sidewalk Labs Project Won't Happen,” Toronto Star, July 2, 2019, https:/www.thestar.com/business/opinion/2019/07/02/forget-googleville-heres-torontos-real-smart-cityproject.html.

${ }^{336}$ Kitchin et al., "Smart Cities, Epistemic Communities, Advocacy Coalitions and the 'last Mile’ Problem,” 6.

337 Tara Deschamps, "Canadian Civil Liberties Association Threatens Lawsuit over Sidewalk Labs Project," Financial Post, March 5, 2019, https://financialpost.com/pmn/business-pmn/canadian-civil-liberties-associationthreatens-lawsuit-over-sidewalk-labs-project.
} 
the organization believes that urban planning should be "something that happens between Torontonians and the City, focused on the public interest." 338 Once Sidewalk Labs published their MIDP, there was substantial pushback from Waterfront Toronto as well. Particularly in relation to the UDT proposed by Sidewalk Labs, Waterfront Toronto and Ontario's Privacy Commissioner called the MIDP “problematic."339

The Sidewalk Labs project can teach us a number of things in terms of smart cities. First, tech companies are trying to fill a gap that has been created since the transition towards urban entrepreneurialism. As governments try to cut spending, they turn to public private partnerships with companies to develop urban areas. Tech companies like IBM, Cisco, and Google have identified these urban areas as areas for investment.

\section{The Future of Smart Cities}

While there is considerable resistance to smart cities, as exemplified in the Sidewalk Labs case study, given the financial and political interest in the concept, I believe they are here to stay. There is too much money to be made in the industry of smart cities for businesses, and politicians are always looking for investment and prestige in themselves and their cities. So, what is the future of smart cities? There will be more chances given to big tech companies to build the smart city of their dreams. This is despite the fact that there is growing understanding of the ways in which tech companies track, store, and analyse our data to make predictions and profits on us, and that other smart cities have not been successful, even when complete, like Songdo.

\footnotetext{
338 “About - Block Sidewalk,” accessed July 16, 2021, https://www.blocksidewalk.ca/about.

${ }^{339}$ Donovan Vincent, "Sidewalk Labs' Urban Data Trust Is 'Problematic,' Says Ontario Privacy Commissioner," Toronto Star, September 26, 2019, https://www.thestar.com/news/gta/2019/09/26/sidewalk-labs-urban-data-trust-isproblematic-says-ontario-privacy-commissioner.html.
} 
Sidewalk Labs seems to be confident in their ability to secure another opportunity at building a smart city at the scale of the Toronto project that they have since been filing patents on some of the proposed technologies that were to be implemented in the IDEA District. ${ }^{340}$

I believe the smart city project in Toronto failing is a good thing for the city. While I have no doubt that in the future, similar initiatives that Sidewalk wanted to undertake will be developed in Toronto, the companies' connections to Google coupled with the fact that what they wanted to implement was untested at that scale and degree made this project too great a risk. Their chances at building their dream city may come in the form of a private city, similar to what was discussed in chapter 3.

${ }^{340}$ McIntyre, "Sidewalk Labs Ramps up Patenting of Technologies Conceived for Now-Defunct Toronto Smart City." 


\section{Bibliography}

Infrastructure Canada. "\$10 Million Prize Category Winner - City of Guelph and Wellington County." Accessed May 17, 2021. https://www.infrastructure.gc.ca/cities-villes/winnersgagnants/10m-guelph-wellington-eng.html.

Infrastructure Canada. "\$10 Million Prize Category Winner - Nunavut Communities." Accessed May 17, 2021. https://www.infrastructure.gc.ca/cities-villes/winners-gagnants/10mnunavut-eng.html.

Infrastructure Canada. "\$5 Million Prize Category Winner." Accessed May 17, 2021. https://www.infrastructure.gc.ca/cities-villes/winners-gagnants/5m-bridgewater-eng.html.

Infrastructure Canada. “\$50 Million Prize Category Winner.” Accessed May 17, 2021. https://www.infrastructure.gc.ca/cities-villes/winners-gagnants/50m-montreal-eng.html.

"About - Block Sidewalk." Accessed July 16, 2021. https://www.blocksidewalk.ca/about.

Waterfront Toronto. “About Us.” Accessed August 10, 2020. https://www.waterfrontoronto.ca/nbe/portal/waterfront/Home/waterfronthome/about-us.

Agustin, Francis. "Amazon Reportedly Wants to Track Customer Service Workers' Biometrics." Business Insider, August 12, 2021. https://www.businessinsider.com/amazon-trackcustomer-service-workers-biometrics-2021-8.

Albino, Vito, Umberto Berardi, and Rosa Maria Dangelico. "Smart Cities: Definitions, Dimensions, Performance, and Initiatives." Journal of Urban Technology 22, no. 1 (2015): 3-21. https://doi.org/10.1080/10630732.2014.942092.

Alexander, Doug. "Sidewalk Labs Aims to Add Canadian Google HQ into Toronto Plans." Toronto Star, January 14, 2020. https://www.thestar.com/business/2020/01/14/sidewalklabs-aims-to-add-canadian-google-hq-into-toronto-plans.html.

Alini, Erica. "Insurance Apps That Track Your Driving Could Now Yield Premium Increases." Global News, March 21, 2021. https://globalnews.ca/news/7704732/auto-insurance-appusage-based-insurance-surcharges-canada/.

Amazon. "Amazon HQ2 RFP.” Amazon, 2017. https://images-na.ssl-imagesamazon.com/images/G/01/Anything/test/images/usa/RFP_3__V516043504_.pdf.

Andersson, Ida, and Laura James. "Altruism or Entrepreneurialism? The Co-Evolution of Green Place Branding and Policy Tourism in Växjö, Sweden.” Urban Studies Journal Limited 55, no. 15 (2018): 3437-53. https://doi.org/10.1177/0042098017749471.

Angelo, Hillary, and David Wachsmuth. "Why Does Everyone Think Cities Can Save the Planet?" Urban Studies 57, no. 11 (2020): 2201-21. https://doi.org/10.1177/0042098020919081.

Appio, Francesco Paolo, Marcos Lima, and Sotirios Paroutis. "Understanding Smart Cities: Innovation Ecosystems, Technological Advancements, and Societal Challenges." Technological Forecasting and Social Change 142, no. December 2018 (2019): 1-14. 
https://doi.org/10.1016/j.techfore.2018.12.018.

Arnstein, Sherry R. "A Ladder Of Citizen Participation." Journal of the American Planning Association 35, no. 4 (1969): 216-24. https://doi.org/10.1080/01944366908977225.

Balkin, Jack. "Information Fiduciaries and the First Amendment." UC Davis Law Review 49, no. 4 (2016): 1183-1234.

Bannerman, Sara, and Angela Orasch. "Privacy and Smart Cities: A Canadian Survey." Canadian Journal of Urban Research 29, no. 1 (2020): 17-38.

Batty, M., K. W. Axhausen, F. Giannotti, A. Pozdnoukhov, A. Bazzani, M. Wachowicz, G. Ouzounis, and Y. Portugali. "Smart Cities of the Future." European Physical Journal: Special Topics 214, no. 1 (2012): 481-518. https://doi.org/10.1140/epjst/e2012-01703-3.

Batty, Michael. "Big Data, Smart Cities and City Planning." Dialogues in Human Geography 3, no. 3 (2013): 274-79. https://doi.org/10.1177/2043820613513390.

Benzie, Robert, and David Rider. "Ford Warns an Expanded Sidewalk Labs Community Is 'a Terrible Deal for Taxpayers." Toronto Star, August 12, 2019.

https://www.thestar.com/politics/provincial/2019/08/12/ford-warns-an-expanded-sidewalklabs-community-is-a-terrible-deal-for-taxpayers.html.

Bickerton, Christopher, and Carlo Invernizzi Accetti. "Technocracy and Political Theory.” In The Technocratic Challenge to Democracy, edited by Eri Bertsou and Daniele Caramani, 29-43. New York: Routledge, 2020.

Bloom, Laura Begley. "Survey Ranks The World's Best And Worst Cities To Live (The U.S. Did Surprisingly Well)." Forbes, February 24, 2021. https://www.forbes.com/sites/laurabegleybloom/2021/02/24/survey-ranks-the-worlds-bestand-worst-cities-to-live-the-us-did-surprisingly-well/?sh=3556df943ca8.

Waterfront Toronto. "Board of Directors." Accessed July 10, 2021. https://www.waterfrontoronto.ca/nbe/portal/waterfront/Home/waterfronthome/aboutus/who-we-are/board+of+directors.

Boudreau, Julie-Anne, Roger Keil, and Douglas Young. Changing Toronto. Toronto: University of Toronto Press Inc., 2009. https://doi.org/10.3138/9781442603363.

Brenner, Neil, and Nik Theodore. "Cities and the Geographies of "Actually Existing Neoliberalism." In Spaces of Neoliberalism: Urban Restructuring in North America and Western Europe, edited by Neil Brenner and Nik Theodore, 2-32. Oxfird: Blackwell Publishing, 2002.

Brownell, Claire. "Best Communities in Canada 2021: Methodology.” Maclean's, 2021. https://www.macleans.ca/economy/best-communities-in-canada-2021-methodology/.

_ . "The Workplace of the Future Will Probably Remain under Surveillance." MacLean's, December 15, 2020. https://www.macleans.ca/work/the-workplace-of-the-future-willprobably-remain-under-surveillance/.

Busch, Henner. "Linked for Action? An Analysis of Transnational Municipal Climate Networks 
in Germany." International Journal of Urban Sustainable Development 7, no. 2 (2015): 213-31. https://doi.org/10.1080/19463138.2015.1057144.

RBC Economics. "Canadian City Finances Ailing from COVID-19," June 9, 2020. https://thoughtleadership.rbc.com/canadian-city-finances-ailing-from-covid-19/.

Cape Breton Regional Municipality. “CBRM Smart Cities Challenge Proposal,” 2018.

Cardoso, Tom, and Josh O'Kane. "Sidewalk Labs Document Reveals Company 's Early Vision for Data Collection, Tax Powers, Criminal Justice." The Globe and Mail, October 30, 2019. https://www.theglobeandmail.com/business/article-sidewalk-labs-document-revealscompanys-early-plans-for-data/.

Cardullo, Paolo, and Rob Kitchin. "Being a 'Citizen' in the Smart City: Up and down the Scaffold of Smart Citizen Participation in Dublin, Ireland." GeoJournal 84, no. 1 (2019): 113. https://doi.org/10.1007/s10708-018-9845-8.

Impact Canada. "Challenge." Accessed May 17, 2021. https://impact.canada.ca/en/challenges/smart-cities.

Choudhury, Saheli Roy. "These Are the World's Most Livable Cities in 2021." CNBC, June 8, 2021. https://www.cnbc.com/2021/06/09/global-liveability-index-2021-world-mostliveable-cities.html.

City of Lethbridge. "Smart Cities Challenge: City of Lethbridge Proposal." City of Lethbridge, 2018.

City of Ottawa. "Smart City 2.0," 2017. https://documents.ottawa.ca/sites/documents/files/smart_city_strategy_en.pdf.

Centre for Advanced Spatial Analysis. "CityDashboard: London.” Accessed July 20, 2021. https://citydashboard.org/london/.

Clauser, Grant. “Amazon's Alexa Never Stops Listening to You | Wirecutter.” The New York Times, August 8, 2019. https://www.nytimes.com/wirecutter/blog/amazons-alexa-neverstops-listening-to-you/.

Infrastructure Canada. "Competition One.” Accessed May 17, 2021. https://www.infrastructure.gc.ca/cities-villes/comp-one-prem-comp-eng.html.

Confessore, Nicholas. "Cambridge Analytica and Facebook: The Scandal and the Fallout So Far." New York Times, 2018. https://www.nytimes.com/2018/04/04/us/politics/cambridgeanalytica-scandal-fallout.html.

Cruickshank, Justin, and Ross Abbinnett. "Social Epistemology A Journal of Knowledge, Culture and Policy Neoliberalism, Technocracy and Higher Education: Editors' Introduction," 2019. https://doi.org/10.1080/02691728.2019.1638983.

Das, Sanghamitra. "The Rise of the Creative Class: Revisited." African Journal of Science, Technology, Innovation and Development 8, no. 5-6 (2016): 509-11. https://doi.org/10.1080/20421338.2016.1256596.

Day, Matt. “Amazon Refuses Arizona's Cactus as Bidders for HQ2 Climb to 118." The Seattle 
Times, 2017. https://www.seattletimes.com/business/amazon/amazon-refuses-arizonascactus-as-bidders-for-hq2-climb-to-118/.

Delacroix, Sylvie, and Neil D Lawrence. "Bottom-up Data Trusts: Disturbing the 'One Size Fits All' Approach to Data Governance.” International Data Privacy Law 9, no. 4 (November 1, 2019): 236-52. https://doi.org/10.1093/idpl/ipz014.

Deschamps, Tara. "Canadian Civil Liberties Association Threatens Lawsuit over Sidewalk Labs Project." Financial Post, March 5, 2019. https://financialpost.com/pmn/business$\mathrm{pmn} /$ canadian-civil-liberties-association-threatens-lawsuit-over-sidewalk-labs-project.

Dodge, Martin, and Rob Kitchin. "The Automatic Management of Drivers and Driving Spaces." Geoforum 38, no. 2 (2007): 264-75. https://doi.org/10.1016/j.geoforum.2006.08.004.

Donovan, Vincent. "Waterfront Toronto Advisory Panel Still Has Concerns about Sidewalk Labs ' Data Collection, New Report Says." The Toronto Star, February 26, 2020. https://www.thestar.com/news/gta/2020/02/26/waterfront-toronto-advisory-panel-still-hasconcerns-about-sidewalk-labs-data-collection-new-report-says.html.

City of Edmonton. "Edmonton: Smart City." Accessed May 12, 2021. https://www.edmonton.ca/city_government/initiatives_innovation/smart-cities.aspx.

Farr, Christina, and Jillian D’Onfro. “Google Sister-Company Sidewalk Has a Secret ' Yellow Book' with Its Plans to Reinvent Cities , plus Possible Sites beyond Toronto." $C N B C$, June 27, 2018. https:/www.cnbc.com/2018/06/25/alphabet-sidewalk-yellow-book-secret-planssites.html.

Florida, Richard. The Rise of the Creative Class. New York: Basic Books, 2019.

Fowler, Geoffrey A. "Hey, Alexa: Stop Recording Me - The Washington Post." The Washington Post, 2019. https://www.washingtonpost.com/technology/2019/05/06/alexa-has-beeneavesdropping-you-this-whole-time/.

Gebel, Titus. "Private Cities: A Path to Liberty - Foundation for Economic Education." Foundation for Economic Education, April 22, 2016. https://fee.org/articles/private-cities-apath-to-liberty/.

Giffinger, Rudolf, Christian Fertner, Hans Kramar, and Evert Meijers. "Smart City: Ranking of European Medium-Sized Cities.” Centre of Regional Science, Vienna UT, 2007.

"Global Smart Cities Market to Reach \$2.5 Trillion by 2026." Cision PR Newswire, June 29, 2021. https://www.prnewswire.com/news-releases/global-smart-cities-market-to-reach-2-5trillion-by-2026--301322145.html.

“Global Smart Home Appliances Market to Reach \$78.7 Billion by 2027." Yahoo Finance, June 3, 2021. https://finance.yahoo.com/news/global-smart-home-appliances-market124900560.html.

Gregory, Derek, Ron Johnston, Geraldine Pratt, Michael J. Watts, and Sarah Whatmore, eds. The Dictionary of Human Geography. 5th ed. Wiley-Blackwell, 2009.

Grossi, Giuseppe, and Daniela Pianezzi. “Smart Cities: Utopia or Neoliberal Ideology?” Cities 
69, no. July (2017): 79-85. https://doi.org/10.1016/j.cities.2017.07.012.

Gulati, Priyanka. " $49 \%$ of over 5,000 Projects for Smart Cities Unfinished as Deadline Nears." Business Standard News, July 4, 2021. https://www.business-standard.com/article/currentaffairs/nearly-49-of-smart-cities-incomplete-targets-distant-as-deadlines-loom121062500133_1.html.

Hadfield, Gillian. "Toronto Can Be a Global Leader in Harnessing AI to Serve Rather than Enslave Us." Toronto Star, January 7, 2020.

https://www.thestar.com/opinion/contributors/2020/01/07/toronto-can-be-a-global-leaderin-harnessing-ai-to-serve-rather-than-enslave-us.html.

Harvey, David. "From Managerialism to Entrepreneurialism: The Transformation in Urban Governance in Late Capitalism." Geografiska Annaler 71, no. B (1989): 3-17.

—. The New Imperialism. Oxford: Oxford University Press, 2003.

Herbbert, Michael. "Planning, Knowledge, and Technocracy in Historical Perspective.” In Planning and Knowledge: How New Forms of Technocracy Are Shaping Contemporary Cities, edited by Mike Raco and Federico Savini, 19-30. Bristol: Policy Press, 2020.

Hill, Kashmir. “'God View': Uber Allegedly Stalked Users For Party-Goers' Viewing Pleasure.” Forbes, 2014. https:/www.forbes.com/sites/kashmirhill/2014/10/03/god-view-uberallegedly-stalked-users-for-party-goers-viewing-pleasure/?sh=37c190313141.

Hollands, Robert G. "Critical Interventions into the Corporate Smart City." Cambridge Journal of Regions, Economy and Society 8, no. 1 (2015): 61-77. https://doi.org/10.1093/cjres/rsu011.

. "Will the Real Smart City Please Stand up? Intelligent, Progressive or Entrepreneurial?" City 12, no. 3 (2008): 303-20. https://doi.org/10.1080/13604810802479126.

Charter Cities Institute. "Introduction to Charter Cities.” Accessed July 1, 2021. https://www.chartercitiesinstitute.org/intro\#why.

MarketWatch. "IoT in Smart Cities Market Insights by Size, Demand, Industry Insights, Opportunities, Future Growth Rate, CAGR Status Till 2023,’ June 2, 2021. https://www.marketwatch.com/press-release/iot-in-smart-cities-market-insights-by-sizedemand-industry-insights-opportunities-future-growth-rate-cagr-status-till-2023-2021-0602? tesla $=\mathrm{y}$.

Juang, Mike. "New Kind of Auto Insurance Can Be Cheaper, but Tracks Your Every Move." $C N B C$, October 6, 2018. https:/www.cnbc.com/2018/10/05/new-kind-of-auto-insurancecan-be-cheaper-but-tracks-your-every-move.html.

Kavaratzis, M., \& Ashworth, G. J. "City Branding: An Effective Assertion Of." Tijdschrift Voor Economische En Sociale 96(5), no. 5 (2005): 506.

Khan, Lina M., and David E. Pozen. “A Skeptical View of Information Fiduciaries.” Harvard Law Review 133, no. 2 (2019): 498-541.

Kipfer, Stefan, and Roger Keil. "Toronto Inc? Planning the Competitive City in the New 
Toronto." Antipode 34, no. 2 (2002): 227-64. https://doi.org/10.1111/1467-8330.00237.

Kirkwood, Isabelle. "Waterfront Toronto Pushes Back Sidewalk Labs Deadline, Responds to CCLA Lawsuit." Betakit, January 2020. https://betakit.com/waterfront-toronto-pushesback-sidewalk-labs-deadline-responds-to-ccla-lawsuit/.

Kitchin, Rob. "The Real-Time City? Big Data and Smart Urbanism." GeoJournal 79, no. 1 (February 2014): 1-14. https://doi.org/10.1007/s10708-013-9516-8.

Kitchin, Rob, Claudio Coletta, Leighton Evans, Liam Heaphy, and Darach Mac Donncha. "Smart Cities, Algorithmic Technocracy and New Urban Technocrats." Planning and Knowledge, 2019, 199-212. https://doi.org/10.2307/j.ctvkjb1z8.20.

Kitchin, Rob, Claudio Coletta, Leighton Evans, Liam Heaphy, and Darach MacDonncha. "Smart Cities, Epistemic Communities, Advocacy Coalitions and the 'last Mile' Problem." It Information Technology 59, no. 6 (2017): 275-84. https://doi.org/10.1515/itit-2017-0004.

Leetaru, Kalev. “When Will Cities Begin To Monetize Their Residents' Data?” Forbes, July 19, 2018. https://www.forbes.com/sites/kalevleetaru/2018/07/19/when-will-cities-begin-tomonetize-their-residents-data/?sh=34563c924661.

Leslie, Deborah, and Mia Hunt. "Securing the Neoliberal City: Discourses of Creativity and Priority Neighborhoods in Toronto, Canada." Urban Geography 34, no. 8 (2013): 1171-92. https://doi.org/10.1080/02723638.2013.823729.

Leydesdorff, Loet, and Mark Deakin. "The Triple-Helix Model of Smart Cities: A NeoEvolutionary Perspective.” Journal of Urban Technology 18, no. 2 (2011): 53-63. https://doi.org/10.1080/10630732.2011.601111.

Lohr, Steve. "Sidewalk Labs, a Start-Up Created by Google, Has Bold Aims to Improve City Living." New York Times, June 10, 2015. https://www.nytimes.com/2015/06/11/technology/sidewalk-labs-a-start-up-created-bygoogle-has-bold-aims-to-improve-city-living.html.

Lynskey, Dorian. “'Alexa, Are You Invading My Privacy?' - the Dark Side of Our Voice Assistants | Amazon Alexa | The Guardian.” The Guardian, 2019. https://www.theguardian.com/technology/2019/oct/09/alexa-are-you-invading-my-privacythe-dark-side-of-our-voice-assistants.

Ottawa Public Health. "Mapping Products." Accessed August 10, 2021. https://www.ottawapublichealth.ca/en/reports-research-and-statistics/mappingproducts.aspx.

Mccann, Eugene J. “'Best Places': Interurban Competition, Quality of Life and Popular Media Discourse." Urban Studies 41, no. 10 (2004). https://doi.org/10.1080/0042098042000256314.

McCue, TJ. “Amazon Alexa Accused Again Of Spying: Here Is Another Solution.” Forbes, July 30, 2019. https://www.forbes.com/sites/tjmccue/2019/07/30/amazon-alexa-accused-againof-spying-here-is-another-solution/?sh=7f0d6db465f3.

McIntyre, Catherine. "Sidewalk Labs Ramps up Patenting of Technologies Conceived for Now- 
Defunct Toronto Smart City." The Logic, April 6, 2021. https://thelogic.co/news/sidewalklabs-ramps-up-patenting-of-technologies-conceived-for-now-defunct-toronto-smart-city/.

Metz, Sam. "In Nevada Desert, a Technology Firm Aims to Be a Government." Associated Press , February 13, 2021. https://apnews.com/article/blockchains-smart-city-nevadae53b6c504ccaf9071cbfb607074eb719.

Molla, Rani. "People Say They Care about Privacy but Buy Devices That Can Spy on Them." Vox, May 13, 2019. https://www.vox.com/recode/2019/5/13/18547235/trust-smart-devicesprivacy-security.

Moser, Sarah, and Laurence Côté-Roy. "New Cities: Power, Profit, and Prestige." Geography Compass 15, no. 1 (2021): 1-15. https://doi.org/10.1111/gec3.12549.

Mouratidis, Kostas. "Is Compact City Livable? The Impact of Compact versus Sprawled Neighbourhoods on Neighbourhood Satisfaction.” Urban Studies 55, no. 11 (2018): 240830. https://doi.org/10.1177/0042098017729109.

Needleman, Sarah E. “Facebook's Ad Business Drives Surge in Revenue, Following Google's Act.” Wall Street Journal, 2021. https://www.wsj.com/articles/facebook-fb-1q-earningsreport-2021-11619610405.

Nevett, Joshua. "Nevada Smart City: A Millionaire's Plan to Create a Local Government.” $B B C$ News, March 18, 2021. https://www.bbc.com/news/world-us-canada-56409924.

O’Kane, Josh. “Indigenous Group Speaks out over 'Grossly Misleading' Sidewalk Labs Consultation." The Globe and Mail, October 25, 2019.

https://www.theglobeandmail.com/business/article-indigenous-leaders-speak-out-overgrossly-misleading-sidewalk-labs/.

Olive, David. "Why the Sidewalk Labs Project Won't Happen.” Toronto Star, July 2, 2019. https://www.thestar.com/business/opinion/2019/07/02/forget-googleville-heres-torontosreal-smart-city-project.html.

Ottawa Tourism. “Ottawa Is a Smart City.” Accessed May 12, 2021. https://ottawatourism.ca/en/meetings/why-ottawa/smart-city.

Smart Cities Edmonton. “Our Smart City Approach.” Accessed May 12, 2021. https://smartcities.edmonton.ca/our-smart-city-approach/.

Palmer, Annie. "How Amazon Prevents Unions by Surveilling Employee Activism." CNBC, October 24, 2020. https://www.cnbc.com/2020/10/24/how-amazon-prevents-unions-bysurveilling-employee-activism.html.

Infrastructure Canada. "Participating Communities.” Accessed May 11, 2021. https://www.infrastructure.gc.ca/sc-vi/map-applications.php.

Paul, Kari. "'Tossed My Fitbit in the Trash': Users Fear for Privacy after Google Buys Company." The Guardian, November 6, 2019.

https://www.theguardian.com/technology/2019/nov/05/fitbit-google-acquisition-health-data.

Peck, Jamie, and Adam Tickell. "Neoliberalizing Space." In Spaces of Neoliberalism: Urban 
Restructuring in North America and Western Europe, edited by Neil Brenner and Nik Theodore, 33-57. Oxford: Blackwell Publishing, 2002.

Perez, Jackie. "COVID-19 Pop-up Vaccination Clinic Held in Ottawa Hotspot Postal Code." CTV News, April 17, 2021. https://ottawa.ctvnews.ca/covid-19-pop-up-vaccination-clinicheld-in-ottawa-hotspot-postal-code-1.5391698.

Pettit, Harry. "Smart City in South Korea Turns into a 'Chernobyl-like Ghost Town."' Daily Mail Online, March 28, 2018. https://www.dailymail.co.uk/sciencetech/article-5553001/28billion-project-dubbed-worlds-Smart-City-turned-Chernobyl-like-ghost-town.html.

Praharaj, Sarbeswar, and Hoon Han. "Cutting through the Clutter of Smart City Definitions: A Reading into the Smart City Perceptions in India." City, Culture and Society 18, no. December 2018 (2019): 1-10. https://doi.org/10.1016/j.ccs.2019.05.005.

PWC. "Cities of Opportunity." New York, 2016. www.pwc.com.

Rebentisch, Hannah, Caroline Thompson, Laurence Côté-Roy, and Sarah Moser. "Unicorn Planning: Lessons from the Rise and Fall of an American 'Smart' Mega-Development." Cities 101 (June 1, 2020): 1-6. https://doi.org/10.1016/j.cities.2020.102686.

Resnick, Brian. 'Cambridge Analytica's 'Psychographic Microtargeting': What's Bullshit and What's Legit." Vox, March 26, 2018. https:/www.vox.com/science-andhealth/2018/3/23/17152564/cambridge-analytica-psychographic-microtargeting-what.

Richards, Rob, Daniel Brothman, and Matthew Leibowitz. "Urban Tech Is the next Frontier in the Digital Revolution." Toronto Star, July 8, 2019. https://www.thestar.com/opinion/contributors/2019/07/08/urban-tech-is-the-next-frontierin-the-digital-revolution.html.

Sadowski, Jathan. Too Smart. Too Smart, 2020. https://doi.org/10.7551/mitpress/12240.001.0001.

Sanchez-Cuenca, Ignacio. "Neoloberal Technocracy: The Challenge to Democratic SelfGovernment." In The Technocratic Challenge to Democracy, edited by Eri Bertsou and Daniele Caramani, 44-60. New York: Routledge, 2020.

Savini, Federico, and Mike Raco. "The Rise of a New Urban Technocracy." In Planning and Knowledge: How New Forms of Technocracy Are Shaping Contemporary Cities, edited by Mike Raco and Federico Savini, 3-17. Bristol: Policy Press, 2020.

Scassa, Teresa. "Crime Data and Analytics: Accounting for Crime in the City." In Data and the City, 59-71, 2017. https://doi.org/10.4324/9781315407388.

Shelton, Taylor, Matthew Zook, and Alan Wiig. "The "Actually Existing Smart City.", Cambridge Journal of Regions, Economy and Society 8, no. 1 (2015): 13-25. https://doi.org/10.1093/cjres/rsu026.

Shepard, Wade. "Inside The Rise Of Private Cities: 'Priority Of Management Is Profit, Not The Needs Of Citizens."” Forbes, January 31, 2020. https://www.forbes.com/sites/wadeshepard/2020/01/31/inside-the-rise-of-private-citiespriority-of-management-is-profit-not-the-needs-of-citizens/?sh=36eb4710c9c2 . 
Sidewalk Labs. "Master Innovation \& Development Plan: Digital Innovation Appendix," 2019. "Master Innovation \& Development Plan: The Overview." Vol. 0, 2019.

__. "Master Innovation \& Development Plan: Volume 1," 2019.

__. "Master Innovation \& Development Plan: Volume 2," 2019.

__. "Master Innovation \& Development Plan: Volume 3," 2019.

__. "Our Team." Sidewalk Labs. Accessed September 15, 2020. https://www.sidewalklabs.com/team/.

Sidewalk Labs. "Sidewalk Labs - Home." Accessed September 13, 2020. https://www.sidewalklabs.com/.

Skinner, B.F. Beyond Freedom and Dignity. Indianapolis/Cambridge: Hackett Publishing Company Inc., 1971.

MarketsandMarkets. "Smart Cities Market Size, Share and Global Market Forecast to 2025," 2020. https://www.marketsandmarkets.com/Market-Reports/smart-cities-market-542.html.

Snyder, Jesse. "Ottawa Frequently Awarding IT Contracts Solely to Cisco, Part of LongStanding Government Dependency on Networking Giant." National Post, March 2, 2021. https://nationalpost.com/news/politics/ottawa-frequently-awarding-it-contracts-solely-tocisco-part-of-long-standing-government-dependency-on-networking-giant.

. "Top Official Defends Ottawa's Procurement Practices Following Report on SoleSourced Contracts to U.S. IT Giant.” National Post, April 28, 2021. https://nationalpost.com/news/top-official-defends-ottawas-procurement-practicesfollowing-report-on-sole-sourced-contracts-to-california-it-giant.

Söderström, Ola, Till Paasche, and Francisco Klauser. "Smart Cities as Corporate Storytelling." City 18, no. 3 (2014): 307-20. https://doi.org/10.1080/13604813.2014.906716.

Star Editorial Board. "We Shouldn't Settle for More of the Same on Toronto's Waterfront." Toronto Star, August 19, 2019. https://www.thestar.com/opinion/editorials/2019/08/19/weshouldnt-settle-for-more-of-the-same-on-torontos-waterfront.html.

Waterfront Toronto. "Stephen Diamond, Chair.” Accessed July 10, 2021. https://www.waterfrontoronto.ca/nbe/portal/waterfront/Home/waterfronthome/aboutus/who-we-are/board+of+directors+bios/stephen+diamond\%2C+chair.

Taylor, Zack, and Neil Bradford. "The New Localism: Canadian Urban Governance in the Twenty-First Century." In Canadian Cities in Transition: Perspectives for an Urban Age, edited by Pierre Filion, Markus Moos, Tara Vinodrai, and Ryan Walker, 5th ed., 194-208. Don Mills, Ontario: Oxford University Press, 2015.

Infrastructure Canada. “The Jury,” May 7, 2019. https://www.infrastructure.gc.ca/citiesvilles/members-membres-eng.html.

United Nations. "68\% of the World Population Projected to Live in Urban Areas by 2050, Says UN.” United Nations. New York, 2018. 
https://www.un.org/development/desa/en/news/population/2018-revision-of-worldurbanization-prospects.html.

The World Bank. "Urban Population (\% of Total Population) - Canada | Data." Accessed August 7, 2021.

https://data.worldbank.org/indicator/SP.URB.TOTL.IN.ZS?end=2020\&locations=CA\&start $=1960 \&$ view $=$ chart.

Vanolo, Alberto. "Cities Are Not Products.” Tijdschrift Voor Economische En Sociale Geografie 111, no. 1 (2019): 10-17. https://doi.org/10.1111/tesg.12385.

"Is There Anybody out There? The Place and Role of Citizens in Tomorrow's Smart Cities." Futures 82 (2016): 26-36. https://doi.org/10.1016/j.futures.2016.05.010.

_. "Smartmentality: The Smart City as Disciplinary Strategy." Urban Studies 51, no. 5 (2014): 883-98. https://doi.org/10.1177/0042098013494427.

Vincent, Donovan. "30 Influential Toronto Leaders Pen Letter Supporting Controversial Sidewalk Labs Plan.” Toronto Star, July 5, 2019. https://www.thestar.com/news/gta/2019/07/04/30-influential-toronto-leaders-pen-lettersupporting-controversial-sidewalk-labs-plan.html.

- "Foot Traffic in Stores, Pay-as-You-Throw Garbage Collection: Sidewalk Labs Shares Data Collection and Use Plans for Toronto Smart City." Toronto Star, November 15, 2019. https://www.thestar.com/news/gta/2019/11/15/foot-traffic-in-stores-pay-as-you-throwgarbage-collection-sidewalk-labs-shares-data-collection-and-use-plans-for-toronto-smartcity.html.

- 'Sidewalk Labs' Urban Data Trust Is 'Problematic,' Says Ontario Privacy Commissioner." Toronto Star, September 26, 2019.

https://www.thestar.com/news/gta/2019/09/26/sidewalk-labs-urban-data-trust-isproblematic-says-ontario-privacy-commissioner.html.

Vynck, Gerrit De, and Rachel Lerman. "Facebook and YouTube Are Still Full of Covid Misinformation." The Washington Post, July 22, 2021. https://www.washingtonpost.com/technology/2021/07/22/facebook-youtube-vaccinemisinformation/.

Waal, Martijn de. "A City in Not a Galaxy: Understanding the City through Urban Data." In Data and the City, edited by Rob Kitchin, Tracey P Lauriault, and Gavin McArdle, 17-30. New York: Routledge, 2018.

Warburton, Moira. “Alphabet's Sidewalk Labs Cancels Toronto 'smart City' Project.” Reuters, May 7, 2020. https://www.reuters.com/article/us-canada-sidewalk-idUSKBN22J2FN.

Waterfront Toronto. "Quayside RFP,” 2017. https://waterfrontoronto.ca/nbe/portal/waterfront/Home/waterfronthome/newsroom/newsarc hive/news/2017/march/waterfront-toronto-takes-first-step-in-building-quayside.

. "Waterfront Toronto and Sidewalk Labs Sign Plan Development Agreement," 2018. https://waterfrontoronto.ca/nbe/portal/waterfront/Home/waterfronthome/newsroom/newsarc hive/news/2018/july/waterfront+toronto+and+sidewalk+labs+sign+plan+development+agre 
ement.

Waterfront Toronto. "Waterfront Toronto and Sidewalk Labs Sign Plan Development Agreement," 2018.

https://waterfrontoronto.ca/nbe/portal/waterfront/Home/waterfronthome/newsroom/newsarc hive/news/2018/july/waterfront + toronto+and + sidewalk + labs + sign + plan + development + agre ement.

Weitzman, Shiran. “How Remote Work Is Changing Workplace Intelligence.” Forbes, August 17, 2021. https://www.forbes.com/sites/forbesfinancecouncil/2021/08/17/how-remotework-is-changing-workplace-intelligence/?sh=34aa9d7952ef.

Waterfront Toronto. "Who We Are.” Accessed July 12, 2021. https://www.waterfrontoronto.ca/nbe/portal/waterfront/Home/waterfronthome/aboutus/who-we-are.

Williams, Annabelle. "5 Ways Amazon Monitors Its Employees, From AI Cameras to a Spy Agency.” Business Insider, April 5, 2021. https://www.businessinsider.com/how-amazonmonitors-employees-ai-cameras-union-surveillance-spy-agency-2021-4.

Economic Development Winnipeg. "Winnipeg Named One of Top 21 'Smart Cities' in Global Competition." Accessed May 12, 2021. https://www.economicdevelopmentwinnipeg.com/media/mediarelease/read,release/1376/winnipeg-named-one-of-top-21-smart-cities-in-globalcompetition.

Wong, Julia Carrie. "The Cambridge Analytica Scandal Changed the World - but It Didn't Change Facebook." The Guardian, 2019. https://www.theguardian.com/technology/2019/mar/17/the-cambridge-analytica-scandalchanged-the-world-but-it-didnt-change-facebook.

Young, Alyson Leigh, and Anabel Quan-haase. "Privacy Protection Strategies on Facebook: The Internet Privacy Paradox Revisited." Information, Communication \& Society 16, no. 4 (2013): 479-500.

Zittrain, Jonathan. "Facebook Could Decide an Election Without Anyone Ever Finding Out." The New Republic, 2014. https://newrepublic.com/article/117878/information-fiduciarysolution-facebook-digital-gerrymandering.

Zoonen, Liesbet van. "Privacy Concerns in Smart Cities." Government Information Quarterly 33, no. 3 (July 1, 2016): 472-80. https://doi.org/10.1016/j.giq.2016.06.004.

Zuboff, Shoshana. The Age of Surveillance Capitalism: The Fight for a Human Future at the New Frontier of Power. First edit. New York: PublicAffairs, 2019. 